\title{
Hydrolysis of S-aryl-cysteinylglycine conjugates catalyzed by porcine kidney cortex membrane dipeptidase
}

\author{
by \\ James Poon \\ A Thesis \\ Presented to \\ The University of Guelph
In partial fulfillment of requirements
for the degree of
Master of Science
in

Molecular and Cellular Biology

Guelph, Ontario, Canada

(C) James Poon, August, 2012 


\section{ABSTRACT \\ Hydrolysis of S-aryl-cysteinylglycine conjugates catalyzed by porcine kidney cortex membrane dipeptidase}

James Poon

University of Guelph, 2012
Advisor:

Professor P. David Josephy

Following conjugation with glutathione, xenobiotics are converted into cysteinylglycine conjugates, cysteine conjugates, and, finally, mercapturic acids. The structural factors determining the activities of dipeptidases for the metabolism of toxicologically-relevant cysteinylglycine conjugates are not well understood. I purified porcine kidney cortex membrane dipeptidase (MDP) to homogeneity, via phosphatidylinositol-specific phospholipase C-mediated cleavage of the protein's membrane anchor and cilastatin affinity chromatography. The homodimeric structure of the MDP protein was confirmed by mass spectrometry. To test the enzyme activity of purified MDP, the cysteinylglycine conjugates of 1-(chloromethyl)naphthalene, 4-nitrobenzyl chloride, and 1-chloro-2,4dinitrobenzene were synthesized and HPLC separation methods for their quantitation were developed. MDP catalyzed the hydrolysis of all three conjugates, but the rate of this activity was strongly dependent on the nature of the substituent on the cysteine sulfur atom. 


\section{ACKNOWLEDGEMENTS}

I wish to thank my advisor Dr. P. David Josephy for his unfaltering patience, support and guidance. I also wish to thank Dr. Frances J. Sharom and Dr. Joseph S. Lam for their knowledgeable advice and for serving on my advisory committee.

I wish to thank all my colleagues in the Josephy lab, both past and present. I also wish to thank the laboratories of Drs. Sharom, John F. Dawson, A. Rod Merrill, and Richard A. Manderville; this project was made possible with the help of their staff, students, and equipment.

We gratefully acknowledge the assistance of Nikole Freeman; Aaron Witham (lyophilization procedures); Joseph Chu and Dr. Frances J. Sharom (protein purification procedures); and Dr. Dyanne Brewer and Dr. Armen Charchoglyan (mass spectrometry). Research support was provided by a Discovery Grant from the Natural Sciences and Engineering Research Council of Canada.

Finally, thank you to my family and friends. Thank you for seeing this through to the end with me; I would not have made it without your support. 


\section{TABLE OF CONTENTS}

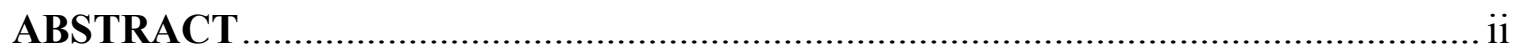

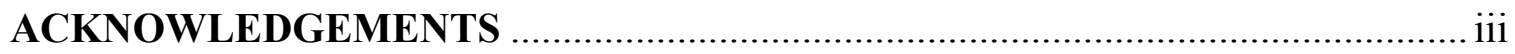

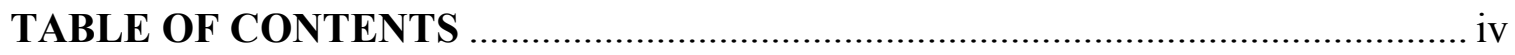

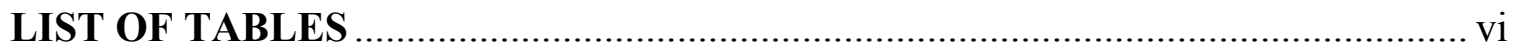

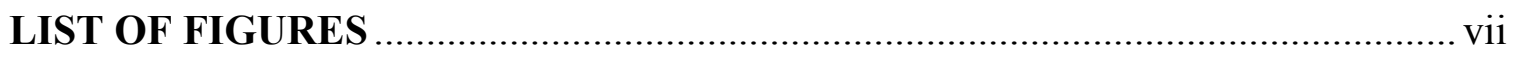

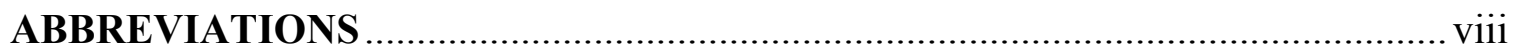

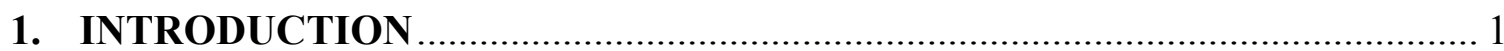

1.1 Bioactivation and reactive intermediate-mediated toxicity................................... 1

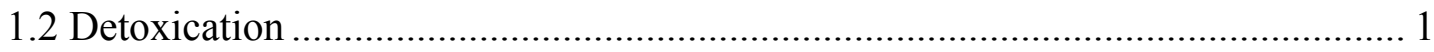

1.3 The mercapturic acid pathway ........................................................................ 3

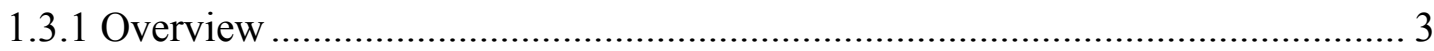

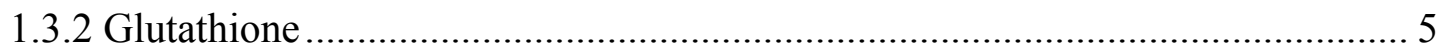

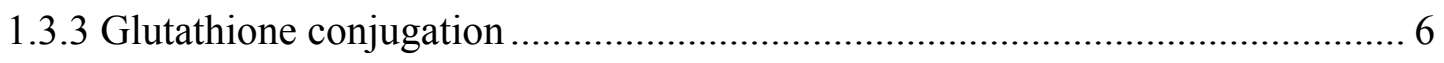

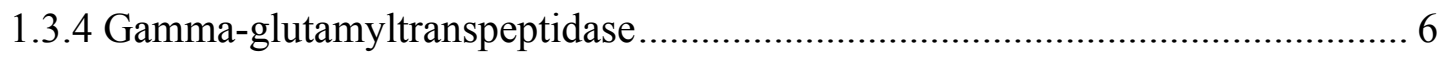

1.3.5 Cys-Gly conjugate hydrolysis ....................................................................... 7

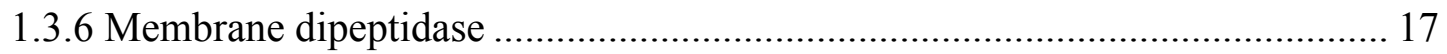

1.3.7 Cysteine S-conjugate $\mathrm{N}$-acetyltransferase …………….................................... 19

1.3.8 Research on enzymes in the mercapturic acid pathway .................................... 21

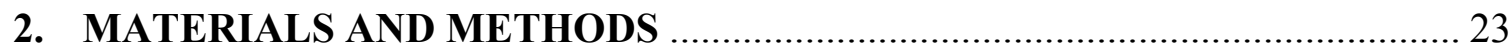

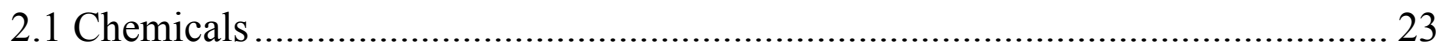

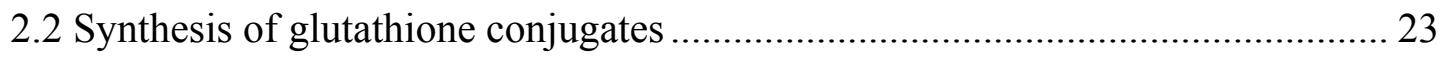

2.3 Electrospray mass spectrometry of conjugates .................................................. 26

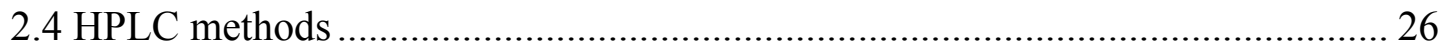




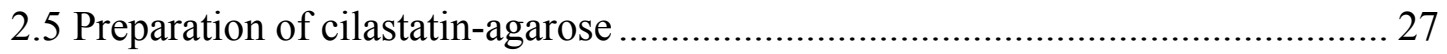

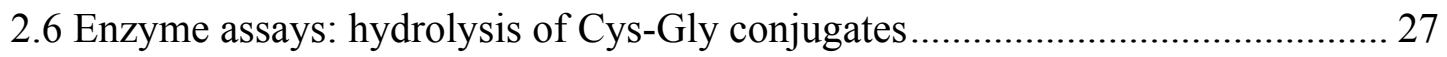

2.7 Porcine kidney cortex microsomal fraction ................................................ 29

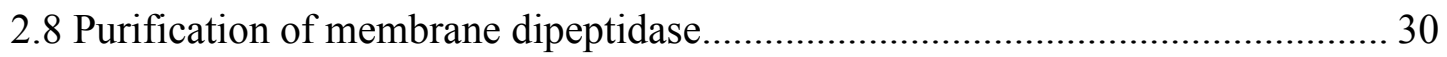

2.9 Time-of-flight mass spectrometry of purified enzyme ................................ 31

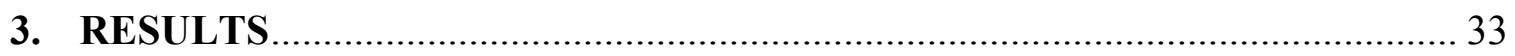

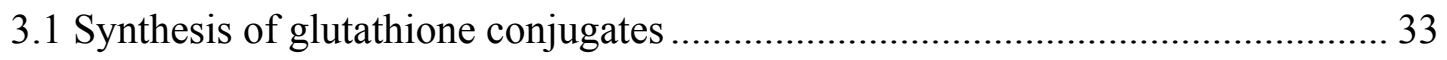

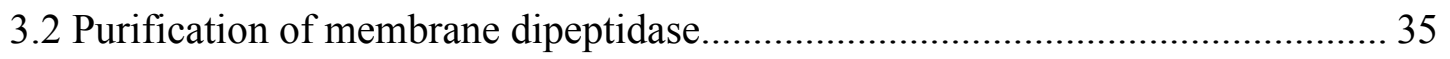

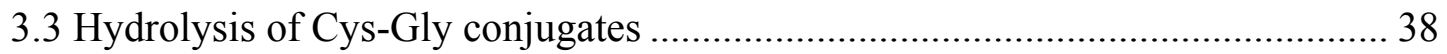

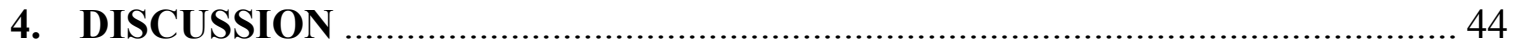

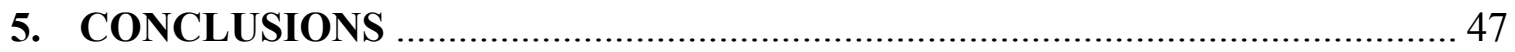

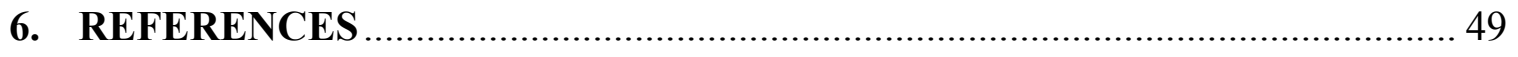

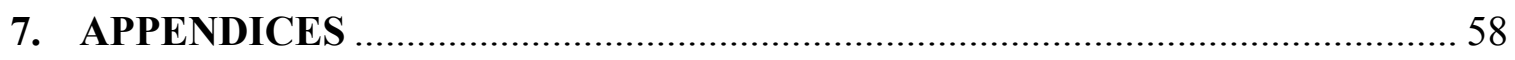

Appendix A: UV-visible spectra of GSH conjugates ........................................ 58

Appendix B: HPLC separation of X-GSH, X-CG, and X-C ................................ 59

Appendix C: LC-MS-MS data for acid hydrolysates of GSH conjugates .................. 60

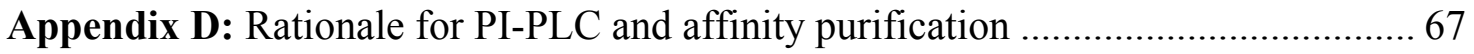

Appendix E: Structures of peptidase inhibitors .............................................. 70

Appendix F: Method for generating HPLC Cys-Gly standard curves..................... 71

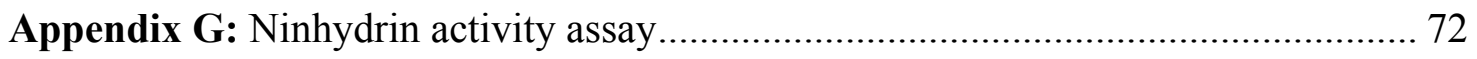




\section{LIST OF TABLES}

Table 1. Enzymes reported to catalyze hydrolysis of Cys-Gly or its conjugates.

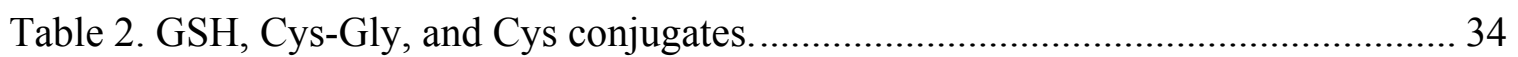

Table 3. Purification of MDP from porcine kidney cortex....................................... 37

Table 4. MDP: kinetic parameters with Cys-Gly and conjugate substrates. 42 


\section{LIST OF FIGURES}

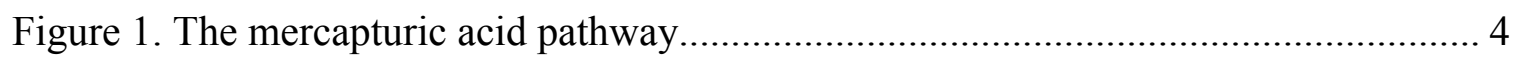

Figure 2. Overall view of human MDP. ................................................................. 10

Figure 3. Human MDP active site with cilastatin ligand............................................. 11

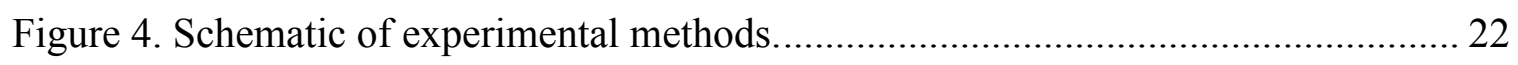

Figure 5. Structure of (A) 1-(Chloromethyl)naphthalene; (B) 1-chloro-2,4-

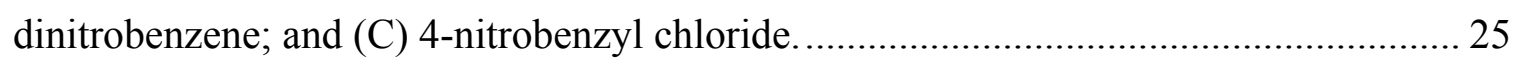

Figure 6. Purification of membrane dipeptidase: SDS-PAGE analysis............................ 36

Figure 7. MALDI-TOF mass spectra of purified membrane dipeptidase......................... 38

Figure 8. Hydrolysis of Cys-Gly S-conjugates: HPLC analysis....................................... 39

Figure 9. Enzyme kinetics of MDP towards Cys-Gly and conjugate substrates. ............. 40 


\section{ABBREVIATIONS}

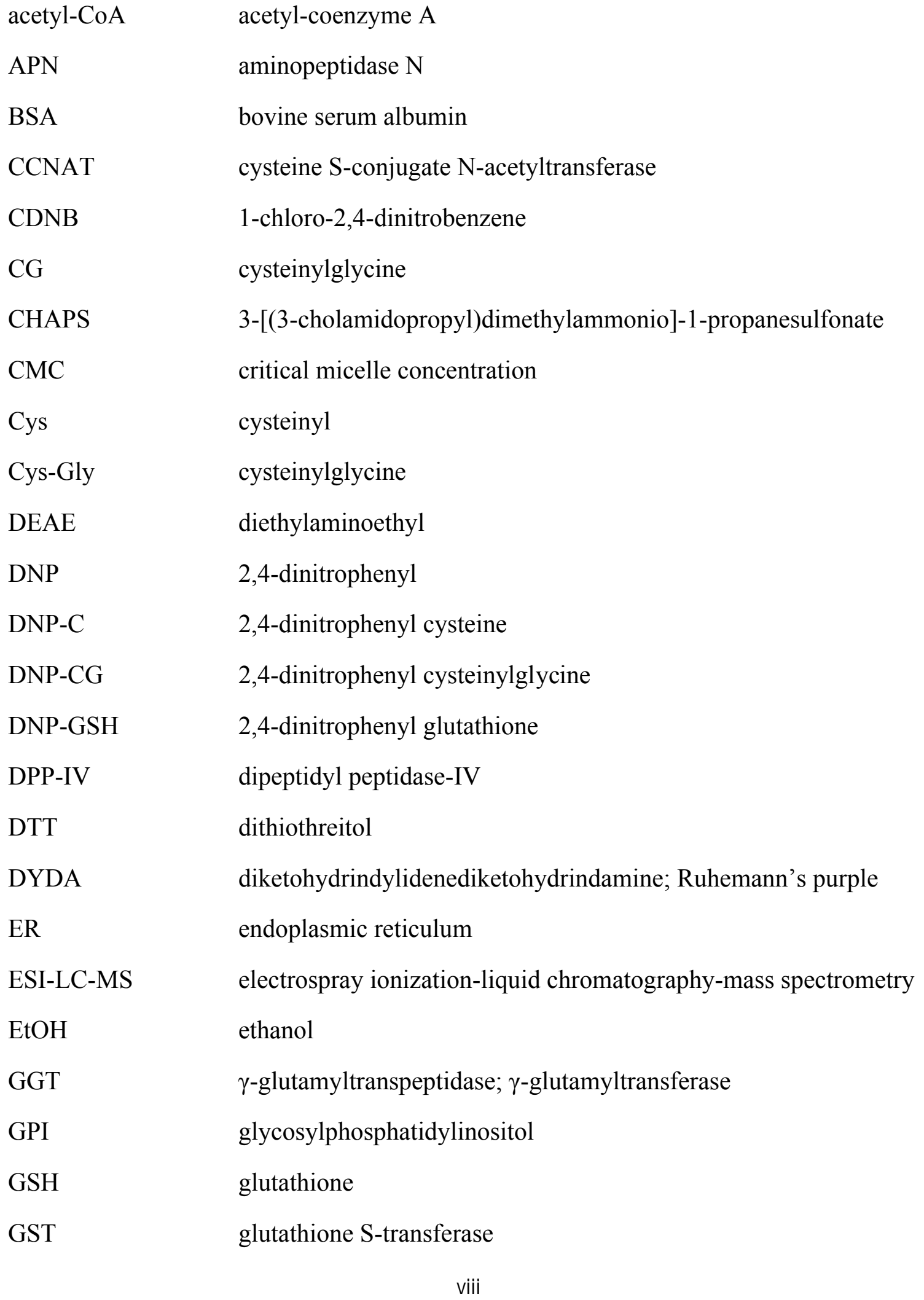




\begin{tabular}{|c|c|}
\hline HPLC & high performance liquid chromatography \\
\hline$K_{\mathrm{i}}$ & dissociation constant for inhibitor binding \\
\hline$K_{\mathrm{m}}$ & $\begin{array}{l}\text { Michaelis constant, equivalent to the substrate concentration at } \\
\text { which the reaction rate is half } V_{\max }\end{array}$ \\
\hline LT & leukotriene \\
\hline M & 1-methylnaphthyl \\
\hline $\mathrm{M}-\mathrm{C}$ & 1-methylnaphthyl cysteine \\
\hline $\mathrm{M}-\mathrm{CG}$ & 1-methylnaphthyl cysteinylglycine \\
\hline M-GSH & 1-methylnaphthyl glutathione \\
\hline MALDI-TOF MS & $\begin{array}{l}\text { matrix-assisted laser desorption-ionization time-of-flight mass } \\
\text { spectometry }\end{array}$ \\
\hline MAPEG & $\begin{array}{l}\text { membrane-associated proteins in eicosanoid and glutathione } \\
\text { metabolism }\end{array}$ \\
\hline MBD & membrane-bound dipeptidase \\
\hline $\mathrm{MCl}$ & 1-(chloromethyl)naphthalene \\
\hline MDP & membrane dipeptidase \\
\hline $\mathrm{MeCN}$ & acetonitrile \\
\hline MRP & multidrug resistance-associated protein \\
\hline MS & mass spectrometry \\
\hline MW & molecular weight \\
\hline $\mathrm{m} / \mathrm{z}$ & mass-to-charge ratio \\
\hline NAT & $\mathrm{N}$-acetyltransferase \\
\hline NB & 4-nitrobenzyl \\
\hline NB-C & 4-nitrobenzyl cysteine \\
\hline NB-CG & 4-nitrobenzyl cysteinylglycine \\
\hline NB-GSH & 4-nitrobenzyl glutathione \\
\hline $\mathrm{NBCl}$ & 4-nitrobenzyl chloride \\
\hline OAT & organic anion transport \\
\hline
\end{tabular}




$\begin{array}{ll}\text { PI-PLC } & \text { phosphatidylinositol-specific phospholipase C } \\ \text { PLG } & \text { prolylleucylglycine; ProLeuGly } \\ \text { ROS } & \text { reactive oxygen species } \\ \text { SDS-PAGE } & \text { sodium dodecyl sulfate polyacrylamide gel electrophoresis } \\ \text { TCA } & \text { trichloroacetic acid } \\ \text { TFA } & \text { trifluoroacetic acid } \\ \text { UV } & \text { ultraviolet } \\ V_{\text {max }} & \text { maximum reaction rate in Michaelis-Menten kinetics } \\ \text { X+ } & \text { fragmented compound } \\ \text { X- } \gamma E C & \text { glutamylcysteine conjugate } \\ \text { X-C } & \text { cysteine conjugate } \\ \text { X-CG } & \text { cysteinylglycine conjugate } \\ \text { X-GSH } & \text { glutathione conjugate }\end{array}$




\section{INTRODUCTION}

\subsection{BIOACTIVATION AND REACTIVE INTERMEDIATE-MEDIATED TOXICITY}

Many xenobiotic compounds, such as drugs or environmental chemicals, can be bioactivated by enzymes such as cytochromes $\mathrm{P} 450$, prostaglandin $\mathrm{H}$ synthases or lipoxygenases to reactive intermediates such as electrophiles or free radicals (Wells et al., 2009). These short-lived reactive intermediates can cause a variety of deleterious effects to the cell. Electrophiles are able to bind covalently (irreversibly) to cellular macromolecules and form adducts. Adducts formed with DNA can stall replication or induce mutation (Minca and Kowalski, 2011), while adducts to the critical residues of protein active sites may disrupt enzyme function (Pumford and Halmes, 1997). Covalent adducts to DNA and proteins mediate the toxic effects of many carcinogens and cytotoxic agents (Pumford et al., 1997; Pumford and Halmes, 1997).

In addition, the partial reduction of molecular oxygen by free radicals can generate reactive oxygen species (ROS). ROS are able to oxidatively damage DNA, potentially leading to hereditary mutations (Cadet and Brannock, 1998; Halliwell, 1999). Other consequences of oxidative stress include disruption of enzyme active sites, changes in the conformation of structural proteins, and lipid peroxidation (Andersen, 2004). ROS may also alter signal transduction pathways, impairing cell function or even causing cell death (Winn and Wells, 2002).

\subsection{DetoxicAtion}

Biotransformation refers to the metabolic conversion of generally water-insoluble xenobiotics to more polar detoxication products, which are eventually excreted. 
Depending on the chemical structure of the xenobiotic and the type of biotransformation reaction, the metabolite can be either more or less biologically active than the parent compound. Many pharmacological agents are synthesized as prodrugs that need to be metabolized in vivo in order to exert a therapeutic effect (Nandurdikar et al., 2012). Drug design and development often incorporates the study and manipulation of functional groups, in order to optimize the pharmacokinetics and bioavailability of a particular compound. Biotransformation reactions may also result in the production of toxic reactive intermediates (bioactivation; see section 1.1).

Often (but not necessarily) following oxidation by P450 enzymes, xenobiotic metabolites are conjugated with an endogenous substrate, resulting in a large increase in drug polarity (Armstrong, 1997). Major conjugation reactions include glucuronidation, sulfation, and glutathione (GSH) conjugation. Several protective pathways also act to prevent endogenous ROS levels from causing oxidative damage. Serious adverse effects can occur when the levels of antioxidants or antioxidative enzymes are low, as in the cases of aging, development, and disease, or when ROS levels are increased following exposure to pro-oxidants (Wells et al., 2009). If reactive intermediates escape scavenging and detoxication, cellular repair mechanisms also exist to correct lesions to DNA (Klungland et al., 1999).

A major pathway for the elimination of electrophiles and other toxic xenobiotics involves conjugation with GSH and the subsequent formation of mercapturic acids (Nacetylcysteine S-conjugates). The metabolism of GSH adducts (X-GSH) is initiated by the action of $\gamma$-glutamyltranspeptidase (GGT; $\gamma$-glutamyltransferase; E.C. 2.3.2.4), giving S-substituted cysteinylglycine (Cys-Gly) conjugates (X-CG); subsequently, dipeptidases 
catalyze hydrolysis of the Cys-Gly peptide bond to yield cysteine (Cys) S-conjugates (XC). Finally, acetyl-coenzyme A (acetyl-CoA)-dependent N-acetylation (Veiga-da-Cunha et al., 2010) produces the corresponding mercapturic acids.

The conjugation of xenobiotics and their metabolites with GSH by glutathione transferases (GSTs; E.C. 2.5.1.18) represents one of the major cellular defense mechanisms against electrophilic insults (Armstrong, 1997). This detoxication reaction produces a water-soluble conjugate that is converted by a series of enzymatic steps into a mercapturic acid (Hinchman and Ballatori, 1994; Josephy and Mannervik, 2006). Despite the widespread recognition of this pathway in the literature, the substrate specificity of membrane dipeptidase (MDP; also known as renal dipeptidase; microsomal dipeptidase; dehydropeptidase I; membrane-bound dipeptidase (MBD); E.C. 3.4.13.19), the enzyme thought to possess the major X-CG hydrolysis activity in mammalian kidney, has yet to be extensively studied with various aromatic Cys-Gly conjugates. This introduction describes the enzymes currently implicated in GSH metabolism, with particular focus on $\mathrm{X}-\mathrm{CG}$ hydrolysis. The objective of the work presented in this thesis was to purify and investigate the substrate specificity of MDP.

\subsection{THE MERCAPTURIC ACID PATHWAY}

\subsubsection{OVERVIEW}

Xenobiotics undergo a series of biochemical conversions following conjugation with GSH (Figure 1). Some metabolic steps take place inside, and some outside the cell. Several organs, such as the liver, the intestine and the kidney, contribute to mercapturic acid formation. Therefore the intermediates and end products of this pathway have to be 


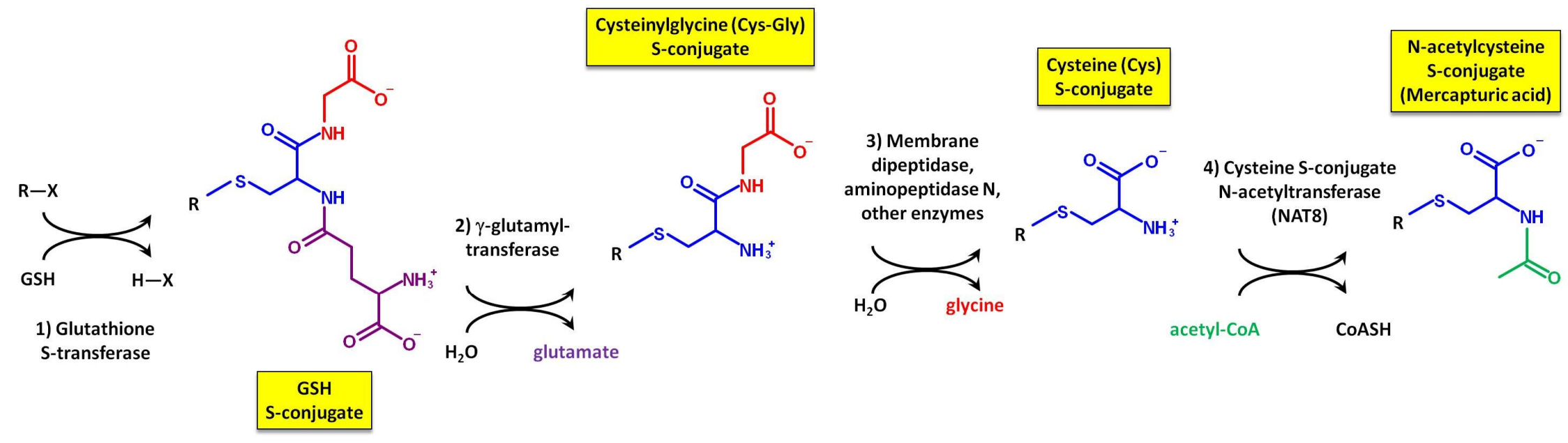

\section{FIGURE 1. THE MERCAPTURIC ACID PATHWAY.}

(1) conjugation of an electrophile with glutathione; (2) hydrolysis of the $\gamma$-glutamyl peptide bond; (3) hydrolysis of the $\alpha$ peptide bond; (4) N-acetylation of the cysteine S-conjugate. 
transported through cell membranes as well as among the organs involved. GSH adducts are usually exported from the cell by the action of transporters and then processed into mercapturic acids, which are excreted in the urine or bile (Cole and Deeley, 2006; Egner et al., 2008; Teichert et al., 2009).

\subsubsection{Glutathione}

The mercapturic acid pathway begins with the small molecule $\gamma$-L-glutamyl-Lcysteinyl-glycine, commonly known as GSH. GSH is a tripeptide that has a variety of cellular functions, primarily participating in biochemical reactions for the maintenance of redox homeostasis and the trapping of electrophiles (Josephy and Mannervik, 2006). GSH also plays a role in the regulation of protein function and gene expression via thiolsulfide exchange reactions, and decreases in reduced GSH have been reported in disease states such as cancer and liver disease (Townsend et al., 2003; Wu et al., 2004). GSH is the most abundant low-molecular-weight thiol in mammalian cells (Combes and Stakelum, 1961; Hayes et al., 2005); its production is estimated at 10 grams per day in the adult human (Meister, 1995).

Structurally, the most distinguishing feature of GSH is the functional thiol group. The sulfur atom is highly polarizable, making it a good nucleophile for reactions with electrophilic compounds. GSH is also a good reducing agent due to the electron-donating nature of the free thiol, and has a role as a key co-factor in a number of biochemical pathways. The GSH molecule features an unusual $\gamma$-peptide linkage between the Nterminal glutamic acid and the cysteine residue; this moiety prevents degradation by cellular peptidases but can be hydrolyzed by $\gamma$-glutamyltranspeptidase (see section 2.3.4). 


\subsubsection{GLUTATHIONE CONJUGATION}

GSH is capable of directly conjugating with some compounds non-enzymatically (Meister, 1995; Reed, 1990). More commonly, conjugation reactions are catalyzed by a family of enzymes known as GSTs. GSTs are comprised of two enzyme superfamilies, the soluble GSTs and the membrane-associated proteins in eicosanoid and glutathione metabolism (MAPEG) GST family (Josephy and Mannervik, 2006). Many mammalian GST enzymes are highly specific for the tripeptide GSH. Once formed, most GSH conjugates are unable to readily diffuse across the plasma membrane due to their polar character. Transport of GSH conjugates out of the cell is mediated by the multidrug resistance-associated protein (MRP) family of transporters (Keppler et al., 1998; Keppler, 1999).

\subsubsection{GAMMA-GLUTAMYLTRANSPEPTIDASE}

The next step in the mercapturic acid pathway is the hydrolysis of GSH conjugates at the $\gamma$-glutamyl bond by GGT. The loss of glutamic acid produces a X-CG. GGT is a cell membrane integral protein with an extracellular-facing active site (Tsao and Curthoys, 1980). It is expressed in the cells of the biliary epithelium, the bile canalicular membrane of hepatocytes, the small-intestinal epithelium, the renal tubular brush-border membrane, and in the basolateral membrane of tubule cells (Silbernagl and Heuner, 1990). Studies have shown that inhibition of GGT prevents the readsorption of $\gamma$ glutamyl peptides, and that the Cys-Gly bond can only be hydrolyzed following the loss of the $\gamma$-glutamyl residue (Silbernagl and Heuner, 1990). 


\subsubsection{Cys-GLy CONJUGATE HYDROLYSIS}

In mammals, the kidney is a major site for the processing of GSH conjugates (McIntyre and Curthoys, 1982). MDP has been implicated in the metabolism of Cys-Gly and the X-CG, leukotriene $\mathrm{D}_{4}\left(\mathrm{LTD}_{4}\right)$ (Adachi et al., 1989). The enzyme is found in the renal brush border microvillar membrane and also in the lung (Brewis et al., 1994; Campbell et al., 1990; Curthoys et al., 1980; Welch and Campbell, 1980). In pig kidney, immunohistochemical analysis revealed that MDP is present in the cortex but not in the medulla (Littlewood et al., 1989). MDP is a glycosylphosphatidylinositol (GPI)-anchored plasma membrane protein and can be released by the action of phosphatidylinositol-specific phospholipase C (PI-PLC) (Brewis et al., 1994; Campbell et al., 1990; Hooper et al., 1987; Hooper et al., 1990; Littlewood et al., 1989). MDP, a $\mathrm{Zn}^{2+}$ containing enzyme, is inhibited by general metalloenzyme inhibitors such as dithiothreitol (DTT) and also by the specific inhibitor cilastatin (Hooper et al., 1987; Littlewood et al., 1989). Renal MDP has been shown to catalyze the degradation of $\beta$ lactam carbapenem antibiotics such as imipenem (Kropp et al., 1982). Consequently, coadministration of cilastatin is used to improve the therapeutic effectiveness of these agents by extending their half-life. It has been shown that patients treated with imipenemcilastatin have significantly increased plasma levels of Cys-Gly, which is in agreement with the inhibitory effect of cilastatin on MDP activity (Badiou et al., 2005).

The gene encoding MDP has been cloned from several species, including pig (Rached et al., 1990), rat (Adachi et al., 1992), mouse (Satoh et al., 1993), and human (Adachi et al., 1990; Nitanai, 1996). Recombinant human MDP has been successfully expressed in Pichia pastoris; following enzymatic removal of oligosaccharides, the 
enzyme was crystallized and X-ray crystal structures were determined, with and without bound cilastatin (Nitanai et al., 2002). It was shown that the human enzyme possesses an elongated ellipsoidal shape; the majority of the subunit structure is composed of $\alpha / \beta$ barrel architecture, and this architecture is aligned at a $40^{\circ}$ angle along the long axis of the protein (Figure 2). The MDP subunits are linked by a disulfide bridge at the Cys361 side-chain, near the C-terminus and GPI anchor. Mutagenesis studies have shown that Cys361 is the only conserved cysteine residue involved in disulfide-linked dimerization of the MDP enzyme (Keynan et al., 1996); the other conserved residues make two disulfide bonds within a subunit. Each subunit has four possible N-glycosylation sites. In the linked homodimer protein, there are additional molecular contacts between the subunits located primarily at helices $\alpha 2$ and $\alpha 3$. The $\mathrm{N}$-terminal ends of the homodimer protein are capped by helices, and the C-terminal ends face the membrane. The active sites are located on the protein surface facing the membrane, which makes them suitable for receiving substrates transported from the membrane.

Although some reports suggest that the ratio of zinc ions per monomer subunit is one (Armstrong et al., 1974), the crystal structure of human MDP clearly shows that each monomer requires two zinc ions in the active site (Nitanai et al., 2002). It was determined that the active site of each subunit is located at the bottom of the $(\alpha / \beta)_{8}$ barrel (Figure 3); it accommodates binding for two zinc ions, bridged by the carboxyl oxygen atoms of Glu125 at the bottom of the pocket. Previous mutagenesis studies have indicated that His20 (Keynan et al., 1997), Glu125 (Adachi et al., 1993), His198 (Keynan et al., 1997), and His219 (Keynan et al., 1994) are involved in the catalytic mechanism of MDP. These residues bind the zinc ions (Figure 3B). Not surprisingly, a non-conservative substitution 

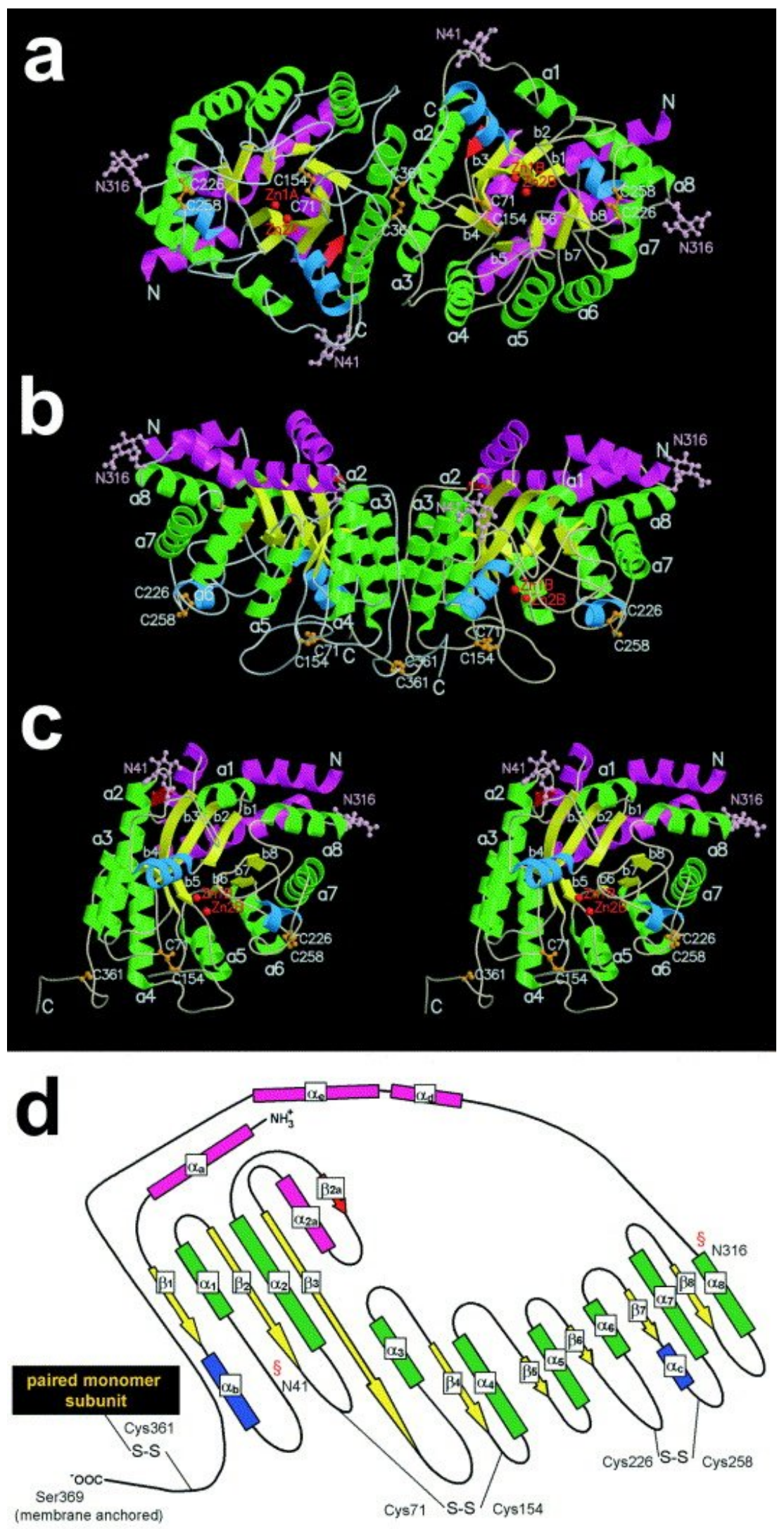


\section{FIGURE 2. OVERALL VIEW OF HUMAN MDP.}

(a) The dimeric structure of human MDP viewed from the membrane-binding side. The active sites are located on this side. The $\alpha$-helices and the $\beta$-strands forming the $(\alpha / \beta)_{8}$ barrels are shown in green and yellow, respectively, and the $\alpha$-helices capping the barrels are shown in magenta. Zinc ions are drawn as red spheres; cysteine residues forming disulfide bonds are drawn as yellow ball-and-sticks; N-linked N-acetylglucosamine molecules are drawn as pink ball-and-sticks. (b) The dimer viewed from a $90^{\circ}$ rotation along the long axis of the dimer. (c) Stereo representation of a monomer subunit. (d) A drawing of the folding of the monomer subunit. The strands or helices are drawn to reflect their relative lengths. The colour scheme and labels are consistent with those in (a) to $(\mathrm{c})$.

With permission from Nitanai et al. (2002).

in any of these residues results in significant reduction of enzyme activity, likely due to the inability of the active site to bind the zinc ion(s). Another residue, His152, is highlyconserved among MDP of different species and has been shown to play an important role in substrate binding (Keynan et al., 1997). His152 does not bind the zinc ions; the nitrogen atom of His152 forms a hydrogen bond with the oxygen atom of the peptide substrate (Figure 3B). His152 is thus responsible for the recognition of a substrate or an inhibitor.

The active site-binding pocket of MDP is small enough to precisely recognize dipeptide substrates; it is able to fully accommodate the dipeptidyl moiety of cilastatin (Figure 3A). The cilastatin molecule adopts a constrained conformation because the dimethylcyclopropyl group produces a subtle displacement of the peptide carbonyl atoms from optimal positions in the binding pocket; this displacement prevents the carbon atom from undergoing nucleophilic attack. However, the complete relationship between the 

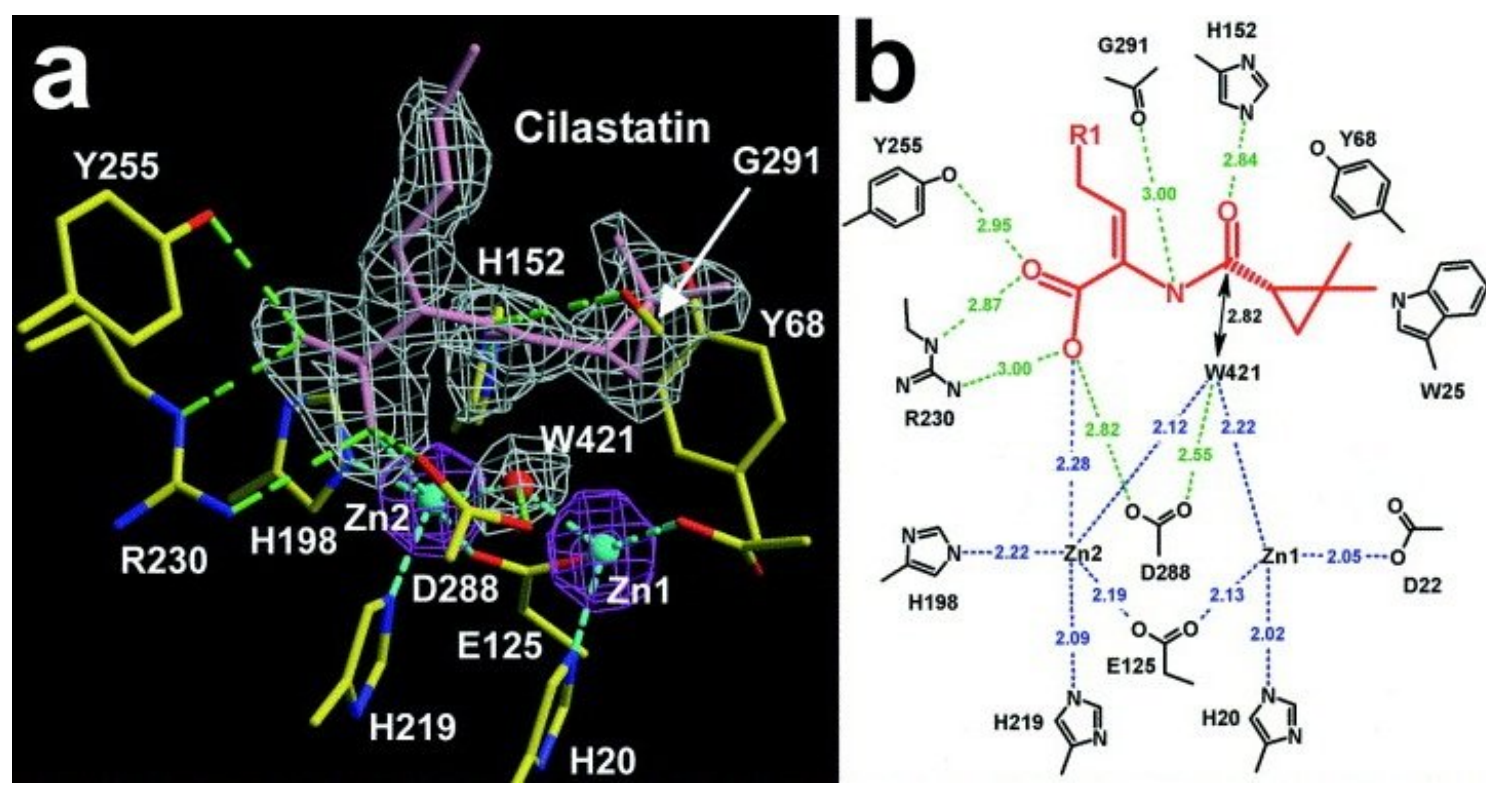

FIGURE 3. HUMAN MDP ACTIVE SITE WITH CILASTATIN LIGAND.

(a) The Fo-Fc electron density maps superimposed on the structural model. The cilastatin ligand is shown as a purple stick. The cysteinyl moiety of the ligand is not discernible in the map and is omitted from the drawing. Hydrogen bonds are drawn as broken green lines, and coordinate bonds to $\mathrm{Zn}$ ions as broken cyan lines. (b) A drawing of the interactions among the cilastatin molecule, the $\mathrm{Zn}$ ions and the residues comprising the active site. $\mathrm{R} 1$ stands for $\left(\mathrm{CH}_{2}\right)_{3} \mathrm{SCH}_{2} \mathrm{CH}\left(\mathrm{NH}_{3}{ }^{+}\right) \mathrm{COO}^{-}$. The hydrogen bonds are indicated as broken green lines, and the coordinate bonds as broken blue lines. The distances are also shown in the figure (in $\AA$ ). The distance between binuclear $\mathrm{Zn}$ ions is $3.3 \AA$ for both of the MDP subunits.

With permission from Nitanai et al. (2002).

MDP active site and its catalytic mechanism towards dipeptide substrates has yet to be established.

In addition to studies of recombinant MDP, the enzyme has also been examined in mammalian systems. MDP knockout mice are viable (Habib et al., 1998); LTD $_{4}$ hydrolysis activity in tissue homogenates from knockout mice was shown to be reduced, 
but not to zero, indicating that other genes/enzymes also contribute. Among the organs examined, the largest reduction (at 16\% of wild-type activity) was observed in the kidney, indicating that MDP may have a critical role in the renal metabolism of X-CG (Habib et al., 1998).

Although MDP has long been suspected to be a major catalyst of the hydrolysis of Cys-Gly xenobiotic conjugates in mammals, few such conjugates have been tested directly as MDP substrates, especially with regard to aromatic substrates that are representative of the detoxication products of aryl and polycyclic aromatic toxicants and drugs (Bakhiya et al., 2007; Poon et al., 2001; Sabatini et al., 2008); the substrate specificity of MDP towards different Cys-Gly conjugates remains unclear.

In addition to MDP, several other enzymes have been implicated in Cys-Gly or XCG hydrolysis, as discussed in this section and summarized in Table 1; these include the membrane-bound enzyme aminopeptidase N (APN; also known as aminopeptidase M; membrane alanyl aminopeptidase; microsomal aminopeptidase; E.C. 3.4.11.2) (Kozak and Tate, 1982; Rankin et al., 1980) and several cytosolic enzymes: cytosol nonspecific dipeptidase (E.C. 3.4.13.18) (Kaur et al., 2009; Teufel et al., 2003), leucyl aminopeptidase (also known as cytosol aminopeptidase; peptidase S; E.C. 3.4.11.1) (Cappiello et al., 2004; Jösch et al., 1998; Jösch et al., 2003), and prolyl aminopeptidase (also known as cytosol aminopeptidase V; E.C. 3.4.11.5) (Turzynski and Mentlein, 1990). The relative roles of these enzymes in the metabolism of xenobiotics are still unclear. 
TABLE 1. ENZYMES REPORTED TO CATALYZE HYDROLYSIS OF CYSGLY OR ITS CONJUGATES.

\begin{tabular}{|c|c|c|c|c|c|}
\hline Enzyme & EC & $\begin{array}{l}\text { Typical substrates } \\
\text { examined }\end{array}$ & Species & Organ & Ref. \\
\hline \multicolumn{6}{|c|}{ Mammalian; membrane-bound } \\
\hline $\begin{array}{l}\text { membrane } \\
\text { dipeptidase } \\
(\mathrm{MDP})\end{array}$ & 3.4.13.19 & $\begin{array}{l}\text { carbapenem antibiotics, } \\
\text { Cys-Gly, S-Me-Cys-Gly }\end{array}$ & $\begin{array}{l}\text { human, pig, } \\
\text { mouse, rat, } \\
\text { rabbit }\end{array}$ & $\begin{array}{l}\text { kidney, } \\
\text { lung }\end{array}$ & $1-9$ \\
\hline $\begin{array}{l}\text { aminopeptidase } \mathrm{N} \\
(\mathrm{APN})\end{array}$ & 3.4 .11 .2 & $\begin{array}{l}\text { Cys-Gly, S-Me-Cys- } \\
\text { Gly, S-benzyl-cysteine- } \\
p \text {-nitroanilide; } \text { LTD }_{4} \text { not } \\
\text { hydrolyzed }\end{array}$ & $\begin{array}{l}\text { human, pig, } \\
\text { rat }\end{array}$ & $\begin{array}{l}\text { kidney, } \\
\text { intestine }\end{array}$ & $\begin{array}{l}1 \\
10- \\
14\end{array}$ \\
\hline \multicolumn{6}{|c|}{ Mammalian; cytosolic } \\
\hline $\begin{array}{l}\text { cytosol } \\
\text { nonspecific } \\
\text { dipeptidase }\end{array}$ & 3.4.13.18 & dipeptides & human & $\begin{array}{l}\text { kidney, } \\
\text { liver, etc. }\end{array}$ & $\begin{array}{l}15- \\
16\end{array}$ \\
\hline $\begin{array}{l}\text { leucyl } \\
\text { aminopeptidase }\end{array}$ & 3.4 .11 .1 & $\begin{array}{l}\text { Cys-Gly, bimane-S-Cys- } \\
\text { Gly, S-nitroso-Cys-Gly, } \\
\text { LTD }_{4}\end{array}$ & bovine, rat & liver, lens & $\begin{array}{l}17- \\
19\end{array}$ \\
\hline $\begin{array}{l}\text { prolyl } \\
\text { aminopeptidase }\end{array}$ & 3.4 .11 .5 & di- and tripeptides & rat & $\begin{array}{l}\text { kidney, } \\
\text { brain }\end{array}$ & 20 \\
\hline \multicolumn{6}{|c|}{ Yeast and bacterial enzymes } \\
\hline $\begin{array}{l}\text { aminopeptidase } \\
\text { A, B, N }\end{array}$ & 3.4 .11 .23 & dipeptides & \multicolumn{2}{|c|}{$\begin{array}{l}\text { Salmonella enterica, } \\
\text { Escherichia coli }\end{array}$} & $\begin{array}{l}21- \\
22\end{array}$ \\
\hline dipeptidase $\mathrm{D}$ & 3.4.13.- & Cys-Gly, Leu-Gly & \multicolumn{2}{|c|}{ Escherichia coli } & 22 \\
\hline DUG1 & 3.4.13.- & Cys-Gly & \multicolumn{2}{|c|}{$\begin{array}{l}\text { Saccharomyces } \\
\text { cerevisiae }\end{array}$} & 16 \\
\hline
\end{tabular}


EC $=$ E.C. number (dash denotes unspecified dipeptidase). References: 1, Kozak and Tate, 1982; 2, Kropp et al., 1982; 3, Farrell et al., 1987; 4, Hirota et al., 1987; 5, Hooper et al., 1987; 6, Campbell et al., 1988; 7, Adachi et al., 1989; 8, Littlewood et al., 1989; 9, Satoh et al., 1993; 10, Rankin et al., 1980; 11, Hussain et al., 1981; 12, McIntyre and Curthoys, 1982; 13, Hirota et al., 1985; 14, Vanderheyden et al., 2006; 15, Teufel et al., 2003; 16, Kaur et al., 2009; 17, Jösch et al., 1998; 18, Jösch et al., 2003; 19, Cappiello et al., 2004; 20, Turzynski and Mentlein, 1990; 21, Mathew et al., 2000; 22, Suzuki et al., 2001.

The ability of APN to hydrolyze Cys-Gly was demonstrated with purified rat renal membrane protein preparations using peptidase activity assays and inactivation studies with Fab antibody fragments (Rankin et al., 1980). It was shown that purified Cys-Gly peptidase activity also displayed activity with leucine- $p$-nitroanilide and alaninep-nitroanilide, which are both APN substrates. These three activities co-migrated on a non-denaturing electrophoretic gel; gel slices were incubated with buffer and re-assayed with the three substrates, providing strong evidence that these activities were due to a single enzyme. Monovalent Fab antibody fragments were generated by immunization of rabbits with purified APN and papain digestion of the ammonium sulfate precipitated serum. Isolated brush border membrane vesicles displayed similar inactivation profiles for these three activities when titrated with the Fab fragment of antibodies specific for this peptidase, indicating that these activities were due to APN. This Cys-Gly hydrolysis activity was corroborated in a study of $\mathrm{Ca}^{2+}$-precipitated microvillus membranes enriched in APN (further discussed in section 1.3.6) (Kozak and Tate, 1982).

Another enzyme with dipeptide hydrolysis activity is cytosol nonspecific dipeptidase, which was first identified as human tissue carnosinase (Lenney et al., 1985). Carnosine ( $\beta$-alanyl-L-histidine) is found at high levels in muscle and brain tissues 
(Mannion et al., 1992; Tabakman et al., 2002); the function of this dipeptide is currently not well understood, but it may be involved in free radical scavenging and neuroprotection (Baran, 2000; Tabakman et al., 2002). Carnosinase may play a role in the homeostasis of carnosine and related dipeptides to protective levels (Teufel et al., 2003). Human tissue carnosinase was later renamed cytosolic nonspecific dipeptidase based on the enzyme's biophysical data (molecular mass, homodimer), its broad substrate specificity and its strong inhibition by the aminopeptidase inhibitor bestatin (Lenney, 1990; Teufel et al., 2003). This enzyme is closely related to human carnosinase (E.C. 3.4.13.20), but does not itself exhibit carnosinase activity except at alkaline $\mathrm{pH}$ (optimum pH 9.5) (Teufel et al., 2003). CNDP2, the gene that encodes cytosol nonspecific dipeptidase, was identified in the Human Genome Science database based on its homology to the gene encoding human carnosinase (49\% identity). Cytosol nonspecific dipeptidase expressed and purified from Chinese hamster ovary cells can hydrolyze a large variety of dipeptide substrates (Teufel et al., 2003). This protein is localized in the cytoplasmic fraction, as analyzed by Western blotting. The CNDP2 protein displays a strong preference for Cys-Gly, but can also hydrolyze other dipeptides and has been shown to rescue Cys-Gly hydrolysis in a S. cerevisiae strain lacking this activity (Kaur et al., 2009).

The enzyme and subcellular localization of X-CG hydrolysis activity may also differ depending on the organ of study. In rat liver, the majority (calculated to be over $95 \%$, based on the soluble fraction comprising $28 \%$ of cellular protein) of total X-CG peptidase activity was found in the cytosol (Jösch et al., 1998); it was shown that this activity co-eluted with leucinamide hydrolysis activity on anion-exchange 
chromatography (diethylaminoethyl (DEAE)-Sephacel), suggesting the identity of this enzyme to be cytosolic leucyl aminopeptidase (Jösch et al., 2003). Inhibition of this activity by bestatin and $o$-phenanthroline indicated this enzyme was a metal-dependent cytosolic aminopeptidase. Futhermore, immunoprecipitation of Pansorbin-coupled antibodies raised against hog kidney leucyl aminopeptidase showed that the isolated enzyme and the cytosolic X-CG activity are both equally bound to the affinity matrix (approx. 80\% activity recovery), confirming that cytosolic leucyl aminopeptidase is responsible for the X-CG hydrolysis activity in rat liver (Jösch et al., 2003).

Mammalian prolyl aminopeptidase may represent another enzyme that is involved in GSH metabolism. It was unclear whether mammalian prolyl aminopeptidase is only specific for peptides containing an N-terminal proline or whether it represents an aminopeptidase with broader substrate specificity. Rat brain and kidney cytosolic prolyl aminopeptidase were purified and separated from other di- and tripeptidases with DEAESephacel, prolylleucylglycine (PLG)-Sepharose, Sephacryl S-300, and Mono Q columns (Turzynski and Mentlein, 1990). Prolyl aminopeptidase activity was determined with a ninhydrin colorimetric assay specific for the release of proline (Messer, 1961). It was shown that mammalian prolyl aminopeptidase, in addition to removing $\mathrm{N}$-terminal proline, also liberates other, more lipophilic amino acids from di-, tri- and oligopeptides (Turzynski and Mentlein, 1990). It was concluded that the mammalian prolyl aminopeptidase is likely identical to leucyl aminopeptidase, at least in rats, based on several lines of evidence including a comparison of their molecular data, co-purification on ion-exchange chromatography, actions on various peptides, and similar responses to inhibitors and activators. 
Enzymes catalyzing X-CG hydrolysis have also been identified in lower organisms, including aminopeptidases A, B, and N of Salmonella enterica (Mathew et al., 2000; Suzuki et al., 2001), dipeptidase D of Escherichia coli (Suzuki et al., 2001), and Cys-Gly metallodipeptidase DUG1 of Saccharomyces cerevisiae (Kaur et al., 2009).

\subsubsection{MEMBRANE DIPEPTIDASE}

Two membrane-bound enzymes, MDP and APN, have been identified by several groups to be largely responsible for X-CG hydrolysis in mammalian kidney (Hughey et al., 1978; Kozak and Tate, 1982; Okajima et al., 1981; Rankin et al., 1980). Both of these enzymes have been shown to be co-localized with GGT on the cell membrane with an extracellular-facing active site (Hughey et al., 1978; Kozak and Tate, 1982). Hydrolysis of the $\alpha$-peptide bond produces the constituent amino acid glycine and a Cys conjugate. Transport of Cys conjugates into the cell is largely mediated by L-amino acid transporter 1 and other members of the heterodimeric amino acid transporter family (Kanai and Endou, 2003).

Kozak and Tate (1982) purified membrane proteins from rat kidney to determine the relative significance of these enzymes in GSH metabolism. They showed that microvillus membranes, purified by $\mathrm{Ca}^{2+}$-precipitation from rat kidney and various other tissues, exhibit GGT, MDP and APN activities. The enzyme activities of solubilized membrane proteins were determined by a ninhydrin-cyanide assay, using several di- and tripeptide substrates. The principle underlying this assay is the condensation of the ninhydrin molecule with primary amines at the $\mathrm{N}$-terminal end of peptides to form a Schiff base (Jelly et al., 2009; Yemm and Cocking, 1955). An intermediate amine is formed when the alkyl group of the amino acid chain is lost. This intermediate reacts with 
a second molecule of ninhydrin to produce the chromophore diketohydrindylidenediketohydrindamine (DYDA; Ruhemann's purple). Thus, the concentration of free amino acids is proportional to the absorbance at $570 \mathrm{~nm}$ and can be determined with a colorimetric assay. Specific activities were expressed as micromoles of product $/ \mathrm{min} / \mathrm{mg}$ of membrane protein. A modified version of this assay is used later in this thesis to study the specific activity of MDP for Cys-Gly dipeptide substrate.

It was found that renal MDP had specific activity several hundred-fold higher than that of APN in the hydrolysis of numerous peptides, including $\mathrm{LTD}_{4}(16.4 \mathrm{units} / \mathrm{mg}$ vs. $<0.001$ units/mg) and S-methyl-Cys-Gly (567 units/mg vs. 2.1 units $/ \mathrm{mg}$ ), a mercapturic acid precursor (Kozak and Tate, 1982). Despite the fact that MDP accounts for considerably less protein than APN in renal membranes (0.1-0.2\% vs. 5\%), the high specific activity of MDP suggested a major physiological role for GSH metabolism in mammalian kidney. Furthermore, Kozak and Tate definitively showed that GGT, MDP and APN are integral membrane proteins; treatment of membrane fractions with $0.01 \mathrm{M}$ Tris-HCl buffer ( $\mathrm{pH}$ 7.4) containing $1 \mathrm{M} \mathrm{NaCl}$ did not significantly reduce enzyme activities, indicating that these proteins were indeed membrane-bound and their results were not an artifact of proteins becoming adsorbed to the membranes during fractionation. Previous studies have shown that vesicles obtained by $\mathrm{Ca}^{2+}$-precipitation are sealed right-side out (Haase et al., 1978; Tsao and Curthoys, 1980); the majority of these enzyme activities were inactivated by the addition of Fab antibody fragments specific to the enzymes of interest, indicating that the active sites of these enzymes were indeed facing the external cell surface. Further characterization by sodium dodecyl sulfate polyacrylamide gel electrophoresis (SDS-PAGE) and gel filtration analysis 
revealed that MDP is a disulfide-linked homodimer composed of two 50-kDa subunits (Kozak and Tate, 1982). MDP is anchored to the phospholipid bilayer by a GPI anchor; this linkage may allow the selective release of certain cell-surface proteins by the action of endogenous phospholipases (Park et al., 2001; Yoon et al., 2007). This membranebound glycoprotein is involved in the hydrolysis of dipeptides, and shows activity only towards substrates with peptide bond moieties (Adachi et al., 1990; Campbell et al., 1966).

\subsubsection{CySteine S-CONJUGATE N-ACETYLTRANSFERASE}

Cys conjugate $\mathrm{N}$-acetyltransferase (CCNAT) is a labile protein that was difficult to purify due to difficulties in solubilizing and stabilizing the enzyme without loss of specific activity. The N-acetyltransferase that is involved in GSH metabolism is distinct from the aromatic amine N-acetyltransferases (Josephy and Mannervik, 2006; Tabor et al., 1953). Mercapturic acids are similar to most organic anions and transported out of the cell by organic anion transport (OAT) systems (Inoue et al., 1981; Inoue et al., 1984). Mercapturate transport may also be mediated by the ATP-dependent export pump, multidrug resistance-associated protein 2 (MRP2) (Keppler, 2005). Studies on microsomal preparations have shown that the active site of CCNAT is localized to the cytoplasmic side of the endoplasmic reticulum (ER) (Elce, 1970; Green and Elce, 1975; Okajima et al., 1984). The CCNAT co-substrate acetyl-CoA is localized in the cytosol at high concentrations to facilitate rapid and efficient $\mathrm{N}$-acetylation of Cys conjugates (Garland et al., 1965). CCNAT is also involved in the metabolism of the cysteinyl leukotrienes $\mathrm{C}_{4}, \mathrm{D}_{4}$, and $\mathrm{E}_{4}$; these fatty lipid-rich molecules play a role in the inflammation response of the immune system (Singh et al., 2010). 
The distribution of CCNAT appears to be greatest in kidney and liver (Duffel and Jakoby, 1982; Hughey et al., 1978). Activity assays with radioactive substrates have shown that the specific activity of CCNAT for Cys conjugates in rat kidneys is nearly two-fold greater than that found in liver (Green and Elce, 1975). Mercapturates formed in the liver are secreted into the bile, where they usually undergo enterohepatic circulation and eventually reach the kidneys (Silbernagl and Heuner, 1990).

Recently, human N-acetyltransferase 8 (NAT8) was identified as one of the enzymes that catalyzes the formation of mercapturic acids (Veiga-da-Cunha et al., 2010). A ClustalX (amino acid sequence alignment program) database search for mammalian proteins with similarity to known NATs and with predicted membrane association led to the identification of NAT8 as a candidate for the previously described CCNAT; Veigada-Cunha and colleagues tested whether NAT8 corresponds to the enzyme that catalyzes the last step of mercapturic acid formation. They cloned human NAT8 and NAT8 variant proteins as His-tagged fusions into HEK293T cells, a human embryonic kidney cell line that is often used for recombinant protein expression studies (Graham et al., 1977). Kinetic studies were performed on crude cell extracts for specific substrates, at fixed concentrations of co-substrates. Kinetic parameters for S-benzyl-L-cysteine were as follows: $K_{\mathrm{m}}=64 \mu \mathrm{M} ; V_{\max }=4.4 \mathrm{nmol} \cdot \mathrm{min}^{-1} \cdot \mathrm{g}^{-1}$ protein. Interestingly, $\mathrm{LTE}_{4}$ was found to be acetylated at a rate about 100-fold lower than S-benzyl-L-cysteine; the implications for cysteinyl leukotriene metabolism remain unknown. In addition, Veiga-da-Cunha and colleagues (2010) confirmed the subcellular localization of NAT8 to the ER by immunofluorescence and confocal microscopy. 


\subsubsection{RESEARCH ON ENZYMES IN THE MERCAPTURIC ACID PATHWAY}

Recent work performed in the Josephy laboratory led to the development of an affinity purification strategy for proteins that bind mercapturic acids (Erin Veldman, unpublished data). Following tryptic digestion, affinity-purified proteins were analyzed by mass spectrometry proteomics for amino acid sequence identification. Although CCNAT was not successfully isolated using this approach, peptidases that were both known (MDP, APN) and previously not known (angiotensin converting enzyme, dipeptidyl-peptidase IV (DPP-IV)) to play a role in the mercapturic acid pathway were identified.

In this study, we have purified MDP to homogeneity by PI-PLC-mediated cleavage of the GPI anchor, followed by cilastatin affinity chromatography; this strategy was based on literature precedents of renal MDP purification (Adachi et al., 1989; Hooper et al., 1987; Kraus et al., 2000) (Figure 4). We also synthesized several aromatic Cys-Gly conjugates and developed high performance liquid chromatography (HPLC) separation methods for their quantitation. The enzyme kinetics of MDP towards these conjugates was studied, providing insight into the factors affecting the enzyme's substrate selectivity. 


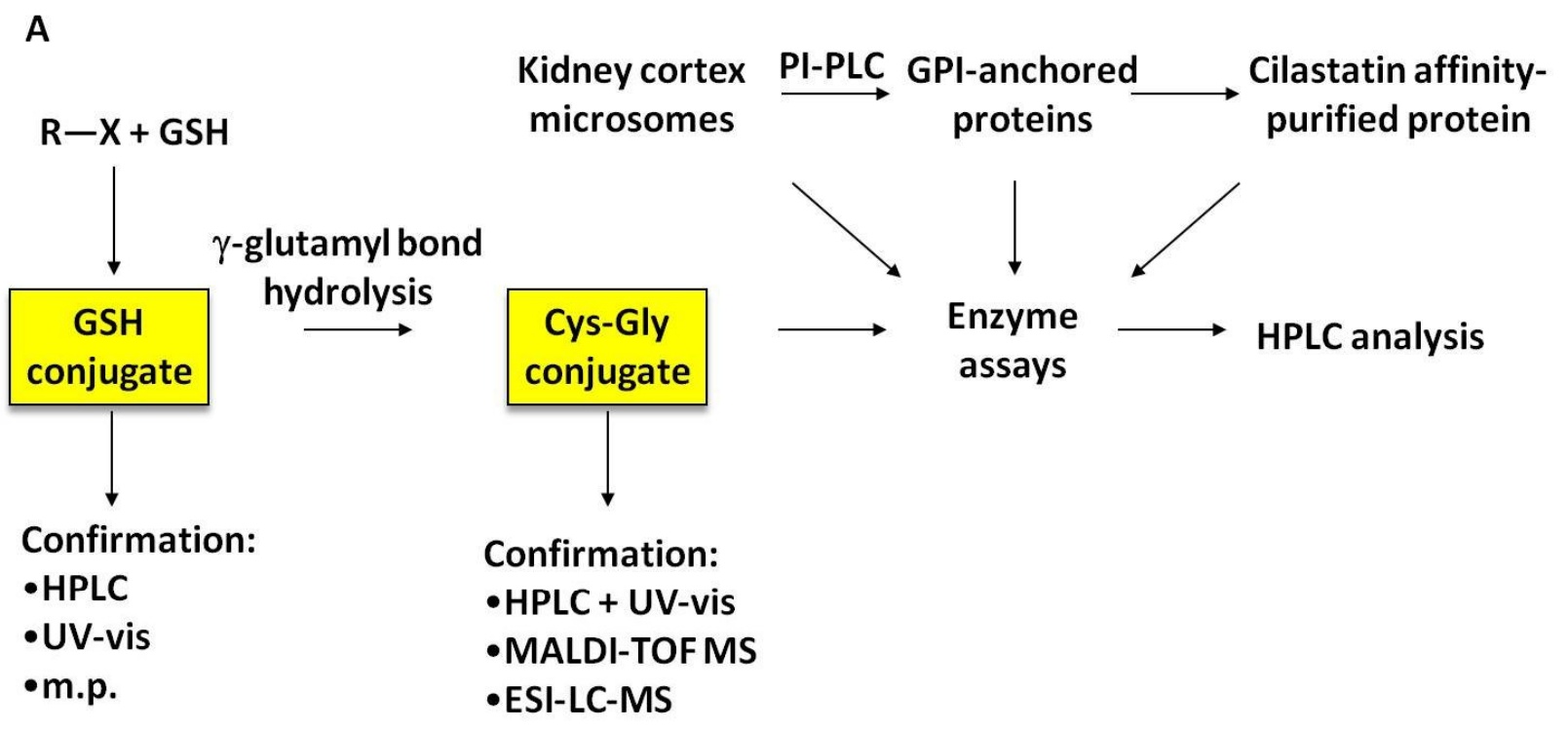

B

Cilastatin affinitypurified protein

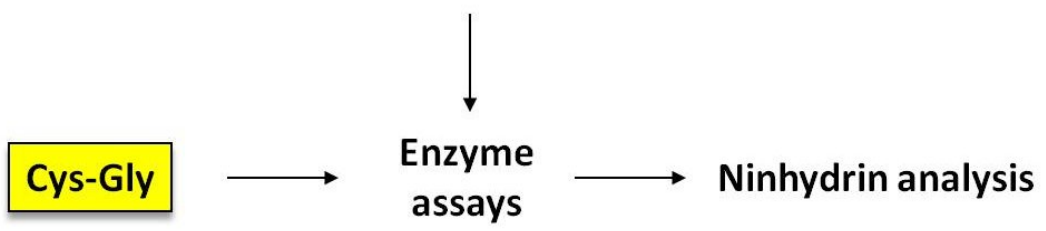

FIGURE 4. SCHEMATIC OF EXPERIMENTAL METHODS.

MDP was purified and assayed with (A) synthesized Cys-Gly conjugates or (B) Cys-Gly dipeptide. 


\section{MATERIALS AND METHODS}

\subsection{CHEMICALS}

Commercial sources of chemicals were as follows: bovine serum albumin (BSA; 98\%), 1-(chloromethyl)naphthalene ( $\mathrm{MCl} ;$ menaphthyl chloride; >97\%), L-cysteine (97\%), cysteinylglycine (Cys-Gly; CG; >85\%), DTT, GSH, ninhydrin, 4-nitrobenzyl chloride (NBCl; 99\%), and trichloroacetic acid (TCA) solution (6.1 N), Sigma Chemicals (St. Louis, MO, USA); benzyl chloride (99\%), 3-[(3-cholamidopropyl)dimethylammonio]-1-propanesulfonate (CHAPS), and trifluoroacetic acid (TFA; 99\%), Fisher Scientific (Whitby, ON, Canada); 1-chloro-2,4-dinitrobenzene (CDNB; 98\%), Alfa Aesar (Ward Hill, MA, USA); cilastatin (98\%), Ontario Chemicals, Inc. (Guelph,

ON, Canada). All other chemicals and reagents were of the highest grades commercially available.

\subsection{SYNTHESIS OF GLUTATHIONE CONJUGATES}

Very few Cys-Gly conjugates are commercially available. Because of the high cost of Cys-Gly dipeptide, and in view of a report that the attempted synthesis of 2,4dinitrophenyl (DNP)-CG by arylation of Cys-Gly was unsuccessful (Vaidya and Gerk, 2007), we prepared X-CG substrates by hydrolysis of the corresponding GSH conjugates. This strategy exploits the lability of the $\gamma$-glutamyl isopeptide bond relative to the $\alpha$ peptide bond in GSH (Figure 1) (Kendall et al., 1930). Syntheses of GSH conjugates of $\mathrm{CDNB}, \mathrm{MCl}$, and $\mathrm{NBCl}$ were based on a previously published protocol (Shiotsuki et al., 1990), as exemplified by the preparation of DNP-GSH. CDNB (202 mg, $1 \mathrm{mmol}$ ) was added to a solution of GSH (307 mg, $1 \mathrm{mmol})$ in $2 \mathrm{M} \mathrm{NaOH}(1.0 \mathrm{~mL})$ and $95 \%$ ethanol 
$(\mathrm{EtOH})(1.2 \mathrm{~mL})$. The mixture was stirred overnight at room temperature and then neutralized with concentrated $\mathrm{HCl}$. The precipitate was filtered and washed with water, $\mathrm{EtOH}$, and ethyl acetate, and the product was recrystallized from hot 50\% EtOH. M-GSH and NB-GSH were synthesized with the same method, substituting CDNB with $\mathrm{MCl}$ (176.64 mg, $1 \mathrm{mmol})$ or $\mathrm{NBCl}(171.58 \mathrm{mg}, 1 \mathrm{mmol})$, respectively. Melting points were determined for recrystallized products from GSH conjugation reactions. Recrystallized products were dissolved in $200 \mu \mathrm{M}$ borate buffer ( $\mathrm{pH} 8.5$ ), then analyzed by UV-visible spectroscopy and HPLC. Solubility issues were encountered with methylnaphthyl conjugates; these conjugates were not soluble in solution above $250 \mu \mathrm{M}$. Numerous attempts to conjugate GSH with benzyl chloride did not yield one major conjugation product. Similar methods were used to synthesize the Cys conjugates of $\mathrm{MCl}$ and $\mathrm{NBCl}$, which were used as HPLC standards for the enzyme assays. Synthesis of the Cys conjugate of CDNB was unsuccessful.

Chromatograms were obtained from initial experiments of boiling GSH conjugates in various concentrations of $\mathrm{HCl}$ that indicated the hydrolysis of the $\gamma$-glutamyl and $\alpha$-peptide bonds. GSH conjugates were hydrolyzed to yield Cys-Gly conjugates (with some Cys conjugate formed as a side product) by boiling at $100^{\circ} \mathrm{C}$ for 1 $\mathrm{h}$ in $1 \mathrm{~N} \mathrm{HCl}$, followed by HPLC separation (see section 2.4). Peaks suspected to be CysGly conjugates were collected, analyzed by UV-visible spectroscopy, and sent for matrixassisted laser desorption-ionization time-of-flight mass spectrometry (MALDI-TOF MS) (see section 2.9). Aliquots of the acid hydrolysates were also submitted for electrospray ionization-liquid chromatography-mass spectrometry (ESI-LC-MS) (see section 2.3). The identity of Cys-Gly conjugates were confirmed by the presence of a UV chromophore 


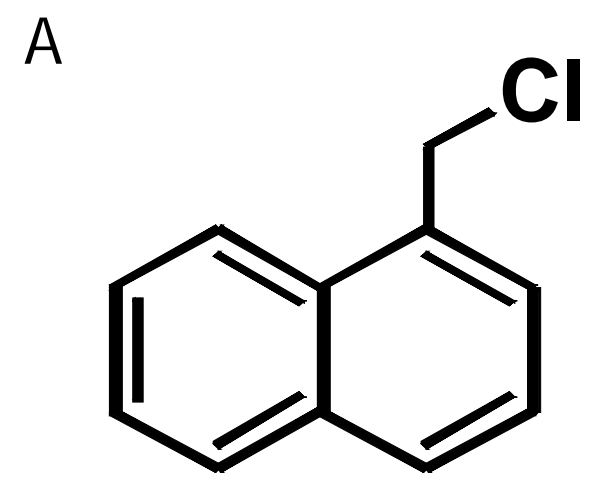

\section{1-(chloromethyl)naphthalene (MCl)}

B

C
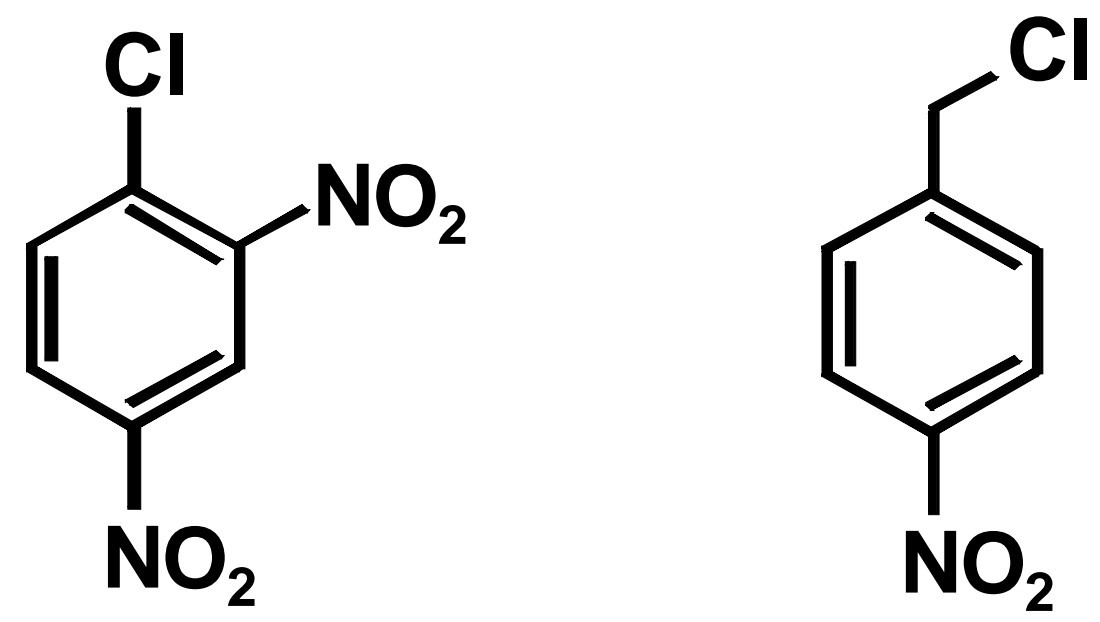

1-chloro-2,4-dinitrobenzene (CDNB)

4-nitrobenzyl chloride (NBCl)

FIGURE 5. STRUCTURE OF (A) 1-(CHLOROMETHYL)NAPHTHALENE; (B) 1CHLORO-2,4-DINITROBENZENE; AND (C) 4-NITROBENZYL CHLORIDE.

Compounds were conjugated with GSH and hydrolyzed to obtain the Cys-Gly conjugates. 
that absorbed at similar wavelengths to the GSH conjugate, comparison of the observed mass-to-charge ratio $(\mathrm{m} / \mathrm{z})$ with the predicted $\mathrm{m} / \mathrm{z}$ of the desired compound, and the fragmentation patterns of the MS-MS spectra.

\subsection{ELECTROSPRAY MASS SPECTROMETRY OF CONJUGATES}

Liquid chromatography-mass spectrometry analyses were performed on a Dionex UHPLC UltiMate ${ }^{\circledR} 3000$ liquid chromatograph interfaced to an AmaZon SL ${ }^{\circledR}$ ion trap mass spectrometer (Bruker Daltonics, Billerica, MA, USA) at the Advanced Analysis Centre, University of Guelph. A C18 column (Phenomenex Kinetix ${ }^{\circledR} ; 2.6 \mu \mathrm{m}, 150 \mathrm{~mm} \times$ $4.6 \mathrm{~mm}$ ) was used for chromatographic separation. The mobile-phase gradient was as follows: initial conditions, formic acid, $0.1 \%$ in water, hold for $5 \mathrm{~min}$; then linear gradient to $100 \%$ acetonitrile $(\mathrm{MeCN})$ at $25 \mathrm{~min}$. The flow rate was maintained at $0.4 \mathrm{~mL} / \mathrm{min}$. The mass spectrometer electrospray capillary voltage was maintained at $4.5 \mathrm{kV}$ and the drying temperature at $220^{\circ} \mathrm{C}$ with a flow rate of $10 \mathrm{~L} / \mathrm{min}$. Nebulizer pressure was 40 psi. Nitrogen was used as both nebulizing and drying gas; helium was used as collision gas at $60 \mathrm{psi}$. The $\mathrm{m} / \mathrm{z}$ was scanned across the range $70-900$ in enhanced resolution positive-ion auto MS/MS mode. The Smart Parameter Setting (SPS) was used to automatically optimize the trap drive level for precursor ions. The instrument was externally calibrated with the ESI TuneMix (Agilent).

\subsection{HPLC METHODS}

For HPLC analysis, a Gilson system equipped with an auto-injector (model 234), dual pumps (model 322), Nova-Pak ${ }^{\circledR} \mathrm{C}_{18}$ precolumn (Waters, Part no. 15220), Waters Symmetry ${ }^{\circledR} \mathrm{C}_{18}$ column $(5 \mu \mathrm{m} ; 4.6 \times 150 \mathrm{~mm}$ ), absorbance detector (model 152), and 
UniPoint ${ }^{\mathrm{TM}}$ software was used. Solvent A was $1 \%$ acetic acid and solvent B was MeCN. For analytical runs, $25 \mu \mathrm{L}$ sample injections were performed using a $100 \mu \mathrm{L}$ sample loop; for preparative runs, $300 \mu \mathrm{L}$ sample injections were performed using a $500 \mu \mathrm{L}$ sample loop. Flow rate was $1.0 \mathrm{~mL} / \mathrm{min}$. The linear solvent gradients employed were as follows: Method I: initial conditions, $20 \% \mathrm{~B}$; 0-2 min, hold $20 \%$; gradient, $2-4$ min, to $30 \% \mathrm{~B}$; gradient, 4-6 min, to 70\% solvent B; 6-8 min, hold 70\% B; 8-10 min, gradient from 70\% to $20 \% \mathrm{~B}$; Method II: initial conditions, $10 \% \mathrm{~B}$; gradient, $0-15$ min, to $35 \% \mathrm{~B}$; gradient, 15-17 min, to $100 \% \mathrm{~B}$; $17-23 \mathrm{~min}$, hold $100 \% \mathrm{~B}$; $23-25 \mathrm{~min}$, gradient to $10 \% \mathrm{~B}$; Method III: initial conditions, $20 \% \mathrm{~B}$; 0-6 min, hold $20 \% \mathrm{~B}$; gradient, $6-8 \mathrm{~min}, 20 \%$ to $100 \% \mathrm{~B}$; 8-13 min, hold $100 \% \mathrm{~B} ; 13-15$ min, gradient to $20 \%$ solvent B. Conjugates were detected by UV absorbance at wavelengths $270 \mathrm{~nm}$ (4-nitrobenzyl; NB) (Tsikas and Brunner, 1992), $285 \mathrm{~nm}$ (1-methylnaphthyl; M), and $340 \mathrm{~nm}$ (DNP) (Henderson et al., 1994).

\subsection{Preparation of Cilastatin-Agarose}

An affinity purification column was prepared using the AminoLink ${ }^{\circledR}$ Immobilization Kit (Thermo Scientific, Rockford, IL, USA). Cilastatin (1.91 mg) was dissolved in $2 \mathrm{~mL}$ coupling buffer ( $0.1 \mathrm{M}$ sodium phosphate, $\left.0.05 \% \mathrm{NaN}_{3}, \mathrm{pH} 7.0\right)$ and covalently coupled to the affinity column according to the manufacturer's recommendations. Coupling efficiency was $>80 \%$, as determined by UV absorbance values of the cilastatin solution before and after coupling.

\subsection{ENZYME ASSAYS: HYDROLYSIS OF CYS-GLY CONJUGATES}

Incubations $(100 \mu \mathrm{L})$ contained X-CG, $90 \mu \mathrm{L}$, in buffer A (50 mM Tris- $\mathrm{HCl}, 0.1$ $\mathrm{mM} \mathrm{ZnCl}_{2}, \mathrm{pH} 7.0$ ), and protein preparation, $10 \mu \mathrm{L}$, and were performed at $37^{\circ} \mathrm{C}$. Reactions were stopped by addition of $20 \mu \mathrm{L}$ cold MeCN and $5 \mu \mathrm{L}$ cold TCA, on ice. 
The reaction mixture was centrifuged for $10 \mathrm{~min}$ at $14,100 \times \mathrm{g}, 4^{\circ} \mathrm{C}$; an aliquot of supernatant was mixed 1:1 (v/v) with $50 \mu \mathrm{M}$ internal standard solution and analysed by HPLC. For each substrate, the corresponding GSH conjugate was used as the internal standard because it contains the same UV chromophore and thus absorbs at a similar wavelength to the Cys-Gly conjugate and Cys conjugate, while maintaining peak separation. Standard curves were based on integrated peak areas (see Appendix F). For a given electrophile, the UV extinction coefficients for the GSH, Cys-Gly, and Cys conjugates are very similar (e.g., sulforaphane $\left(\varepsilon=7.46,8.2\right.$, and $7.02 \mathrm{mM}^{-1} \mathrm{~cm}^{-1}$, respectively) (Egner et al., 2008); DNP $\left(\varepsilon=10.3,8.9\right.$, and $9.0 \mathrm{mM}^{-1} \mathrm{~cm}^{-1}$, respectively) (Hinchman et al., 1991); we assumed them to be identical. Initial velocities were determined from rates of product (Cys conjugate) formation, which were verified to be the same as rates of substrate depletion. All assays were performed in triplicate.

Assays were also performed with Cys-Gly as substrate. Hydrolysis activity was quantified with a modification of a previously published protocol, whereby acid ninhydrin reagent reacts specifically with cysteine to form a pink product $\left(\lambda_{\max }=560 \mathrm{~nm}\right)$ (Gaitonde, 1967). Enzyme assay incubations $(100 \mu \mathrm{L})$ were prepared as for the conjugates (above). Following the $37^{\circ} \mathrm{C}$ incubation, aliquots of incubation, glacial acetic acid, and acid ninhydrin reagent ( $33.3 \mu \mathrm{L}$ each) were mixed, boiled for 10 min, rapidly cooled, and diluted to $1 \mathrm{~mL}$ with $95 \% \mathrm{EtOH}$; absorbance was measured at $562 \mathrm{~nm}$. Standard curves were prepared. Six replicate enzyme assays were performed at each concentration of Cys-Gly. 
Michaelis-Menten kinetic parameters were determined by non-linear curve fitting to the Michaelis-Menten equation $\left(v_{0}=V_{\max }[\mathrm{S}] /\left(K_{\mathrm{M}}+[\mathrm{S}]\right)\right)$ with SigmaPlot software (Systat Software, Inc., Chicago, IL, USA). In the case of CG hydrolysis, substrate inhibition was observed and the data were fitted to Haldane's equation (Reed et al., 2010):

$v_{0}=V_{\max }[\mathrm{S}] /\left(K_{\mathrm{M}}+[\mathrm{S}]+[\mathrm{S}]^{2} / K_{\mathrm{i}}\right)$, again using the non-linear curve fitting software.

Assays were performed where proteins were either absent or heat-inactivated (boiled at $100^{\circ} \mathrm{C}$ for $10 \mathrm{~min}$ ) before incubation with substrate. Cys conjugate formation was not observed in these control incubations, indicating that product formation was enzyme-dependent (data not shown).

\subsection{PORCINE KIDNEY CORTEX MICROSOMAL FRACTION}

The procedure for purification of MDP was based on previous methods (Adachi et al., 1989; Hooper et al., 1987; Kraus et al., 2000). Sow kidneys were obtained from the Meat Science Laboratory, University of Guelph and stored at $-70^{\circ} \mathrm{C}$. Homogenization and all subsequent centrifugation steps were performed at $4^{\circ} \mathrm{C}$. Kidney cortex is the primary site of filtration and filtrate reabsorption (Witzmann et al., 1998), and has been reported to be a major source of peptidase activity (Hooper et al., 1987; Hughey et al., 1978). Cortex tissue (100 g) was dissected and then homogenized in $250 \mathrm{mM}$ sucrose (approx. $100 \mathrm{~mL}$ ) containing $1 \mathrm{mM}$ DTT and one Complete Mini ${ }^{\mathrm{TM}}$ protease inhibitor tablet (Roche, Mississauga, ON, Canada) and centrifuged at $8,000 \times g$ for $10 \mathrm{~min}, 13,800 \times g$ for $15 \mathrm{~min}$, and $100,000 \times \mathrm{g}$ for $60 \mathrm{~min}$, retaining the supernatants from the first two spins. The final pellet (microsomal fraction) was re-suspended in $150 \mathrm{mM}$ Tris $\mathrm{HCl}(\mathrm{pH}$ 
8) and again centrifuged at $13,800 \times g$ for $15 \mathrm{~min}$ and $100,000 \times g$ for $60 \mathrm{~min}$ to remove residual cytosol. Using a syringe with a 26 gauge needle, the final pellet ( $2.58 \mathrm{~g})$ was re-suspended in $250 \mathrm{mM}$ sucrose solution $(258 \mathrm{~mL})$ with $1 \mathrm{mM} \mathrm{DTT}, 200 \mathrm{mM} \mathrm{KCl}, 20$ $\mathrm{mM}$ potassium phosphate buffer, and $30 \mathrm{mM}$ CHAPS; to ensure sufficient solubilization of microsomal proteins, the concentration of CHAPS used was well above the critical micelle concentration (CMC) of CHAPS $(6.41 \mathrm{mM})$ (Chattopadhyay and Harikumar, 1996). The solubilized microsomal fraction was stirred on ice for $30 \mathrm{~min}$, centrifuged briefly to remove insoluble material, and the supernatant $(\sim 0.87 \mathrm{mg}$ protein $/ \mathrm{mL}$, Bradford assay, BSA standard) was aliquoted and frozen at $-70^{\circ} \mathrm{C}$.

\subsection{PURIFICATION OF MEMBRANE DIPEPTIDASE}

PI-PLC (Bacillus thuringiensis) was a kind gift of Dr. Frances J. Sharom (Molecular and Cellular Biology, University of Guelph). CHAPS-solubilized microsomal fraction (42 mg protein; see section 2.7) was incubated with PI-PLC, $480 \mu \mathrm{g}$, in buffer A, $48 \mathrm{~mL}$, at $25^{\circ} \mathrm{C}$ for $2 \mathrm{~h}$. The preparation was placed on ice and then centrifuged for $1 \mathrm{~h}$ at $100,000 \times g$. Both the supernatant and the pellet (resuspended in buffer A, $100 \mu \mathrm{L}$ ) were assayed for activity. In control experiments, enzyme assays were performed on supernatants from mock incubations that did not contain PI-PLC; no peptidase activity was found in the resulting supernatant fractions (data not shown).

PI-PLC-released enzyme was further purified by affinity chromatography on cilastatin-agarose. The column was equilibrated at room temperature with 10 column volumes (20 mL) of buffer B (50 mM Tris-HCl, $\left.0.1 \mathrm{mM} \mathrm{ZnCl}_{2}, 0.5 \mathrm{M} \mathrm{NaCl}, \mathrm{pH} 7.0\right)$. All purification steps were performed at room temperature. Supernatant from the PI-PLC 
digestion reaction ( $48 \mathrm{~mL}, 36 \mathrm{mg}$ protein) was applied to the affinity column, which was allowed to drain and then washed with $20 \mathrm{~mL}$ buffer B. Bound proteins were eluted with $1 \mathrm{mM}$ cilastatin in buffer $\mathrm{B}, 5 \mathrm{~mL}$. The eluate was dialyzed against $1 \mathrm{~L}$ buffer A, overnight at $4{ }^{\circ} \mathrm{C}$, concentrated (Ultrafree ${ }^{\circledR}-0.5$ Centrifugal Filter Device, NMWL: 10,000 Da; Millipore, Billerica, MA, USA), and assayed immediately. Some eluate was aliquoted and kept at $4{ }^{\circ} \mathrm{C}$ and $-70^{\circ} \mathrm{C}$ for short- or long-term storage, respectively. The protein concentration of the eluate was determined with the Micro-BCA Protein assay (Pierce Thermo Scientific, Rockford, IL, USA) and also by UV absorbance at $280 \mathrm{~nm}$; the values from the Micro-BCA assay were used in all calculations. A sample of eluate was submitted for MALDI-TOF MS. A second sample of eluate $(10 \mu \mathrm{L})$ was incubated with $10 \mu \mathrm{L}$ DTT $(10 \mathrm{mg} / \mathrm{mL})$ for $30 \mathrm{~min}$ at $50^{\circ} \mathrm{C}$; the reaction was centrifuged briefly, concentrated and resuspended in $5 \mu \mathrm{L}$ water, then submitted for MALDI-TOF MS. Multiple purifications were performed to obtain sufficient protein for enzyme kinetic assays.

\subsection{TIME-OF-FLIGHT MASS SPECTROMETRY OF PURIFIED ENZYME}

MALDI-TOF MS was performed at the Advanced Analysis Centre, University of Guelph. For small molecules, the sample was mixed directly with matrix solution $(3,4-$ dihydroxybenzoic acid, $2 \mathrm{mg}$, in $20 \% \mathrm{EtOH})$ in an analyte:matrix ratio $1: 2(\mathrm{v} / \mathrm{v}) ; 1 \mathrm{~mL}$ was spotted on the MALDI sample target and allowed to dry at room temperature. The analyses were performed using a Reflex III (Bruker) instrument equipped with a $337 \mathrm{~nm}$ nitrogen laser. Samples were analyzed in reflectron and positive ion modes, scanning from $50-500 \mathrm{~m} / \mathrm{z}$, using ion suppression up to $150 \mathrm{~m} / \mathrm{z}$. For proteins, analytes were mixed directly with matrix solution (sinapinic acid, $2 \mathrm{mg}$, in $100 \mu \mathrm{L} \mathrm{MeCN}$ :water, 50:50 (v/v), 
with $0.1 \%$ TFA), in an analyte-to-matrix ratio $1: 1(\mathrm{v} / \mathrm{v})$. Positive ions were detected in linear mode scanning from $2,000-170,000 \mathrm{~m} / \mathrm{z}$, using ion suppression up to $500 \mathrm{~m} / \mathrm{z}$. For all experiments, ion sources 1 and 2 were held at $20 \mathrm{kV}$ and $16.35 \mathrm{kV}$, respectively; guiding lens voltage was $9.75 \mathrm{kV}$. Reflector detection gain was set at 5.3 with pulsed ion extraction at 200 ns. Two-point or four-point external calibration was performed, using the $[\mathrm{M}+\mathrm{H}]^{+}(155.01 \mathrm{Da})$ and $[2 \mathrm{M}+\mathrm{H}]^{+}(449.12 \mathrm{Da})$ peaks of dihydroxybenzoic acid and the dimer of sinapinic acid, respectively, and using the $[\mathrm{M}+\mathrm{H}]^{+}$ion of $12,361.1 \mathrm{Da}$ (cytochrome c), 16,952.6 Da (horse myoglobin), 23,981.9 (trypsinogen) and 66,431 (BSA) peaks. 


\section{RESULTS}

\subsection{SYNTHESIS OF GLUTATHIONE CONJUGATES}

GSH conjugates were prepared as described in Materials and Methods and subsequently subjected to acid hydrolysis to obtain the corresponding X-CG. HPLC analysis of the products of $\mathrm{GSH}$ reactions with $\mathrm{CDNB}, \mathrm{NBCl}$, or $\mathrm{MCl}$ indicated formation of a single major product in each case. Crude product yields of $66 \%, 94 \%$, and $31 \%$ were obtained for $\mathrm{GSH}$ reactions with $\mathrm{CDNB}, \mathrm{NBCl}$, and $\mathrm{MCl}$, respectively. It should be noted that as the polarity of the parent compound decreased, there was also a decrease in the solubility of the GSH reaction mixture in polar solvents (e.g. water, EtOH); this lack of solubility likely contributed to the lower yields obtained from the reactions with $\mathrm{CDNB}$ and $\mathrm{MCl}$. Increasing the volume of reaction solvent $(\mathrm{EtOH})$ and the application of heat for the overnight stirring may increase product yields, and in some cases may be necessary for the conjugation of GSH with some polycyclic compounds, such as 4-(bromomethyl)biphenyl and 9-(chloromethyl)anthracene. Yields, HPLC retention times, UV absorbance peak wavelengths, mass-to-charge ratios, and melting points are summarized in Table 2.

HPLC analysis of acid hydrolysates of DNP-GSH showed the presence of peaks corresponding to the starting material, DNP-CG, and DNP-C. DNP-C was identified by HPLC co-retention with Cys conjugate standards. The major product, DNP-CG, was collected, analyzed by UV-visible spectroscopy, and characterized by MALDI-TOF MS (Table 2). 
TABLE 2. GSH, CYS-GLY, AND CYS CONJUGATES.

\begin{tabular}{|c|c|c|c|c|c|c|c|c|c|c|}
\hline \multirow{2}{*}{ Compound } & \multirow{2}{*}{$\begin{array}{c}\text { Yield } \\
(\%)\end{array}$} & \multicolumn{2}{|c|}{ HPLC } & \multicolumn{2}{|c|}{$\lambda_{\max }(\mathrm{nm})$} & \multicolumn{3}{|c|}{$\mathbf{m} / \mathbf{z}$} & \multicolumn{2}{|c|}{ m.p. $\left({ }^{\circ} \mathbf{C}\right)$} \\
\hline & & Meth. & RT & lit. & obs. & pred. & $\begin{array}{c}\text { obs. } \\
{[\mathrm{M}+\mathrm{H}]^{+}}\end{array}$ & frag. & lit. & obs. \\
\hline DNP-GSH & 66 & III & $6-7.5$ & $340^{1}$ & 337 & 473.08 & 474.1 & $345.0^{\mathrm{a}}$ & $\begin{array}{l}190- \\
194^{2}\end{array}$ & 194 \\
\hline DNP-CG & - & III & $2.5-3.5$ & - & 339 & 344.04 & 345.0 & $288.0^{\mathrm{b}}$ & - & N.D. \\
\hline DNP-C & - & III & $4-4.5$ & - & 332 & 287.02 & 288.0 & 198.8 & $\begin{array}{l}144- \\
147^{2}\end{array}$ & N.D. \\
\hline$\overline{D N P}-\gamma \mathrm{EC}$ & - & - & - & - & - & 416.06 & 417.0 & 288.0 & - & N.D. \\
\hline NB-GSH & 94 & II & $9.5-10$ & $270^{5}$ & 279 & 442.12 & 443.1 & $314.0^{\mathrm{a}}$ & - & 201 \\
\hline NB-CG & - & II & $5-5.5$ & - & 280 & 313.07 & 314.0 & $257.0^{b}$ & - & N.D. \\
\hline NB-C & - & II & $7-7.5$ & - & 279 & 256.05 & 257.0 & 239.9 & - & N.D. \\
\hline M-GSH & 31 & II & $14-14.5$ & - & 285 & 447.15 & 448.1 & $319.1^{\mathrm{a}}$ & $210^{4}$ & 209 \\
\hline M-CG & - & II & $9.5-10$ & - & 285 & 318.10 & 319.1 & $262.0^{b}$ & - & N.D. \\
\hline M-C & - & II & $12-12.5$ & - & 284 & 261.08 & 262.0 & $141.0^{c}$ & - & N.D. \\
\hline $\mathrm{M}-\gamma \mathrm{EC}$ & - & - & - & - & - & 390.12 & 391.1 & 262.0 & - & N.D. \\
\hline
\end{tabular}

Conjugates were synthesized and analyzed by LC-MS-MS, as described in Materials and Methods. Purified conjugates were dissolved in $50 \mathrm{mM}$ Tris-HCl, $0.1 \mathrm{mM} \mathrm{ZnCl}_{2}(\mathrm{pH} 7.0)$, and analyzed by HPLC and UV-visible spectroscopy. Melting point determinations were performed on recrystallized GSH conjugates. Values given for yield, $\lambda_{\max }, \mathrm{m} / \mathrm{z}$, and m.p. are from single determinations.

$\mathrm{RT}=$ HPLC retention time $(\mathrm{min})$; Meth. $=$ HPLC method used for conjugate separation; $\mathrm{m} . \mathrm{p} .=$ melting point; N.D. $=$ not determined; lit. $=$ literature value for parameter; obs. $=$ observed value for parameter; frag. $=$ major fragment ions observed in MS-MS mode are indicated.

${ }^{a}$ loss of glutamic acid (129 Da); ${ }^{b}$ loss of glycine $(57 \mathrm{Da}) ;{ }^{c}$ loss of cysteine (121 Da) by cleavage of benzylic C-S bond.

References: 1, Henderson et al., 1994; 2, Hinchman et al., 1991; 3, Tsikas and Brunner, 1992; 4, Hyde and Young, 1968. 
LC-MS-MS analysis of an acid hydrolysate of DNP-GSH revealed the presence of ions corresponding to the starting material (474.1 Da), DNP-CG (345 Da), DNP-C (288 Da), and DNP- $\gamma$-glutamylcysteine (417 Da; the product of hydrolysis of the $\alpha$-peptide bond of DNP-GSH, which was not studied further). The MS-MS spectrum of DNP-GSH showed that the parent ion fragmented with loss of glutamic acid (129 Da) to yield an ion peak at $345 \mathrm{Da}$ (DNP-CG), characteristic of GSH adducts (Baillie and Davis, 1993). Additional hydrolysate samples were separated by HPLC; fractions were lyophilized to dryness and used as substrates in the enzyme assays. The X-CG of the other electrophiles were identified and prepared in the same manner. Fragment ions corresponding to $\mathrm{M}+(141.0)$ and $\mathrm{NB}+(136.8)$ were observed in LC-MS-MS chromatograms of acid hydrolysates of M-GSH and NB-GSH, respectively. Fragment ions corresponding to glutamic acid (130.0) were observed in the LC-MS-MS chromatograms of acid hydrolysates of all three conjugates.

\subsection{PURIFICATION OF MEMBRANE DIPEPTIDASE}

The enzyme purification protocol (Table 3) was based on those of previous publications (Adachi et al., 1989; Hooper et al., 1987; Kraus et al., 2000). Following PI-PLC incubation of the CHAPS-solubilized microsomal fraction and centrifugation, the supernatants and resuspended pellets were assayed for peptidase activity with DNP-CG substrate $(500 \mu \mathrm{M})$. Almost all of the activity (approximately 95\%) was found in the supernatant fraction. (The pellets were not washed before the enzyme assay; therefore, the resuspended pellets would be contaminated with some soluble material.)

The supernatant fraction from the PI-PLC incubations was further separated by cilastatin-affinity chromatography. Specific elution with cilastatin afforded a small amount of 
protein with high enzyme activity (Table 3). (The amount of enzyme applied to the column exceeded its binding capacity, and substantial activity was also eluted in the flow-through fraction.) The affinity-purified protein preparation was homogenous, as assessed by SDS-PAGE and silver staining; a single band at apparent molecular mass $\left(\mathrm{M}_{\mathrm{r}}\right) 47 \mathrm{kDa}$ was observed (Figure 6, Lane 5). Based on activity assays with NB-CG, $100 \mu \mathrm{M}$, as substrate, an overall 53-fold purification was achieved, with $76 \%$ recovery (Table 3).

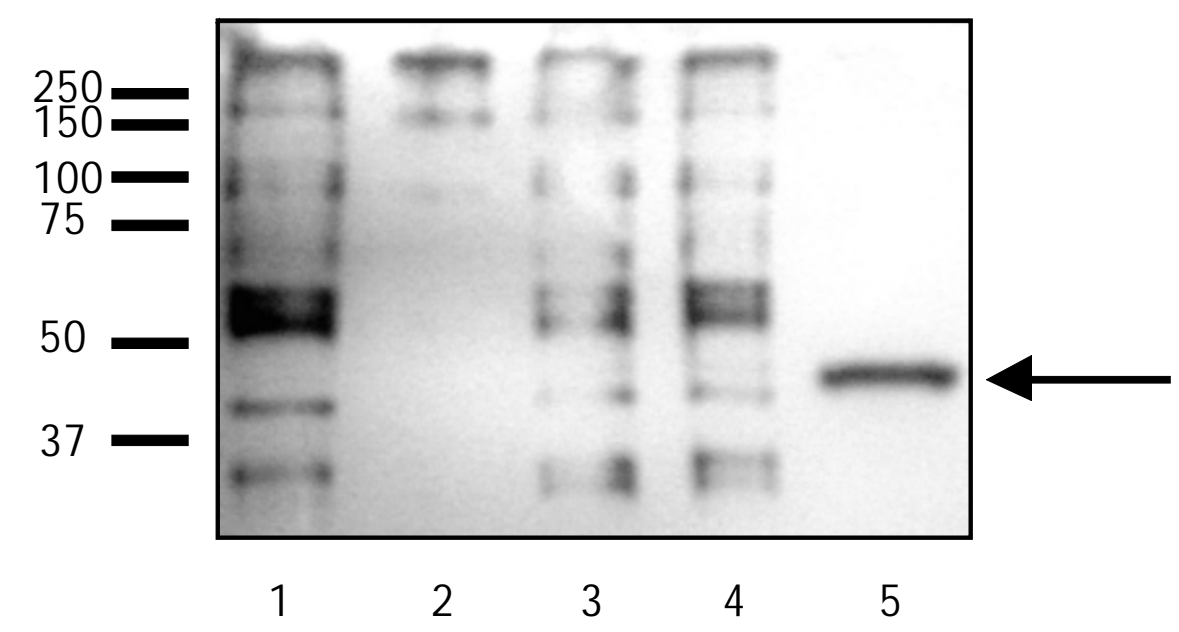

FIGURE 6. PURIFICATION OF MEMBRANE DIPEPTIDASE: SDS-PAGE ANALYSIS.

Lanes represent: 1 , detergent-solubilized porcine kidney microsomal fraction $(0.87 \mu \mathrm{g}) ; 2$, pellet $(0.1 \mu \mathrm{g})$ and 3 , supernatant $(1.5 \mu \mathrm{g})$ fractions, following PI-PLC treatment and centrifugation; 4, affinity column flow-through $(1.4 \mu \mathrm{g}) ; 5$, purified enzyme $(0.13 \mu \mathrm{g})$. Precision Plus Protein ${ }^{\mathrm{TM}}$ Dual Color molecular weight standards (10-250 kDa; Bio-Rad, Mississauga, ON, Canada) were used. Arrow indicates purified MDP. Proteins were visualized by silver staining. Fractions shown are from a single representative purification; multiple purifications were performed to obtain sufficient protein for enzyme kinetic assays. 
TABLE 3. PURIFICATION OF MDP FROM PORCINE KIDNEY CORTEX.

\begin{tabular}{|c|c|c|c|c|c|c|}
\cline { 2 - 6 } \multicolumn{1}{c|}{} & Step & $\begin{array}{c}\text { Total } \\
\text { protein } \\
(\mathbf{m g})\end{array}$ & Total activity & Recovery & $\begin{array}{c}\text { Sp. Act. } \\
(\boldsymbol{\mu m o l ~ p e r} \\
\mathbf{m i n} \text { per } \mathbf{~ m g})\end{array}$ & $\begin{array}{c}\text { Purification } \\
\text { (-fold) }\end{array}$ \\
\hline 1 & Microsomal fraction & 42 & 2.86 & 100 & 0.33 & - \\
\hline 2 & $\begin{array}{c}\text { PI-PLC-treated } \\
\text { microsomes }\end{array}$ & 48.5 & 3.26 & 114 & 0.32 & 1.0 \\
\hline 3 & $\begin{array}{c}\text { PI-PLC-released } \\
\text { supernatant }\end{array}$ & 36 & 2.96 & 103 & 0.39 & 1.2 \\
\hline 5 & $\begin{array}{c}\text { Cilastatin affinity } \\
\text { chromatography: flow- } \\
\text { through }\end{array}$ & 33.6 & 2.86 & 100 & 0.41 & 1.2 \\
\hline & $\begin{array}{c}\text { Cilastatin affinity } \\
\text { chromatography: bound }\end{array}$ & 0.06 & 2.19 & 76 & 17 & 53 \\
\hline
\end{tabular}

MDP was solubilized with bacterial PI-PLC and purified as described in Materials and Methods. NB-CG hydrolysis activity was measured as described in text. Protein concentrations for steps 14 and 5 were determined by the Bradford assay and the Micro-BCA Protein assay, respectively. Values shown are from a single representative purification; multiple purifications were performed to obtain sufficient protein for enzyme kinetic assays.

MALDI-TOF MS of the affinity-purified protein gave a major ion peak at $\mathrm{m} / \mathrm{z}=92,508$ and a minor peak at $\mathrm{m} / \mathrm{z}=46,227$. When a sample of eluate was reduced with DTT $(10 \mathrm{mg} / \mathrm{mL})$ before analysis, the higher-molecular weight (MW) peak was reduced and the lower-MW peak became more intense (Figure 7), consistent with the previously reported disulfide-linked homodimer structure (Keynan et al., 1996). The X-ray crystal structure of the human enzyme shows that the two subunits are linked by a single disulfide bond (Nitanai et al., 2002) between the Cys residues at position 361 in the N-terminal-trimmed recombinant protein. This residue corresponds to position 377 in the full sequence. In the porcine sequence, Cys is also found at 
position 377, and the adjacent sequences are very similar (human residues 361-380: QAPEEEPIPL DGLGGSCRTH YGYSSGASSL vs. porcine 361-380: QVPGEEPIPL GQLEASCRTN YGYSAAPSLH). The MW predicted from the primary sequence (409 amino acid residues) is 44,705 ; the larger MW observed $(46,938)$ presumably reflects glycosylation, as previously noted (Adachi et al., 1989; Littlewood et al., 1989).
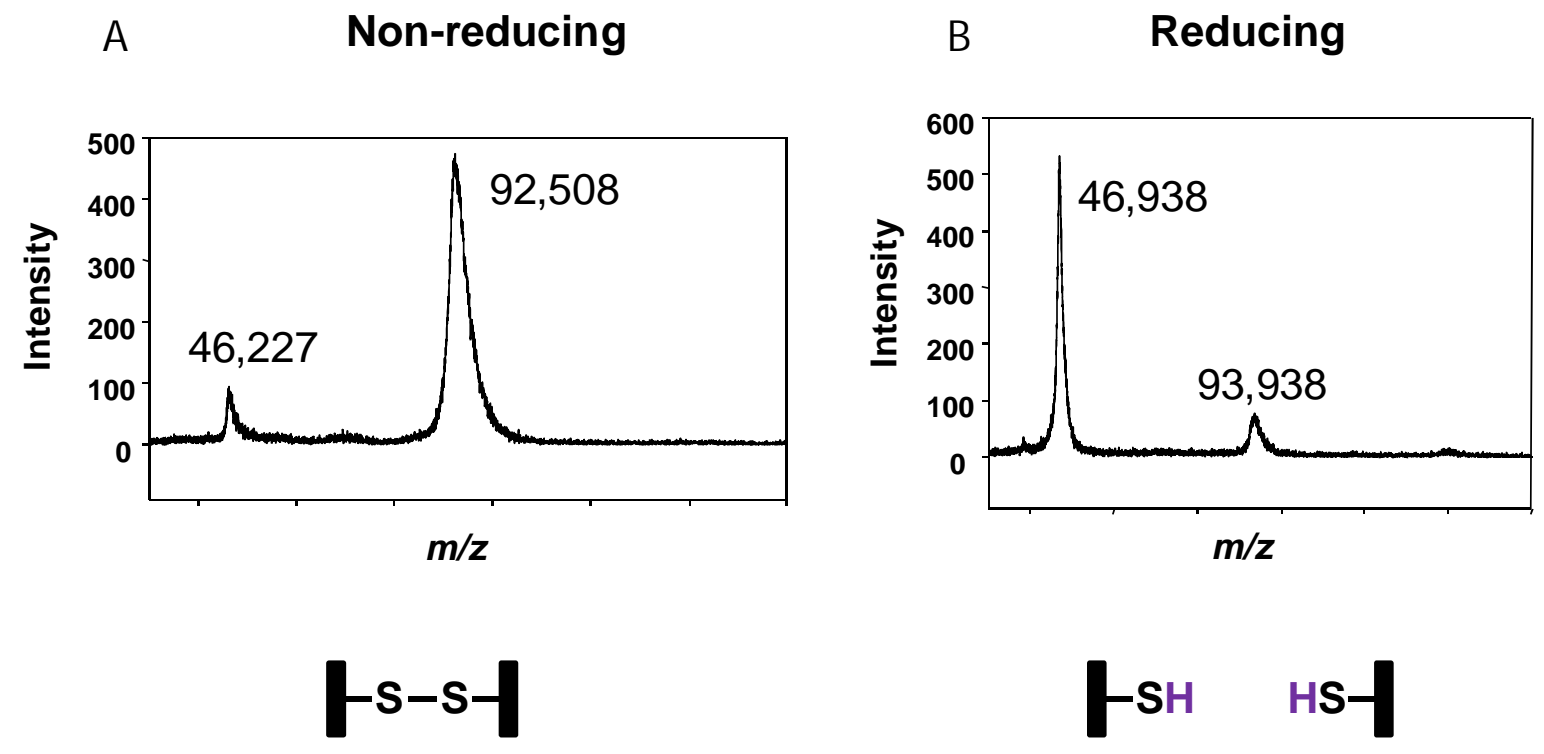

\section{FIGURE 7. MALDI-TOF MASS SPECTRA OF PURIFIED MEMBRANE DIPEPTIDASE.}

Mass spectra of affinity-purified enzyme (A) before and (B) after reduction with DTT (10 $\mathrm{mg} / \mathrm{mL}$ ).

\subsection{Hydrolysis OF CYs-GLY CONJUGATES}

Our main objective was to examine the activity of MDP for hydrolysis of aromatic XCG, representative of the products of detoxication of toxicants such as polycyclic aromatic hydrocarbons and aromatic drugs via the mercapturic acid pathway. HPLC methods were 
developed for each required separation, as presented in the Materials and Methods section. A representative chromatogram is shown in Figure 8.

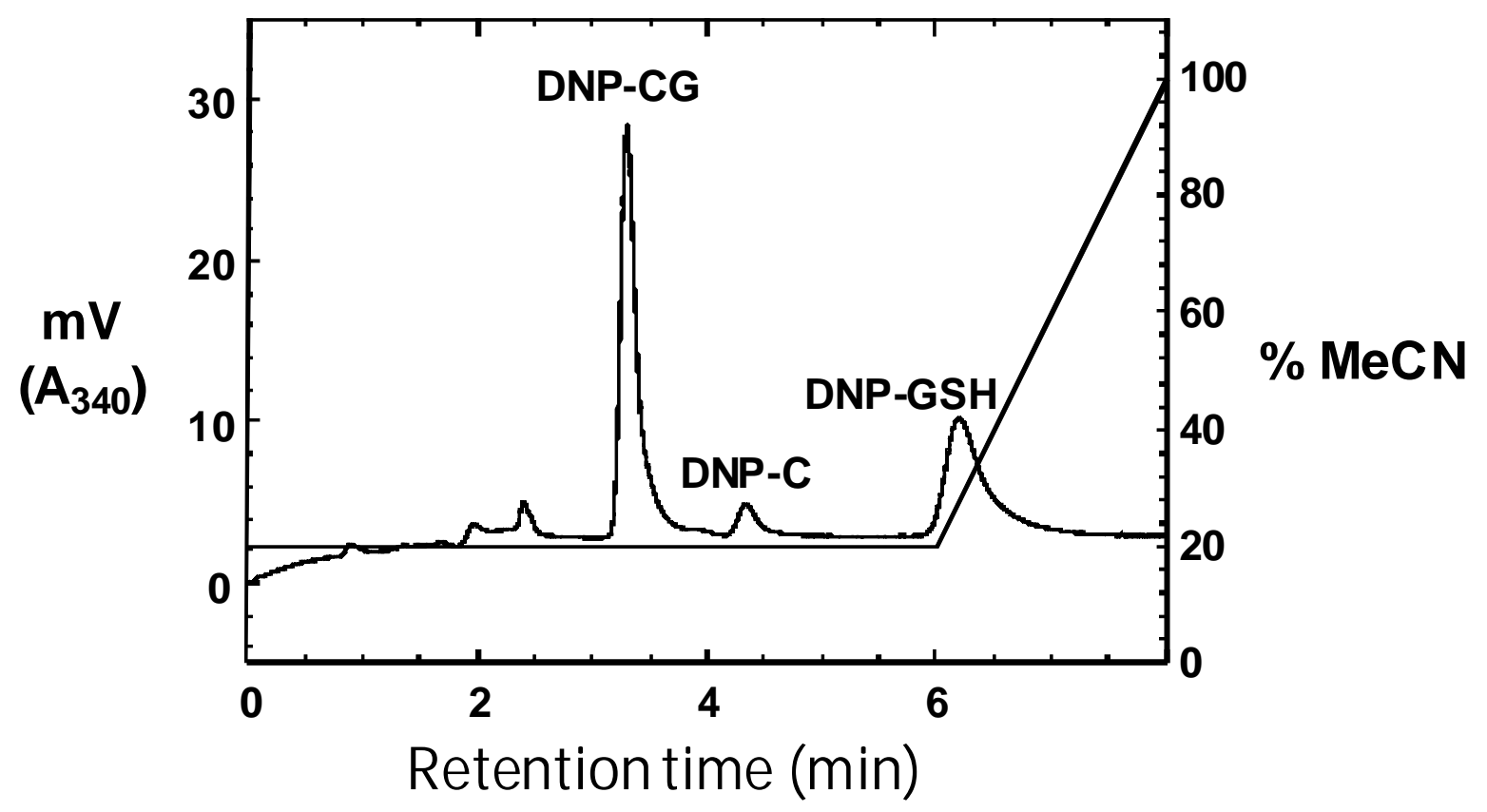

FIGURE 8. HYDROLYSIS OF CYS-GLY S-CONJUGATES: HPLC ANALYSIS.

A representative chromatogram is shown for DNP-CG.

Enzyme kinetic studies were performed with purified MDP. Results are shown in Figure 9, and the kinetic parameters are given in Table 4A. The highest value of $V_{\max }$ was observed for NB-CG. With M (1-methylnaphthyl)-CG, MDP displayed a low $K_{\mathrm{m}}(2.5 \mu \mathrm{M})$, but the specific activity was also low. With Cys-Gly, substrate inhibition was observed, consistent with results previously reported (Kozak and Tate, 1982). Due to the strong substrate inhibition effect, the values of $K_{\mathrm{m}}, K_{\mathrm{i}}, V_{\max }$ and $V_{\max } / K_{\mathrm{m}}$ could not be determined reliably from curve-fitting. Estimation from the first four data points places $K_{\mathrm{m}}$ to be approximately $0.3-0.5 \mu \mathrm{M}$ for Cys-Gly hydrolysis. 

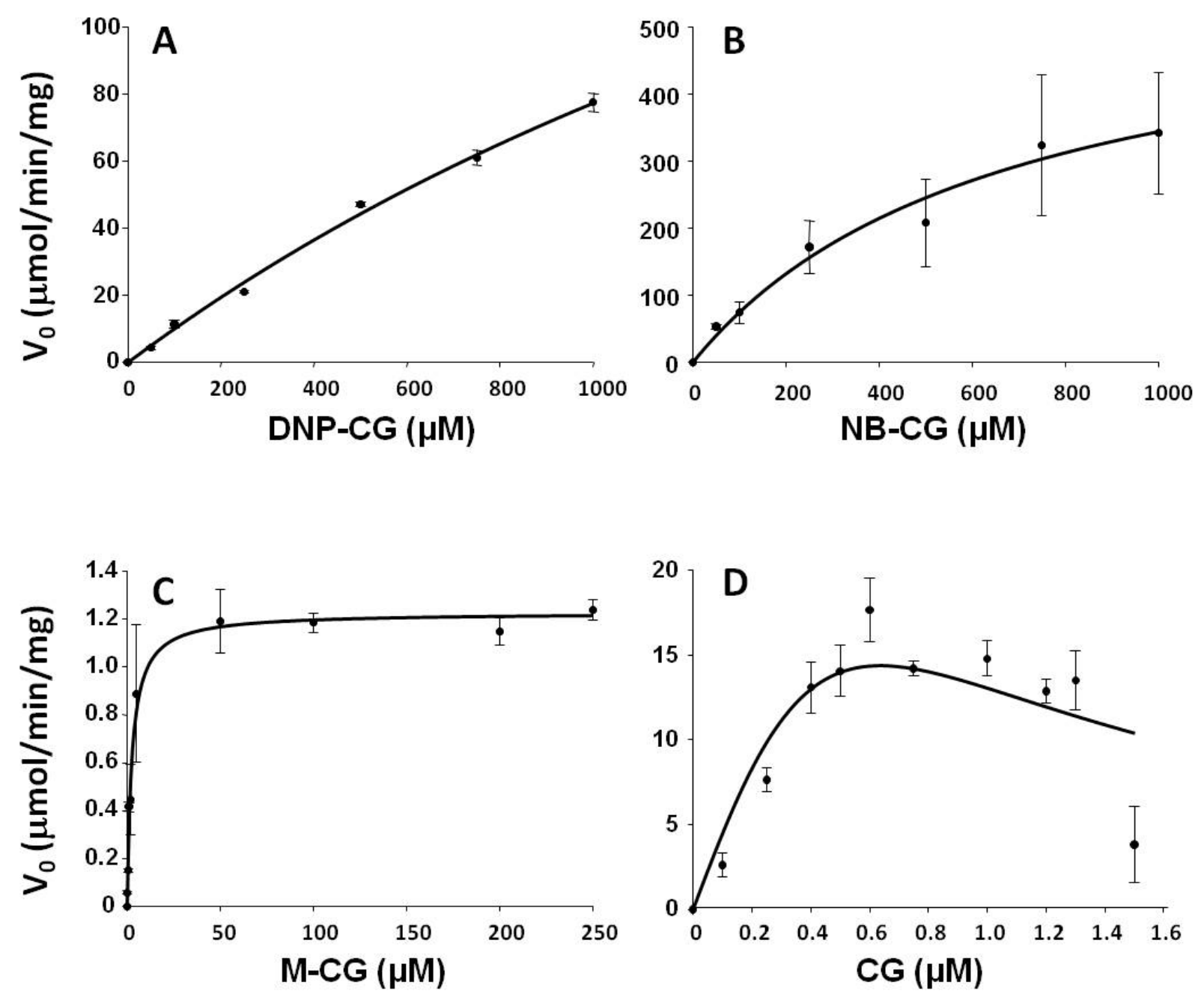

FIGURE 9. ENZYME KINETICS OF MDP TOWARDS CYS-GLY AND CONJUGATE SUBSTRATES.

The enzyme was assayed with substrates: (A) DNP-CG; (B) NB-CG; (C) M-CG; and (D) CysGly (CG). Michaelis-Menten curves are drawn using the curve-fitting method A from Table 4. Each data point represents mean $+/-$ standard error. Three independent kinetic experiments were performed for each X-CG substrate. Six independent kinetic experiments were performed for CG. 
Non-linear curve fitting to Michaelis-Menten kinetics $\left(v_{0}=V_{\max }[\mathrm{S}] /\left(K_{\mathrm{M}}+[\mathrm{S}]\right)\right)$ were performed for either mean (Table 4A) or raw (Table 4B) kinetic data using SigmaPlot software (Systat Software, Inc., Chicago, IL, USA). Values and 95\% confidence intervals for $K_{\mathrm{m}}$ and $V_{\max }$ were similar using either method, with the exception of NB-CG, which displayed larger $95 \%$ confidence intervals when fitted to the raw data (reflective of the inherent scatter in the original data). Regardless of the analysis method, the data are robust enough for our interpretation of differential MDP substrate specificity to remain true.

Throughout the DNP-CG assays, we observed a second peak that appeared to grow with increased incubation time (at a comparable rate to DNP-C), representing a second potential product of enzymatic hydrolysis. However, this peak still formed during incubations with heat-inactivated enzyme, indicating that it was a non-enzymatic product. This peak is not observed following acid hydrolysis of DNP-GSH, and may be formed by the $\beta$-elimination of the DNP group, which occurs under basic or neutral conditions (Hashmi et al., 1992); the resulting product of this reaction would be 2,4-dinitrothiophenol. This product is in agreement with our HPLC results, which show this peak eluting in the highly non-polar phase of the gradient. 


\section{TABLE 4. MDP: KINETIC PARAMETERS WITH CYS-GLY AND CONJUGATE SUBSTRATES.}

A

\begin{tabular}{|l|l|l|l|}
\cline { 2 - 4 } \multicolumn{1}{c|}{} & $\begin{array}{l}K_{\mathrm{m}} \\
(\mathbf{m M})\end{array}$ & $\begin{array}{l}V_{\max } \\
(\mu \mathrm{mol} / \mathbf{m i n} / \mathbf{m g})\end{array}$ & $\begin{array}{l}\boldsymbol{V}_{\max } / K_{\mathrm{m}} \\
(\mathrm{L} / \mathbf{m i n} / \mathbf{m g})\end{array}$ \\
\hline DNP-CG & $2.9(0.39-5.4)$ & $303(96-511)$ & 0.10 \\
\hline NB-CG & $0.67(0.08-1.3)$ & $573(316-831)$ & 0.85 \\
\hline M-CG & $0.0025(0.0018-0.0033)$ & $1.2(1.1-1.3)$ & 0.48 \\
\hline CG & $0.3-0.5^{*}$ & N.D. ${ }^{*}$ & N.D.* \\
\hline
\end{tabular}

B

\begin{tabular}{|l|l|l|l|}
\cline { 2 - 4 } \multicolumn{1}{c|}{} & $\begin{array}{l}K_{\mathrm{m}} \\
(\mathbf{m M})\end{array}$ & $\begin{array}{l}V_{\max } \\
(\mu \mathrm{mol} / \mathbf{m i n} / \mathbf{m g})\end{array}$ & $\begin{array}{l}V_{\max } / K_{\mathbf{m}} \\
(\mathbf{L} / \mathbf{m i n} / \mathbf{m g})\end{array}$ \\
\hline DNP-CG & $3.0(1.29-4.62)$ & $307(170-443)$ & 0.10 \\
\hline NB-CG & $0.57(-0.35-1.48)$ & $544(162-962)$ & 0.95 \\
\hline M-CG & $0.0025(0.0013-0.0036)$ & $1.2(1.1-1.3)$ & 0.48 \\
\hline CG & N.D.* & N.D.* & N.D.* \\
\hline
\end{tabular}

The $95 \%$ confidence intervals for $K_{\mathrm{m}}$ and $V_{\max }$, as determined by the non-linear curve fitting routine, are given in parentheses. The non-linear curve-fitting to determine the Michaelis-Menten parameters $K_{\mathrm{m}}$ and $V_{\max }$ for each substrate was done in two different ways. (A) Only the mean values of $v_{0}$ (one value for each value of $S$ ) obtained by averaging all of the replicates, were entered into the curve-fitting software. This analysis tests the goodness of fit of the means to the Michaelis-Menten equation, while ignoring inter- and intra-experiment variations in the determination of $v_{0}$. (B) Each $\left(v_{0}, S\right)$ pair, from each experiment, was entered into the curve-fitting software. This analysis tests both the goodness of fit of the data to the Michaelis-Menten equation, and the uncertainty 
due to inter- and intra-experiment variations in the data. Note that the estimated parameters obtained with methods $\mathrm{A}$ and $\mathrm{B}$ are similar. Three independent kinetic experiments were performed for each X-CG substrate. Six independent kinetic experiments were performed for $\mathrm{CG}$.

*Because of the strong substrate inhibition effect, the values of $K_{\mathrm{m}}, K_{\mathrm{i}}, V_{\max }$ and $V_{\max } / K_{\mathrm{m}}$ could not be determined reliably for CG hydrolysis. $K_{\mathrm{m}}$ was estimated by eye from the first four data points in Figure 9D. 


\section{DISCUSSION}

Purified MDP catalyzes the hydrolysis of a variety of aromatic X-CG; the activity is strongly dependent on the S-substituent. Our results suggest that the active site of MDP may bind the aryl substituent of these CG adducts, in addition to engaging in polar interactions with the amino acid residues which can be inferred from the X-ray crystal structure of the cilastatin-bound human enzyme (Nitanai et al., 2002). In contrast, for the enzyme GGT, it has been suggested that the active site binds only the GSH moiety of GSH conjugates, and that the nature of the S-substituent does not greatly affect GGT activity (Han et al., 2007; Okada et al., 2006).

Although the number of substrates tested is too small to establish a definitive structure-activity relationship, there appears to be a trend towards increased affinity for the MDP active site with decreasing polarity of the substituent on the X-CG cysteine sulfur atom. This is suggested by the low $K_{\mathrm{M}}$ value for M-CG relative to DNP-CG and NB-CG. It is possible that the S-substituent, which is probably bound in about the same location as the cilastatin R1 group shown in Figure 3B, close to residue Tyr255, participates in strong hydrophobic interactions with the enzyme. Assaying the activity of MDP with CG conjugates of other other non-polar polycyclic electrophiles, such as 9(chloromethyl)anthracene, should put this hypothesis to the test.

We observed that the total activity recovered following PI-PLC treatment (flowthrough plus bound) was greater than the starting total activity (Table 3); it has previously been suggested that conformational constraints on the active site may be relaxed following PI-PLC-mediated cleavage of the GPI anchor on MDP, resulting in an increase 
in the affinity of the active site for substrate (Brewis et al., 1994; Campbell et al., 1990). Following centrifugation, almost all of the hydrolysis activity was found in the supernatant. The remaining activity in the pellet fraction could be due to a number of factors such as contamination with supernatant, a sub-population of PI-PLC-resistant MDP, or other membrane proteins with peptidase activity such as APN (Kozak and Tate, 1982) and DPP-IV (Tanaka et al., 1993).

It was later realized that the affinity-purified eluate should have been dialyzed more thoroughly due to the use of the MDP inhibitor cilastatin. Experiments were performed to test the effect of extensive dialysis on X-CG hydrolysis activity and it was shown to have minimal effect; assays of MDP, before and after extensive dialysis, with M-CG $(2 \mu \mathrm{M})$ produced initial rates of $0.5 \mu \mathrm{mol} / \mathrm{min} / \mathrm{mg}$ and $0.6 \mu \mathrm{mol} / \mathrm{min} / \mathrm{mg}$, respectively. Ideally, in future experiments, purified MDP should be dialyzed extensively to remove cilastatin inhibitor (incurred during affinity purification), to prevent its potential interference with enzyme activity measurements. Depending on the binding and release kinetics of cilastatin, gel filtration procedures could alternatively be used to remove inhibitor.

CG potently inhibited its own hydrolysis (substrate inhibition), a phenomenon that has been previously reported in small detail for MDP (Kozak and Tate, 1982; McIntyre and Curthoys, 1982). This effect has been ascribed to reduction by CG of the disulfide bond linking the enzyme subunits, since no substrate inhibition was observed with Leu-Leu or other dipeptides (Adachi et al., 1989; Kozak and Tate, 1982). Future experiments should compare incubations between DTT-treated and untreated enzyme to test this hypothesis. 
Preliminary studies indicate that M-C does not inhibit the activity of MDP (data not shown). Nonetheless, the high binding affinity of M-CG for MDP suggests that it may be a useful lead compound for the development of novel MDP inhibitors.

Jösch and colleagues (Jösch et al., 1998; Jösch et al., 2003), studying rat liver, reported that cytosolic leucyl aminopeptidase is responsible for the majority of X-CG hydrolysis activity in that organ, indicating a significant difference between the mammalian liver and kidney. Furthermore, leucyl aminopeptidase was shown to have high specific activity only with polar substrates, and displayed low specific activity with the relatively non-polar substrate $\mathrm{LTD}_{4}$ (Jösch et al., 2003). Hence, the relative contribution of a particular enzyme to X-CG hydrolysis, and its subcellular localization, may differ depending on the organ. Studies are currently underway (by student Nadine Frost) investigating the hydrolysis activity towards aromatic X-CG in bovine liver. 


\section{CONCLUSIONS}

MDP is thought to be the enzyme responsible for the major X-CG hydrolyzing activity in mammalian kidney. The aim of this study was to purify MDP and characterize its substrate specificity for various aromatic X-CG. We developed an HPLC quantitation method for the determination of $\mathrm{X}-\mathrm{CG}$ and related compounds. We confirmed that the majority of X-CG hydrolysis activity can be solubilized from porcine kidney microsomes by treatment with PI-PLC, and that this activity is attributable to MDP; these findings are consistent with the results of previous studies (Hooper et al., 1987; Littlewood et al., 1989). We purified MDP to homogeneity by releasing the membrane-bound enzyme with PI-PLC and performing cilastatin-affinity chromatography.

Our results extend the range of compounds proven to be MDP substrates and show that aryl X-CG representative of the detoxication of aromatic xenobiotics are efficiently hydrolyzed by the enzyme. The $K_{\mathrm{M}}$ values for these substrates are in the micromolar to millimolar range and the $V_{\max }$ values are in the $\mu \mathrm{mol} / \mathrm{min} / \mathrm{mg}$ to $\mathrm{mmol} / \mathrm{min} / \mathrm{mg}$ range. Adachi and colleagues, studying human MDP, reported $K_{\mathrm{M}}$ and $V_{\max }$ values of $0.15 \mathrm{mM}$ and $36.4 \mu \mathrm{mol} / \mathrm{min} / \mathrm{mg}$, respectively, for $\mathrm{LTD}_{4}$; and $56 \mu \mathrm{M}$ and $30 \mu \mathrm{mol} / \mathrm{min} / \mathrm{mg}$, respectively, for leucylleucine (Adachi et al., 1989). Therefore, the aryl X-CG studied here are comparable to those endogenous substrates in terms of catalytic efficiency $\left(V_{\max } / K_{\mathrm{M}}\right)$. Our findings support the interpretation that renal MDP can play an important role in the metabolism of GSH-xenobiotic conjugates to mercapturic acids. 
More substrates need to be tested in order to elucidate the structural factors that are important for recognition and binding to the MDP active site. Further study of the structure-function relationship may provide insight into how cilastatin works as an inhibitor, rather than as a substrate. Students in the Josephy laboratory (Anita Agblor, Minah Hwang) have recently conjugated GSH with 4-(bromomethyl)biphenyl and 9(chloromethyl)anthracene; GSH conjugation reaction yields are currently being optimized and HPLC separation methods are being developed for these compounds and their hydrolysis products. This research may lead to the discovery or development of structurally novel MDP inhibitors.

Preliminary experiments suggest that purified MDP displays hydrolysis activity with the CG conjugate of 9-(chloromethyl)anthracene. Current and future work will be focused on developing an HPLC-fluorescence detection method for 9-methylanthraceneCG and other compounds. Fluorescence detection has the advantage over UV of having several-fold higher sensitivity in the detection of enzyme assay product formation (to at least $1 \mu \mathrm{M}$ ), allowing for accurate determination of enzyme kinetics with aromatic X-CG substrates. 


\section{REFERENCES}

Adachi H, Ishida N, Tsujimoto M. (1992). Primary structure of rat renal dipeptidase and expression of its mRNA in rat tissues and COS-1 cells. Biochim Biophys Acta 1132:311-314.

Adachi H, Katayama T, Nakazato H, Tsujimoto M. (1993). Importance of Glu-125 in the catalytic activity of human renal dipeptidase. Biochim Biophys Acta 1163:42-48.

Adachi H, Kubota I, Okamura N, Iwata H, Tsujimoto M, Nakazato H, Nishihara T, Noguchi T. (1989). Purification and characterization of human microsomal dipeptidase. J Biochem 105:957961.

Adachi H, Tawaragi Y, Inuzuka C, Kubota I, Tsujimoto M, Nishihara T, Nakazato H. (1990). Primary structure of human microsomal dipeptidase deduced from molecular cloning. J Biol Chem 265:3992-3995.

Andersen JK. (2004). Oxidative stress in neurodegeneration: cause or consequence? Nat Med 10 SupplS18-25.

Armstrong DJ, Mukhopadhyay SK, Campbell BJ. (1974). Physicochemical characterization of renal dipeptidase. Biochemistry 13:1745-1750.

Armstrong RN. (1997). Structure, catalytic mechanism, and evolution of the glutathione transferases. Chem Res Tox 10:2-18.

Badiou S, Bellet H, Lehmann S, Cristol JP, Jaber S. (2005). Elevated plasma cysteinylglycine levels caused by cilastatin-associated antibiotic treatment. Clin Chem Lab Med 43:332-334.

Baillie TA, Davis MR. (1993). Mass-spectrometry in the analysis of glutathione conjugates. Biol Mass Spectrom 22:319-325.

Bakhiya N, Batke M, Laake J, Monien BH, Frank H, Seidel A, Engst W, Glatt H. (2007). Directing role of organic anion transporters in the excretion of mercapturic acids of alkylated polycyclic aromatic hydrocarbons. Drug Metab Dispos 35:1824-1831.

Baran EJ. (2000). Metal complexes of carnosine. Biochemistry (Mosc) 65:789-797.

Benajiba A, Maroux S. (1981). Subunit structure of pig small-intestinal brush-border aminopeptidase N. Biochem J 197:573-580.

Blum H, Beier H, Gross HJ. (1987). Improved silver staining of plant proteins, RNA and DNA in polyacrylamide gels. Electrophoresis 8:93-99.

Bradford MM. (1976). A rapid and sensitive method for the quantitation of microgram quantities of protein utilizing the principle of protein-dye binding. Anal Biochem 72:248-254. 
Brewis IA, Turner AJ, Hooper NM. (1994). Activation of the glycosyl-phosphatidylinositolanchored membrane dipeptidase upon release from pig kidney membranes by phospholipase C. Biochem J 303:633-638.

Cadet JL, Brannock C. (1998). Free radicals and the pathobiology of brain dopamine systems. Neurochem Int 32:117-131.

Campbell BJ, Baker SF, Shukla SD, Forrester LJ, Zahler WL. (1990). Bioconversion of leukotriene $\mathrm{D}_{4}$ by lung dipeptidase. Biochim Biophys Acta 1042:107-112.

Campbell BJ, Di SY, Forrester LJ, Zahler WL. (1988). Specificity and inhibition studies of human renal dipeptidase. Biochim Biophys Acta 956:110-118.

Cappiello M, Lazzarotti A, Buono F, Scaloni A, D'Ambrosio C, Amodeo P, Mendez BL, Pelosi P, Del Corso A, Mura U. (2004). New role for leucyl aminopeptidase in glutathione turnover. Biochem J 378:35-44.

Chattopadhyay A, Harikumar KG. (1996). Dependence of critical micelle concentration of a zwitterionic detergent on ionic strength: Implications in receptor solubilization. FEBS Lett 391:199-202.

Cole SPC, Deeley RG. (2006). Transport of glutathione and glutathione conjugates by MRP1. Trends Pharmacol Sci 27:438-446.

Combes B, Stakelum GS. (1961). A liver enzyme that conjugates sulfobromophthalein sodium with glutathione. J Clin Invest 40:981-988.

Curthoys NP, Rankin BB, Tsao B. (1980). Membrane association and orientation of rat renal activities capable of degrading glutathione. Int J Biochem 12:219-222.

Duffel MW, Jakoby WB. (1982). Cysteine S-conjugate N-acetyltransferase from rat kidney microsomes. Mol Pharmacol 21:444-448.

Egner PA, Kensler TW, Chen JG, Gange SJ, Groopman JD, Friesen MD. (2008). Quantification of sulforaphane mercapturic acid pathway conjugates in human urine by high-performance liquid chromatography and isotope-dilution tandem mass spectrometry. Chem Res Toxicol 21:19911996.

Elce JS. (1970). Metabolism of a glutathione conjugate of 2-hydroxyoestradiol by rat liver and kidney preparations in vitro. Biochem J 116:913-917.

Farrell CA, Allegretto NJ, Hitchcock MJ. (1987). Cilastatin-sensitive dehydropeptidase I enzymes from three sources all catalyze carbapenem hydrolysis and conversion of leukotriene $\mathrm{D}_{4}$ to leukotriene $\mathrm{E}_{4}$. Arch Biochem Biophys 256:253-259.

Gaitonde MK. (1967). A spectrophotometric method for direct determination of cysteine in presence of other naturally occurring amino acids. Biochem J 104:627-633. 
Garland PB, Shepherd D, Yates DW. (1965). Steady-state concentrations of coenzyme A, acetylcoenzyme A and long-chain fatty acyl-coenzyme A in rat-liver mitochondria oxidizing palmitate. Biochem J 97:587-594.

Graham FL, Smiley J, Russell WC, Nairn R. (1977). Characteristics of a human cell line transformed by DNA from human adenovirus type 5. J Gen Virol 36:59-74.

Green RM, Elce JS. (1975). Acetylation of S-substituted cysteines by a rat liver and kidney microsomal N-acetyltransferase. Biochem J 147:283-289.

Haase W, Schafer A, Murer H, Kinne R. (1978). Studies on the orientation of brush-border membrane vesicles. Biochem J 172:57-62.

Habib GM, Shi ZZ, Cuevas AA, Guo QX, Matzuk MM, Lieberman MW. (1998). Leukotriene D4 and cystinyl-bis-glycine metabolism in membrane-bound dipeptidase-deficient mice. Proc Natl Acad Sci USA 95:4859-4863.

Halliwell B. (1999). Oxygen and nitrogen are pro-carcinogens, Damage to DNA by reactive oxygen, chlorine and nitrogen species: measurement, mechanism and the effects of nutrition. Mutat Res 443:37-52.

Han L, Hiratake J, Kamiyama A, Sakata K. (2007). Design, synthesis, and evaluation of $\gamma$ phosphono diester analogues of glutamate as highly potent inhibitors and active site probes of $\gamma$ glutamyl transpeptidase. Biochemistry 46:1432-1447.

Hashmi M, Vamvakas S, Anders MW. (1992). Bioactivation mechanism of S-(3-oxopropyl)-Nacetyl-L-cysteine, the mercapturic acid of acrolein. Chem Res Toxicol 5:360-365.

Hayes JD, Flanagan JU, Jowsey IR. (2005). Glutathione transferases. Annu Rev Pharmacol Toxicol 45:51-88.

Henderson GB, Hughes TR, Saxena M. (1994). Functional implications from the effects of 1chloro-2,4-dinitrobenzene and ethacrynic acid on efflux routes for methotrexate and cholate in L1210 cells. J Biol Chem 269:13382-13389.

Hinchman CA, Ballatori N. (1994). Glutathione conjugation and conversion to mercapturic acids can occur as an intrahepatic process. J Toxicol Environ Health 41:387-409.

Hinchman CA, Matsumoto H, Simmons TW, Ballatori N. (1991). Intrahepatic conversion of a glutathione conjugate to its mercapturic acid. Metabolism of 1-chloro-2,4-dinitrobenzene in isolated perfused rat and guinea pig livers. J Biol Chem 266:22179-22185.

Hirota T, Nishikawa Y, Takahagi H, Igarashi T, Kitagawa H. (1985). Simultaneous purification and properties of dehydropeptidase-I and aminopeptidase-M from rat kidney. Res Commun Chem Pathol Pharmacol 49:435-445. 
Hirota T, Nishikawa Y, Tanaka M, Fukuda K, Igarashi T, Kitagawa H. (1987). Localization of dehydropeptidase-I, an enzyme processing glutathione, in the rat kidney. J Biochem 102:547550 .

Hooper NM, Keen JN, Turner AJ. (1990). Characterization of the glycosyl-phosphatidylinositolanchored human renal dipeptidase reveals that it is more extensively glycosylated than the pig enzyme. Biochem J 265:429-433.

Hooper NM, Low MG, Turner AJ. (1987). Renal dipeptidase is one of the membrane proteins released by phosphatidylinositol-specific phospholipase C. Biochem J 244:465-469.

Hughey RP, Rankin BB, Elce JS, Curthoys NP. (1978). Specificity of a particulate rat renal peptidase and its localization along with other enzymes of mercapturic acid synthesis. Arch Biochem Biophys 186:211-217.

Hussain MM, Tranum-Jensen J, Noren O, Sjostrom H, Christiansen K. (1981). Reconstitution of purified amphiphilic pig intestinal microvillus aminopeptidase. Mode of membrane insertion and morphology. Biochem J 199:179-186.

Hyde CW, Young L. (1968). Biochemical studies of toxic agents. The metabolic formation of 1and 2-menaphthylmercapturic acid. Biochem J 107:519-522.

Inoue M, Okajima K, Morino Y. (1981). Renal transtubular transport of mercapturic acid in vivo. Biochim Biophys Acta 641:122-128.

Inoue M, Okajima K, Morino Y. (1984). Hepato-renal cooperation in biotransformation, membrane transport, and elimination of cysteine S-conjugates of xenobiotics. J Biochem 95:247254.

Jelly R, Patton EL, Lennard C, Lewis SW, Lim KF. (2009). The detection of latent fingermarks on porous surfaces using amino acid sensitive reagents: a review. Anal Chim Acta 652:128-142.

Jösch C, Klotz LO, Sies H. (2003). Identification of cytosolic leucyl aminopeptidase (EC 3.4.11.1) as the major cysteinylglycine-hydrolysing activity in rat liver. Biol Chem 384:213-218.

Jösch C, Sies H, Akerboom TP. (1998). Hepatic mercapturic acid formation: involvement of cytosolic cysteinylglycine S-conjugate dipeptidase activity. Biochem Pharmacol 56:763-771.

Josephy PD, Mannervik B. (2006). Molecular Toxicology, 2nd edn, Oxford University Press.

Kanai Y, Endou H. (2003). Functional properties of multispecific amino acid transporters and their implications to transporter-mediated toxicity. J Toxicol Sci 28:1-17.

Kaur H, Kumar C, Junot C, Toledano MB, Bachhawat AK. (2009). Dug1p is a Cys-Gly peptidase of the $\gamma$-glutamyl cycle of Saccharomyces cerevisiae and represents a novel family of Cys-Gly peptidases. J Biol Chem 284:14493-14502. 
Kendall EC, Mason HL, McKenzie BF. (1930). A study of glutathione: IV. Determination of the structure of glutathione. J Biol Chem 88:409-423.

Kenny AJ, Maroux S. (1982). Topology of microvillar membrance hydrolases of kidney and intestine. Physiol Rev 62:91-128.

Keppler D. (1999). Export pumps for glutathione S-conjugates. Free Radic Biol Med 27:985991.

Keppler D. (2005). Uptake and efflux transporters for conjugates in human hepatocytes. Methods Enzymol 400:531-542.

Keppler D, Leier I, Jedlitschky G, Konig J. (1998). ATP-dependent transport of glutathione Sconjugates by the multidrug resistance protein MRP1 and its apical isoform MRP2. Chem Biol Interact 112:153-161.

Keynan S, Habgood NT, Hooper NM, Turner AJ. (1996). Site-directed mutagenesis of conserved cysteine residues in porcine membrane dipeptidase. Cys 361 alone is involved in disulfide-linked dimerization. Biochemistry 35:12511-12517.

Keynan S, Hooper NM, Turner AJ. (1994). Directed mutagenesis of pig renal membrane dipeptidase - His(219) is critical but the Dhxxh motif is not essential for zinc-binding or catalytic activity. FEBS Lett 349:50-54.

Keynan S, Hooper NM, Turner AJ. (1997). Identification by site-directed mutagenesis of three essential histidine residues in membrane dipeptidase, a novel mammalian zinc peptidase. Biochem J 326:47-51.

Klungland A, Rosewell I, Hollenbach S, Larsen E, Daly G, Epe B, Seeberg E, Lindahl T, Barnes DE. (1999). Accumulation of premutagenic DNA lesions in mice defective in removal of oxidative base damage. Proc Natl Acad Sci USA 96:13300-13305.

Kozak EM, Tate SS. (1982). Glutathione-degrading enzymes of microvillus membranes. J Biol Chem 257:6322-6327.

Kraus T, Uttamsingh V, Anders MW, Wolf S. (2000). Porcine kidney microsomal cysteine Sconjugate $\mathrm{N}$-acetyltransferase-catalyzed $\mathrm{N}$-acetylation of haloalkene-derived cysteine $\mathrm{S}$ conjugates. Drug Metab Dispos 28:440-445.

Kropp H, Sundelof JG, Hajdu R, Kahan FM. (1982). Metabolism of thienamycin and related carbapenem antibiotics by the renal dipeptidase, dehydropeptidase. Antimicrob Agents Chemother 22:62-70.

Laemmli UK. (1970). Cleavage of structural proteins during the assembly of the head of bacteriophage T4. Nature 227:680-685. 
Lenney JF. (1990). Human cytosolic carnosinase - evidence of identity with prolinase, a nonspecific dipeptidase. Biol Chem Hoppe Seyler 371:167-171.

Lenney JF, Peppers SC, Kuceraorallo CM, George RP. (1985). Characterization of human-tissue carnosinase. Biochem J 228:653-660.

Littlewood GM, Hooper NM, Turner AJ. (1989). Ectoenzymes of the kidney microvillar membrane. Affinity purification, characterization and localization of the phospholipase Csolubilized form of renal dipeptidase. Biochem J 257:361-367.

Mannion AF, Jakeman PM, Dunnett M, Harris RC, Willan PL. (1992). Carnosine and anserine concentrations in the quadriceps femoris muscle of healthy humans. Eur J Appl Physiol Occup Physiol 64:47-50.

Mathew Z, Knox TM, Miller CG. (2000). Salmonella enterica serovar typhimurium peptidase B is a leucyl aminopeptidase with specificity for acidic amino acids. J Bacteriol 182:3383-3393.

McIntyre T, Curthoys NP. (1982). Renal catabolism of glutathione. Characterization of a particulate rat renal dipeptidase that catalyzes the hydrolysis of cysteinylglycine. J Biol Chem 257:11915-11921.

Meister A. (1995). Glutathione Metabolism. Methods Enzymol Pt A 251:3-7.

Messer M. (1961). Interference by amino acids and peptides with photometric estimation of proline. Anal Biochem 2:353-359.

Minca EC, Kowalski D. (2011). Replication fork stalling by bulky DNA damage: localization at active origins and checkpoint modulation. Nucleic Acids Res 39:2610-2623.

Nandurdikar RS, Maciag AE, Holland RJ, Cao Z, Shami PJ, Anderson LM, Keefer LK, Saavedra JE. (2012). Structural modifications modulate stability of glutathione-activated arylated diazeniumdiolate prodrugs. Bioorg Med Chem 20:3094-3099.

Nitanai Y. (1996). Crystallization and preliminary X-ray investigation of a glycoprotein, human renal dipeptidase. J Cryst Growth 168:280-283.

Nitanai Y, Satow Y, Adachi H, Tsujimoto M. (2002). Crystal structure of human renal dipeptidase involved in $\beta$-lactam hydrolysis. J Mol Biol 321:177-184.

Ogata S, Misumi Y, Ikehara Y. (1989). Primary structure of rat liver dipeptidyl peptidase IV deduced from its cDNA and identification of the $\mathrm{NH}_{2}$-terminal signal sequence as the membrane-anchoring domain. J Biol Chem 264:3596-3601.

Okada T, Suzuki H, Wada K, Kumagai H, Fukuyama K. (2006). Crystal structures of $\gamma$ glutamyltranspeptidase from Escherichia coli, a key enzyme in glutathione metabolism, and its reaction intermediate. Proc Natl Acad Sci USA 103:6471-6476. 
Okajima K, Inoue M, Morino Y. (1981). Topology and some properties of the renal brush border membrane-bound peptidase(s) participating in the metabolism of S-carbamidomethyl glutathione. Biochim Biophys Acta 675:379-385.

Okajima K, Inoue M, Morino Y, Itoh K. (1984). Topological aspects of microsomal Nacetyltransferase, an enzyme responsible for the acetylation of cysteine S-conjugates of xenobiotics. Eur J Biochem 142:281-286.

Park SW, Choi K, Kim IC, Lee HH, Hooper NM, Park HS. (2001). Endogenous glycosylphosphatidylinositol-specific phospholipase $\mathrm{C}$ releases renal dipeptidase from kidney proximal tubules in vitro. Biochem J 353:339-344.

Poon GK, Chen Q, Teffera Y, Ngui JS, Griffin PR, Braun MP, Doss GA, Freeden C, Stearns RA, Evans DC, Baillie TA, Tang W. (2001). Bioactivation of diclofenac via benzoquinone imine intermediates - identification of urinary mercapturic acid derivatives in rats and humans. Drug Metab Dispos 29:1608-1613.

Pumford NR, Halmes NC. (1997). Protein targets of xenobiotic reactive intermediates. Annu Rev Pharmacol Toxicol 37:91-117.

Pumford NR, Halmes NC, Hinson JA. (1997). Covalent binding of xenobiotics to specific proteins in the liver. Drug Metab Rev 29:39-57.

Rached E, Hooper NM, James P, Semenza G, Turner AJ, Mantei N. (1990). cDNA cloning and expression in Xenopus laevis oocytes of pig renal dipeptidase, a glycosyl-phosphatidylinositolanchored ectoenzyme. Biochem J 271:755-760.

Rankin BB, McIntyre TM, Curthoys NP. (1980). Brush border membrane hydrolysis of Sbenzyl-cysteine-p-nitroanilide, and activity of aminopeptidase M. Biochem Biophys Res Commun 96:991-996.

Reed DJ. (1990). Glutathione - toxicological implications. Annu Rev Pharmacol Toxicol 30:603631.

Reed MC, Lieb A, Nijhout HF. (2010). The biological significance of substrate inhibition: a mechanism with diverse functions. Bioessays 32:422-429.

Sabatini L, Barbieri A, Indiveri P, Mattioli S, Violante FS. (2008). Validation of an HPLCMS/MS method for the simultaneous determination of phenylmercapturic acid, benzylmercapturic acid and $O$-methylbenzyl mercapturic acid in urine as biomarkers of exposure to benzene, toluene and xylenes. J Chromatogr B Analyt Technol Biomed Life Sci 863:115-122.

Satoh S, Keida Y, Konta Y, Maeda M, Matsumoto Y, Niwa M, Kohsaka M. (1993). Purification and molecular cloning of mouse renal dipeptidase. Biochim Biophys Acta 1163:234-242. 
Shiotsuki T, Koiso A, Eto M. (1990). Inhibition of glutathione transferase by S-benzyl glutathione analogous to the conjugate of saligenin cyclic phosphate. Pesticide Biochem Physiol $37: 121-129$.

Silbernagl S, Heuner A. (1990). Renal transport and metabolism of mercapturic acids and their precursors. Toxicol Lett 53:45-51.

Singh RK, Gupta S, Dastidar S, Ray A. (2010). Cysteinyl leukotrienes and their receptors: molecular and functional characteristics. Pharmacology 85:336-349.

Suzuki H, Kamatani S, Kim ES, Kumagai H. (2001). Aminopeptidases A, B, and N and dipeptidase D are the four cysteinylglycinases of Escherichia coli K-12. J Bacteriol 183:14891490 .

Tabakman R, Lazarovici P, Kohen R. (2002). Neuroprotective effects of carnosine and homocarnosine on pheochromocytoma PC12 cells exposed to ischemia. J Neurosci Res 68:463469.

Tabor H, Mehler AH, Stadtman ER. (1953). The enzymatic acetylation of amines. J Biol Chem 204:127-138.

Tanaka T, Kameoka J, Yaron A, Schlossman SF, Morimoto C. (1993). The costimulatory activity of the CD26 antigen requires dipeptidyl peptidase IV enzymatic activity. Proc Natl Acad Sci USA 90:4586-4590.

Teichert J, Sohr R, Hennig L, Baumann F, Schoppmeyer K, Patzak U, Preiss R. (2009). Identification and quantitation of the N-acetyl-L-cysteine S-conjugates of bendamustine and its sulfoxides in human bile after administration of bendamustine hydrochloride. Drug Metab Dispos 37:292-301.

Teufel M, Saudek V, Ledig JP, Bernhardt A, Boularand S, Carreau A, Cairns NJ, Carter C, Cowley DJ, Duverger D, Ganzhorn AJ, Guenet C, Heintzelmann B, Laucher V, Sauvage C, Smirnova T. (2003). Sequence identification and characterization of human carnosinase and a closely related non-specific dipeptidase. J Biol Chem 278:6521-6531.

Townsend DM, Tew KD, Tapiero H. (2003). The importance of glutathione in human disease. Biomed Pharmacother 57:145-155.

Tsao B, Curthoys NP. (1980). The absolute asymmetry of orientation of $\gamma$-glutamyltranspeptidase and aminopeptidase on the external surface of the rat renal brush-border membrane. J Biol Chem 255:7708-7711.

Tsikas D, Brunner G. (1992). High-performance liquid chromatography of glutathione conjugates. Fresenius J Anal Chem 343:330-334.

Turzynski A, Mentlein R. (1990). Prolyl aminopeptidase from rat brain and kidney. Action on peptides and identification as leucyl aminopeptidase. Eur J Biochem 190:509-515. 
Vaidya SS, Gerk PM. (2007). Simultaneous determination of 1-chloro-2,4-dinitrobenzene, 2,4dinitrophenyl-S-glutathione and its metabolites for human placental disposition studies by highperformance liquid chromatography. J Chromatogr B Analyt Technol Biomed Life Sci 859:94102.

Vanderheyden PM, Demaegdt H, Swales J, Lenaerts PJ, De Backer JP, Vogel LK, Vauquelin G. (2006). Synergistic inhibition of the enzymatic activity of aminopeptidase $\mathrm{N}$ by divalent metal ion chelators. Fundam Clin Pharmacol 20:613-619.

Veiga-da-Cunha M, Tyteca D, Stroobant V, Courtoy PJ, Opperdoes FR, Van Schaftingen E. (2010). Molecular identification of NAT8 as the enzyme that acetylates cysteine S-conjugates to mercapturic acids. J Biol Chem 285:18888-18898.

Walker, J. 2002, "SDS polyacrylamide gel electrophoresis of proteins," in The Protein Protocols Handbook, Humana Press Inc., pp. 61-72.

Welch CL, Campbell BJ. (1980). Uptake of glycine from L-alanylglycine into renal brush border vesicles. J Membr Biol 54:39-50.

Wells PG, McCallum GP, Chen CS, Henderson JT, Lee CJJ, Perstin J, Preston TJ, Wiley MJ, Wong AW. (2009). Oxidative stress in developmental origins of disease: teratogenesis, neurodevelopmental deficits, and cancer. Toxicol Sci 108:4-18.

Winn LM, Wells PG. (2002). Evidence for Ras-dependent signal transduction in phenytoin teratogenicity. Toxicol Appl Pharmacol 184:144-152.

Witzmann FA, Fultz CD, Grant RA, Wright LS, Kornguth SE, Siegel FL. (1998). Differential expression of cytosolic proteins in the rat kidney cortex and medulla: Preliminary proteomics. Electrophoresis 19:2491-2497.

Wu GY, Fang YZ, Yang S, Lupton JR, Turner ND. (2004). Glutathione metabolism and its implications for health. J Nutr 134:489-492.

Yemm EW, Cocking EC. (1955). The determination of amino-acids with ninhydrin. Analyst 209-213.

Yoon HJ, Park SW, Lee HB, Im SY, Hooper NM, Park HS. (2007). Release of renal dipeptidase from glycosylphosphatidylinositol anchor by insulin-triggered phospholipase $\mathrm{C} /$ intracellular $\mathrm{Ca}^{+}$. Arch Pharm Res 30:608-615. 


\section{APPENDICES}

\section{APPENDiX A: UV-Visible SPECTRA OF GSH CONJUGATES}
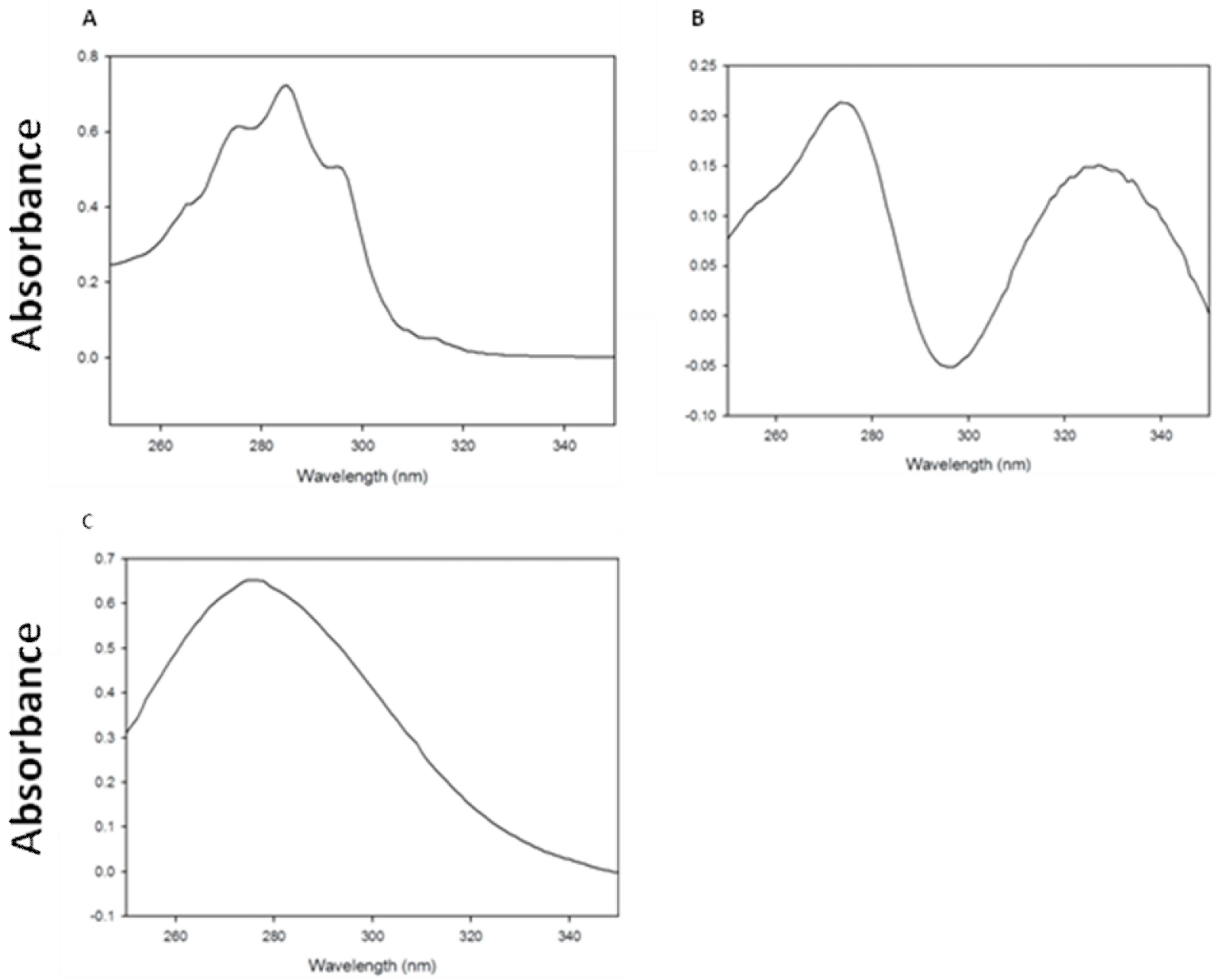

Recrystallized (A) M-GSH; (B) DNP-GSH; and (C) NB-GSH conjugates were dissolved in borate buffer, which was also used as the reference solvent. X-CG and X-C conjugates had similar UV-visible spectra with minor shifting. 


\section{APPENDiX B: HPLC SEPARATION OF X-GSH, X-CG, AND X-C}

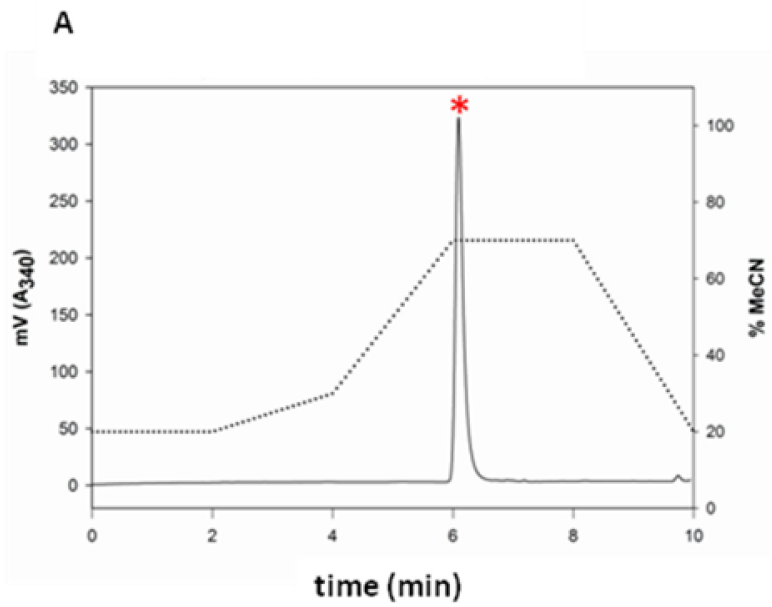

GSH conjugate *

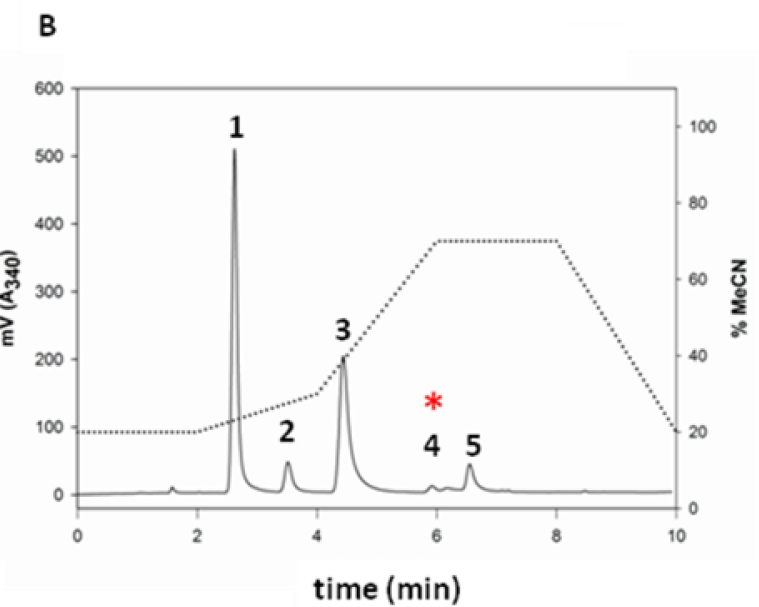

$1 \mathrm{~N} \mathrm{HCl}$

$1 \mathrm{~h}$ boil

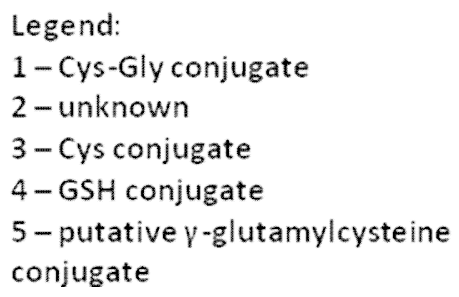

Synthesis and hydrolysis of conjugates: HPLC analysis. A representative chromatogram is shown for DNP-GSH (A) before and (B) after acid hydrolysis. 


\section{APPENDIX C: LC-MS-MS DATA FOR ACID HYDROLYSATES OF GSH CONJUGATES}

DNP-GSH, $\mathrm{m} / \mathrm{z}=474.0$
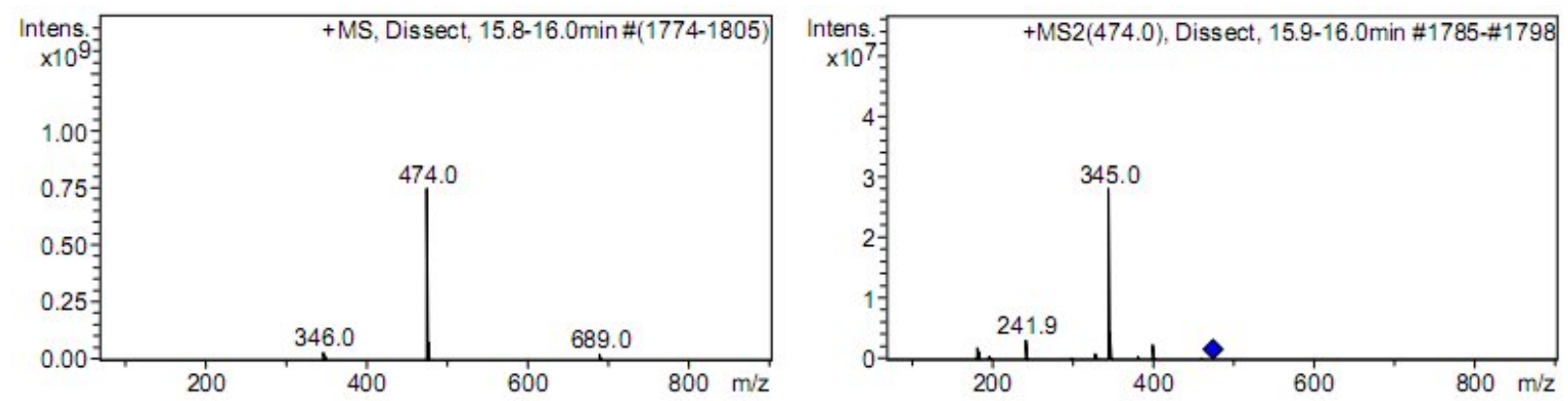

\begin{tabular}{rrr}
$\#$ & $\mathbf{m} / \mathbf{z}$ & I \\
\hline 1 & 346.0 & 36091496 \\
2 & 346.9 & 6562777 \\
3 & 349.0 & 22882016 \\
4 & 474.0 & 748954816 \\
5 & 475.0 & 133813656 \\
6 & 476.0 & 76717776 \\
7 & 477.0 & 8417431 \\
8 & 688.4 & 5096066 \\
9 & 689.0 & 25342266 \\
10 & 689.9 & 4885222
\end{tabular}

\begin{tabular}{rrr}
$\#$ & $\mathbf{m} / \mathbf{z}$ & I \\
\hline 1 & 182.9 & 1972862 \\
2 & 196.8 & 499455 \\
3 & 241.9 & 3244893 \\
4 & 242.9 & 844751 \\
5 & 328.0 & 961791 \\
6 & 328.9 & 840942 \\
7 & 345.0 & 28135470 \\
8 & 346.0 & 4311056 \\
9 & 347.0 & 1764454 \\
10 & 399.1 & 2370277
\end{tabular}

DNP-CG, $\mathrm{m} / \mathrm{z}=345.0$
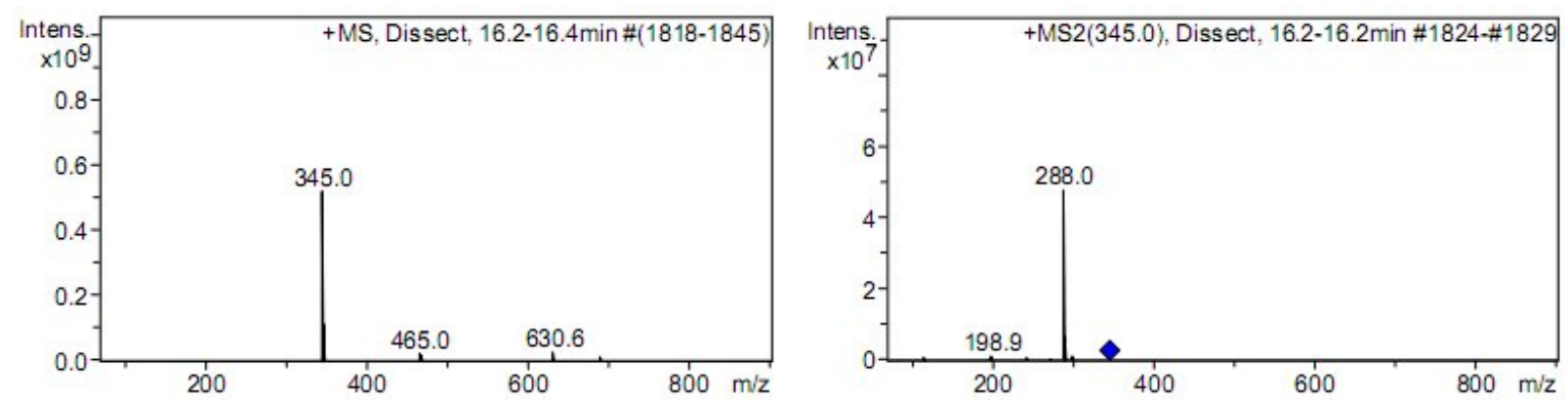

\begin{tabular}{rrr}
$\#$ & $\mathbf{m} / \mathbf{z}$ & I \\
\hline 1 & 345.0 & 520334304 \\
2 & 345.5 & 13610601 \\
3 & 346.0 & 112407344 \\
4 & 347.0 & 17202290 \\
5 & 465.0 & 23084486 \\
6 & 467.0 & 19028982 \\
7 & 630.6 & 28382000 \\
8 & 688.2 & 5957301 \\
9 & 688.6 & 3748838 \\
10 & 689.0 & 16857638
\end{tabular}

\begin{tabular}{rrr}
$\#$ & $\mathbf{m} / \mathbf{z}$ & $\mathbf{I}$ \\
\hline 1 & 115.1 & 795976 \\
2 & 196.9 & 355214 \\
3 & 198.9 & 1333179 \\
4 & 200.8 & 265543 \\
5 & 241.9 & 803764 \\
6 & 270.9 & 311901 \\
7 & 288.0 & 47868148 \\
8 & 288.9 & 7153006 \\
9 & 290.0 & 1476486 \\
10 & 299.0 & 1300163
\end{tabular}


DNP-C, $\mathrm{m} / \mathrm{z}=288.0$
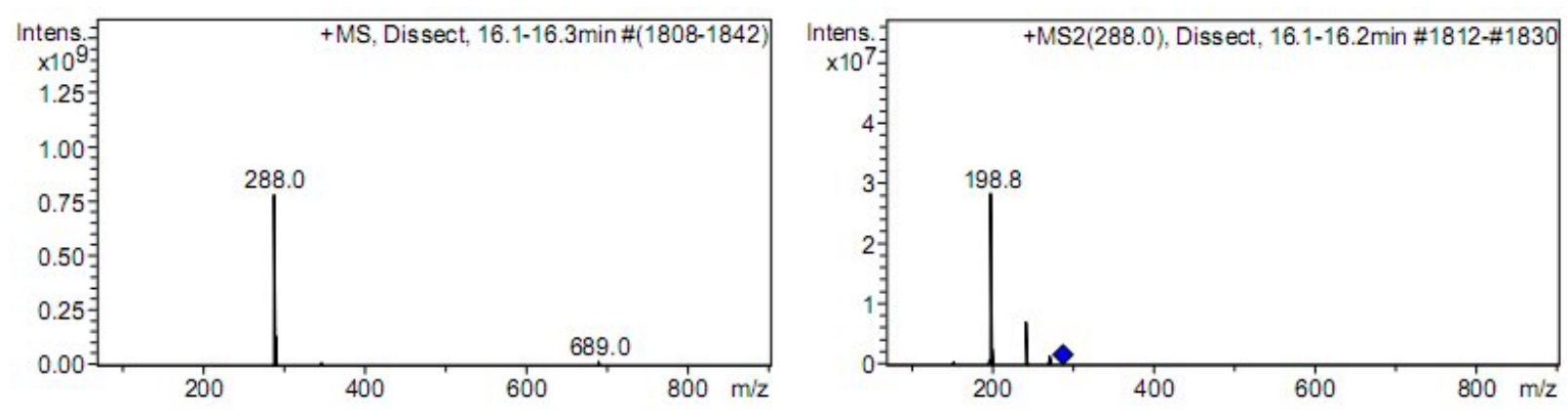

\begin{tabular}{rrr}
$\#$ & $\mathbf{m} / \mathbf{z}$ & $\mathbf{I}$ \\
\hline 1 & 287.6 & 4134704 \\
2 & 288.0 & 785450752 \\
3 & 289.0 & 137035808 \\
4 & 290.0 & 37072940 \\
5 & 346.0 & 8513144 \\
6 & 347.0 & 12505467 \\
7 & 348.0 & 2151372 \\
8 & 689.0 & 21555870 \\
9 & 689.8 & 1207526 \\
10 & 690.1 & 1099379
\end{tabular}

\begin{tabular}{rrr}
$\#$ & $\mathrm{~m} / \mathbf{z}$ & I \\
\hline 1 & 150.9 & 249964 \\
2 & 152.8 & 464670 \\
3 & 196.9 & 789778 \\
4 & 198.8 & 28449598 \\
5 & 199.8 & 2422370 \\
6 & 241.9 & 7236055 \\
7 & 242.9 & 986518 \\
8 & 270.9 & 1520599 \\
9 & 271.7 & 312308 \\
10 & 272.1 & 250522
\end{tabular}

DNP- $\gamma E C, m / z=417.0$
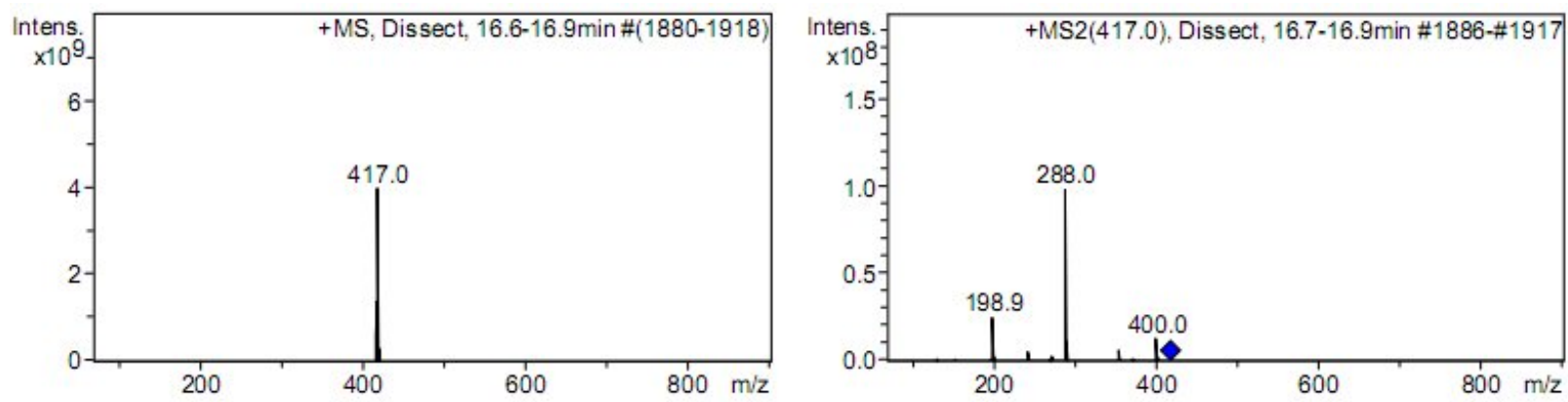

\begin{tabular}{rrr}
$\#$ & $\mathbf{m} / \mathbf{z}$ & $\mathbf{I}$ \\
\hline 1 & 416.5 & 6567368 \\
2 & 417.0 & 3991507200 \\
3 & 417.6 & 5922049 \\
4 & 418.0 & 698446912 \\
5 & 419.0 & 304687488 \\
6 & 420.0 & 47593768 \\
7 & 832.8 & 24720600 \\
8 & 833.5 & 9004083 \\
9 & 833.8 & 9713169 \\
10 & 834.1 & 8021948
\end{tabular}

\begin{tabular}{rrr}
$\#$ & $\mathbf{m} / \mathbf{z}$ & I \\
\hline 1 & 198.9 & 25076362 \\
2 & 199.8 & 2266744 \\
3 & 241.9 & 5128214 \\
4 & 270.9 & 2625024 \\
5 & 288.0 & 98565576 \\
6 & 288.9 & 12885214 \\
7 & 289.9 & 4974431 \\
8 & 354.0 & 5754471 \\
9 & 400.0 & 13265044 \\
10 & 401.0 & 2823612
\end{tabular}


NB-GSH, $\mathrm{m} / \mathrm{z}=443.1$
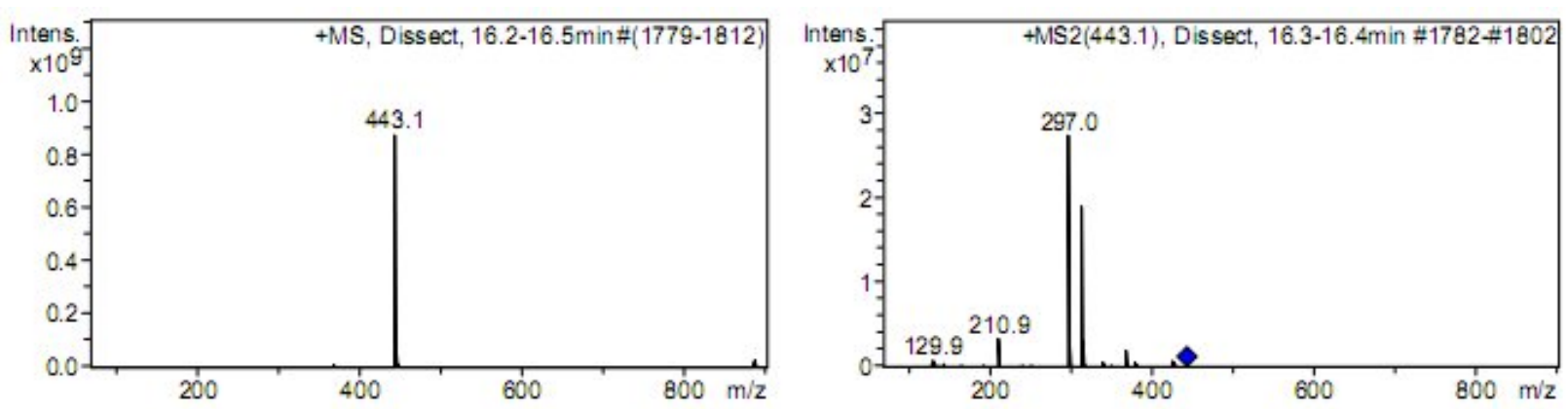

\begin{tabular}{rrr}
$\#$ & $\mathrm{~m} / \mathbf{z}$ & । \\
\hline 1 & 368.1 & 12466159 \\
2 & 369.0 & 9667686 \\
3 & 443.1 & 874309696 \\
4 & 444.1 & 215141552 \\
5 & 445.1 & 61501616 \\
6 & 446.1 & 18308240 \\
7 & 884.7 & 17068556 \\
8 & 885.1 & 27583582 \\
9 & 886.1 & 12754034 \\
10 & 886.9 & 8404703
\end{tabular}

\begin{tabular}{rrr}
$\#$ & $\mathrm{~m} / \mathbf{z}$ & । \\
\hline 1 & 129.9 & 754413 \\
2 & 210.9 & 3396116 \\
3 & 297.0 & 27392352 \\
4 & 298.0 & 4149946 \\
5 & 299.0 & 1538348 \\
6 & 314.0 & 18928394 \\
7 & 315.0 & 3071288 \\
8 & 316.1 & 777139 \\
9 & 368.1 & 1935768 \\
10 & 426.0 & 804107
\end{tabular}

NB-CG, $\mathrm{m} / \mathrm{z}=314.0$
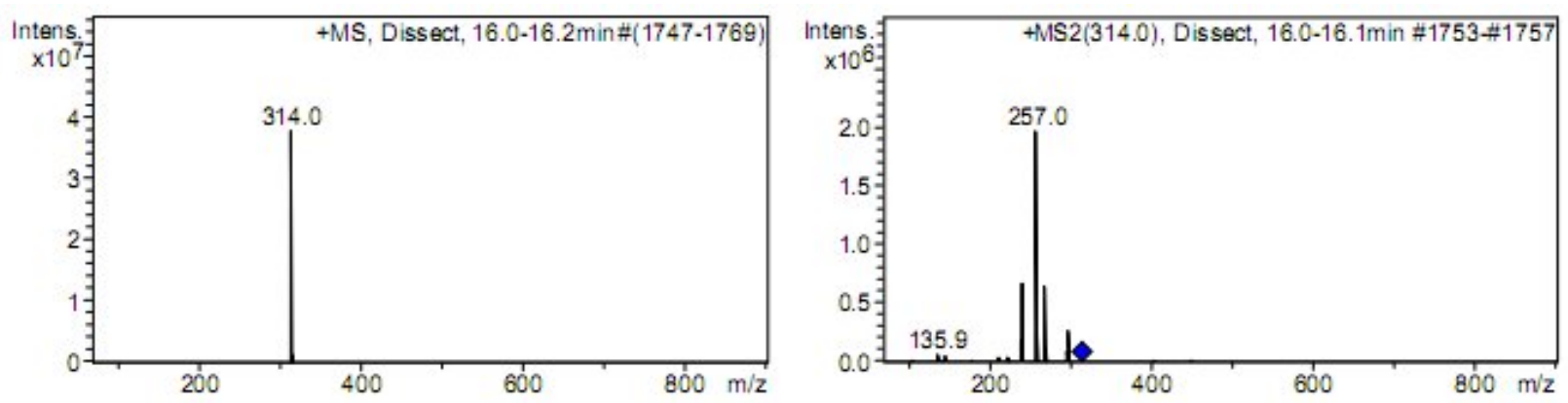

\begin{tabular}{rrr}
$\#$ & $\mathrm{~m} / \mathrm{z}$ & $\mathrm{I}$ \\
\hline 1 & 314.0 & 37769880 \\
2 & 315.0 & 1325105
\end{tabular}

\begin{tabular}{rrr}
$\#$ & $\mathbf{m} / \mathbf{z}$ & । \\
\hline 1 & 135.9 & 66942 \\
2 & 238.9 & 185767 \\
3 & 239.9 & 673065 \\
4 & 240.9 & 111568 \\
5 & 257.0 & 1965750 \\
6 & 257.9 & 261339 \\
7 & 268.0 & 650822 \\
8 & 269.0 & 103977 \\
9 & 296.0 & 95568 \\
10 & 297.0 & 265534
\end{tabular}


NB-C, $\mathrm{m} / \mathrm{z}=257.0$
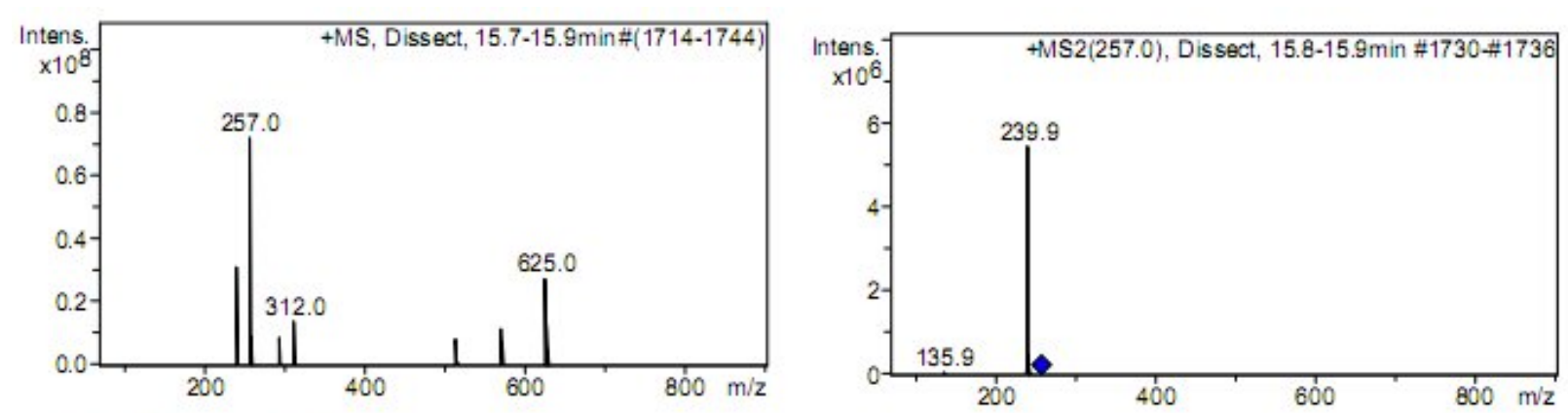

\begin{tabular}{rrr}
$\#$ & $\mathrm{~m} / \mathbf{z}$ & $\mathrm{I}$ \\
\hline 1 & 240.0 & 31085840 \\
2 & 257.0 & 72171888 \\
3 & 258.0 & 8832220 \\
4 & 294.0 & 9111548 \\
5 & 312.0 & 13937487 \\
6 & 513.0 & 8418895 \\
7 & 570.0 & 11652897 \\
8 & 625.0 & 27657106 \\
9 & 626.0 & 8091541 \\
10 & 627.0 & 13197312
\end{tabular}

\begin{tabular}{rrr}
$\#$ & $\mathrm{~m} / \mathbf{z}$ & I \\
\hline 1 & 106.1 & 17455 \\
2 & 135.9 & 82265 \\
3 & 136.9 & 12678 \\
4 & 210.7 & 15412 \\
5 & 239.9 & 5450135 \\
6 & 240.9 & 875085 \\
7 & 241.9 & 179760 \\
8 & 411.9 & 14371
\end{tabular}

$\mathrm{NB}+, \mathrm{m} / \mathrm{z}=136.8$
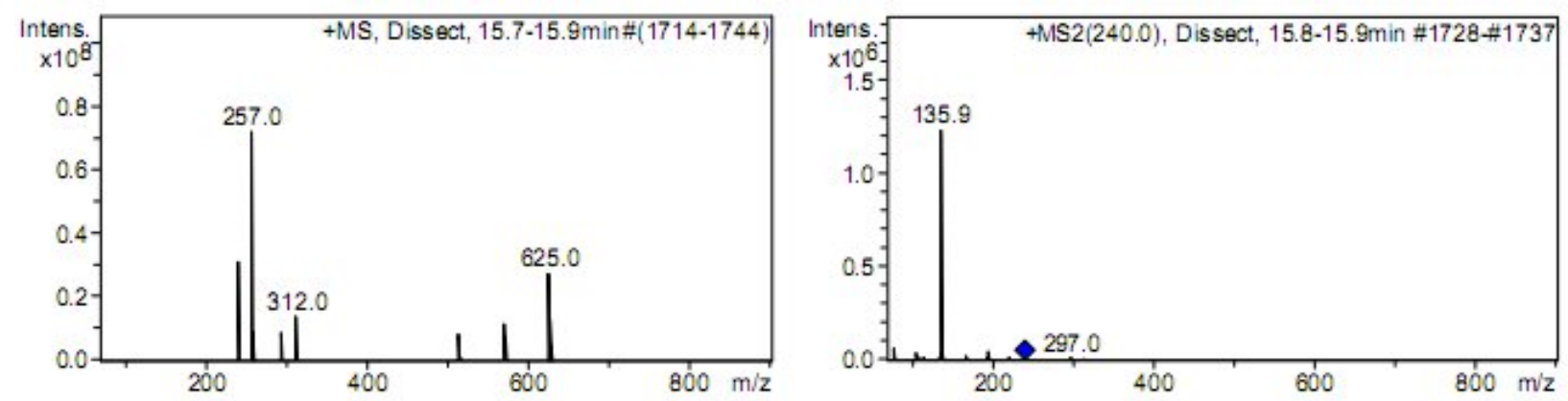

\begin{tabular}{rrr}
$\#$ & $\mathrm{~m} / \mathbf{z}$ & $\mathrm{I}$ \\
\hline 1 & 240.0 & 31085840 \\
2 & 257.0 & 72171888 \\
3 & 258.0 & 8832220 \\
4 & 294.0 & 9111548 \\
5 & 312.0 & 13937487 \\
6 & 513.0 & 8418895 \\
7 & 570.0 & 11652897 \\
8 & 625.0 & 27657106 \\
9 & 626.0 & 8091541 \\
10 & 627.0 & 13197312
\end{tabular}

\begin{tabular}{rrr}
$\#$ & $\mathrm{~m} / \mathbf{z}$ & । \\
\hline 1 & 78.2 & 65418 \\
2 & 106.0 & 43916 \\
3 & 113.8 & 19924 \\
4 & 134.9 & 14475 \\
5 & 135.9 & 1230715 \\
6 & 136.8 & 115940 \\
7 & 167.8 & 23620 \\
8 & 194.0 & 52768 \\
9 & 220.9 & 13941 \\
10 & 297.0 & 20186
\end{tabular}


M-GSH, $\mathrm{m} / \mathrm{z}=448.1$
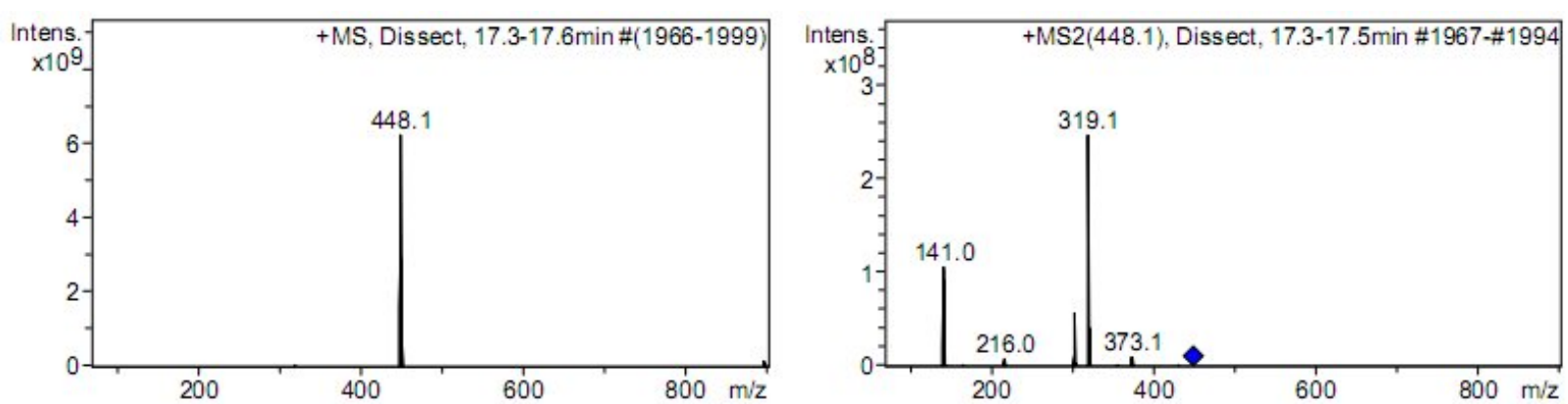

\begin{tabular}{rrr}
$\#$ & $\mathbf{m} / \mathbf{z}$ & $\mathbf{I}$ \\
\hline 1 & 319.1 & 49453052 \\
2 & 448.1 & 6241821696 \\
3 & 449.1 & 1816995328 \\
4 & 450.1 & 654117760 \\
5 & 451.1 & 91757392 \\
6 & 894.7 & 57799160 \\
7 & 895.2 & 172682688 \\
8 & 895.9 & 53561564 \\
9 & 896.2 & 70303584 \\
10 & 897.2 & 36866148
\end{tabular}

\begin{tabular}{rrr}
$\#$ & $\mathbf{m} / \mathbf{z}$ & I \\
\hline 1 & 141.0 & 105428640 \\
2 & 141.9 & 12882169 \\
3 & 216.0 & 8981020 \\
4 & 302.0 & 56488728 \\
5 & 303.0 & 10431742 \\
6 & 319.1 & 246712480 \\
7 & 320.0 & 44520252 \\
8 & 321.1 & 10381630 \\
9 & 373.1 & 10597442 \\
10 & 374.1 & 4188123
\end{tabular}

$\mathrm{M}-\mathrm{CG}, \mathrm{m} / \mathrm{z}=319.1$
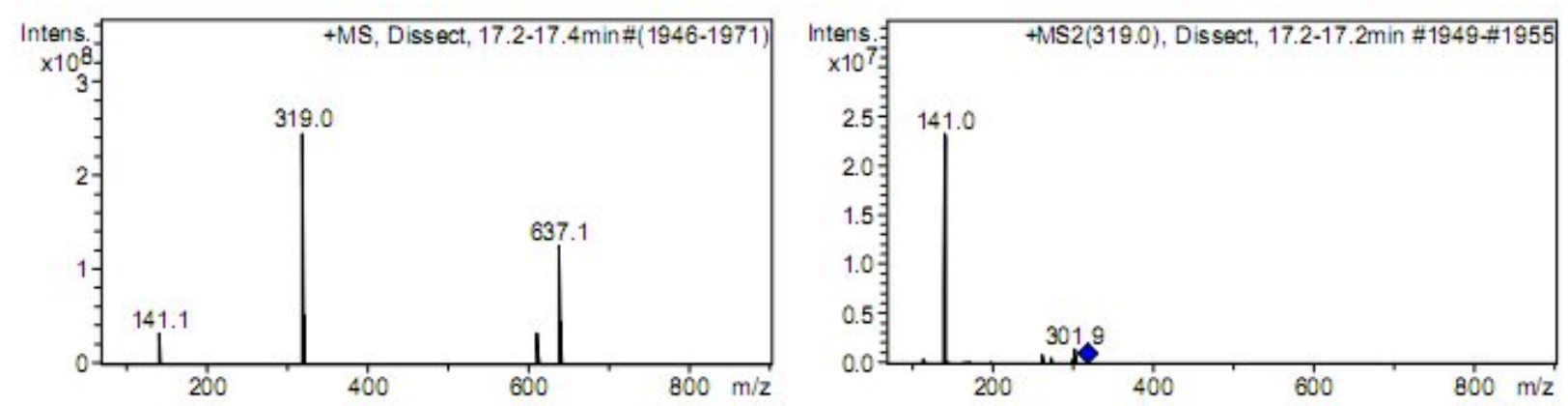

\begin{tabular}{rrr}
$\#$ & $\mathrm{~m} / \mathbf{z}$ & $\mathrm{I}$ \\
\hline 1 & 141.1 & 33234430 \\
2 & 319.0 & 244626448 \\
3 & 320.0 & 51531320 \\
4 & 610.2 & 33563132 \\
5 & 611.2 & 12096695 \\
6 & 637.1 & 125323952 \\
7 & 637.6 & 9514004 \\
8 & 637.8 & 9623884 \\
9 & 638.1 & 44168084 \\
10 & 639.2 & 23420736
\end{tabular}

\begin{tabular}{rrr}
$\#$ & $\mathrm{~m} / \mathrm{z}$ & $\mathrm{I}$ \\
\hline 1 & 115.0 & 493955 \\
2 & 141.0 & 23246704 \\
3 & 142.0 & 3566687 \\
4 & 173.0 & 204724 \\
5 & 199.0 & 172965 \\
6 & 262.0 & 989812 \\
7 & 273.0 & 703965 \\
8 & 301.0 & 471634 \\
9 & 301.9 & 1467660 \\
10 & 303.0 & 364184
\end{tabular}


$\mathrm{M}-\mathrm{C}, \mathrm{m} / \mathrm{z}=262.0$
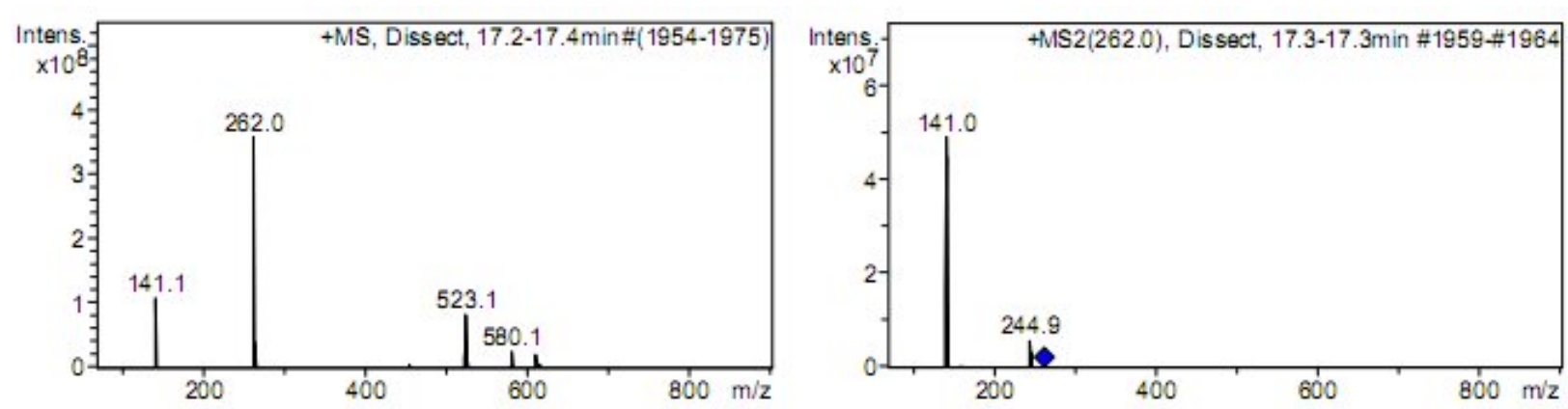

\begin{tabular}{rrr}
$\#$ & $\mathrm{~m} / \mathbf{z}$ & $\mathbf{I}$ \\
\hline 1 & 141.1 & 107842104 \\
2 & 262.0 & 358854688 \\
3 & 263.0 & 66059156 \\
4 & 264.0 & 40156436 \\
5 & 522.7 & 15097631 \\
6 & 523.1 & $\mathbf{8} 177824$ \\
7 & 524.1 & 13287178 \\
8 & 580.1 & $\mathbf{6 1 0 8 9 9 0}$ \\
9 & 610.1 & 21179896 \\
10 & 611.2 & 11743415
\end{tabular}

\begin{tabular}{rrr}
$\#$ & $\mathrm{~m} / \mathrm{z}$ & $\mathbf{1}$ \\
\hline 1 & 141.0 & 49065988 \\
2 & 141.9 & 6875327 \\
3 & 142.9 & 630349 \\
4 & 144.3 & 68773 \\
5 & 159.7 & 283337 \\
6 & 161.3 & 97052 \\
7 & 244.3 & 694544 \\
8 & 244.9 & 5783993 \\
9 & 245.9 & 586433 \\
10 & 247.0 & 226283
\end{tabular}

$\mathrm{M}-\gamma \mathrm{EC}, \mathrm{m} / \mathrm{z}=391.1$
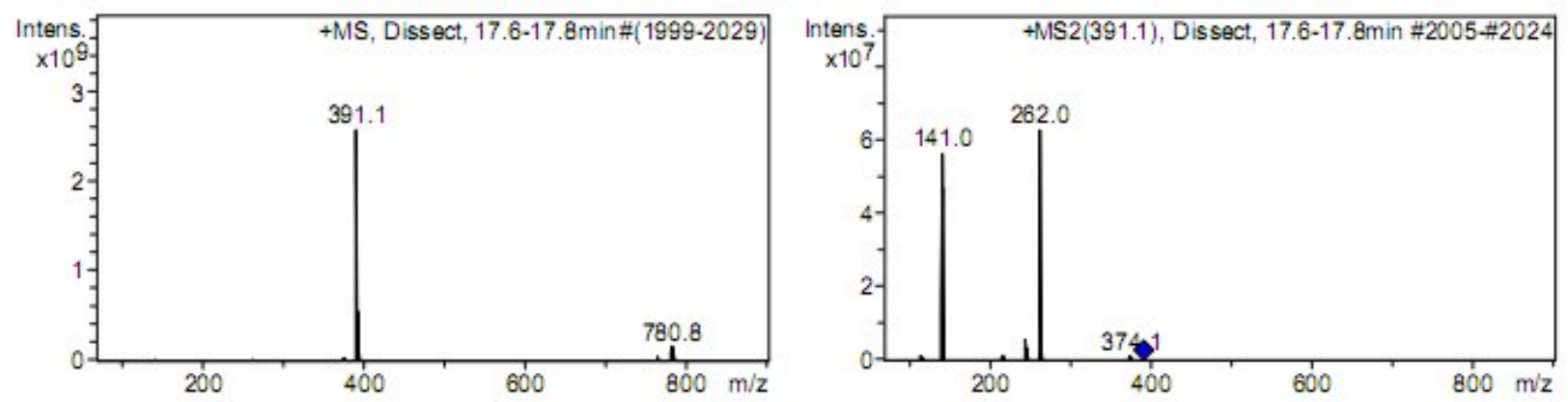

\begin{tabular}{rrr}
$\#$ & $\mathrm{~m} / \mathbf{z}$ & $\mathbf{1}$ \\
\hline 1 & 391.1 & 2575641600 \\
2 & 392.1 & 572356992 \\
3 & 393.1 & 155251600 \\
4 & 762.8 & 52437492 \\
5 & 780.8 & 161266544 \\
6 & 781.1 & 159513856 \\
7 & 781.8 & 70546256 \\
8 & 782.0 & 101425040 \\
9 & 782.2 & 88639768 \\
10 & 782.9 & 74691480
\end{tabular}

\begin{tabular}{rrr}
$\#$ & $\mathrm{~m} / \mathbf{z}$ & $\mathrm{I}$ \\
\hline 1 & 115.1 & 1446247 \\
2 & 141.0 & 56507924 \\
3 & 142.0 & 7506227 \\
4 & 215.9 & 1178982 \\
5 & 244.9 & 5747872 \\
6 & 245.9 & 1141909 \\
7 & 262.0 & 62815124 \\
8 & 263.0 & 11665699 \\
9 & 264.0 & 2638475 \\
10 & 374.1 & 1431235
\end{tabular}


Glutamic acid, $\mathrm{m} / \mathrm{z}=130.0$
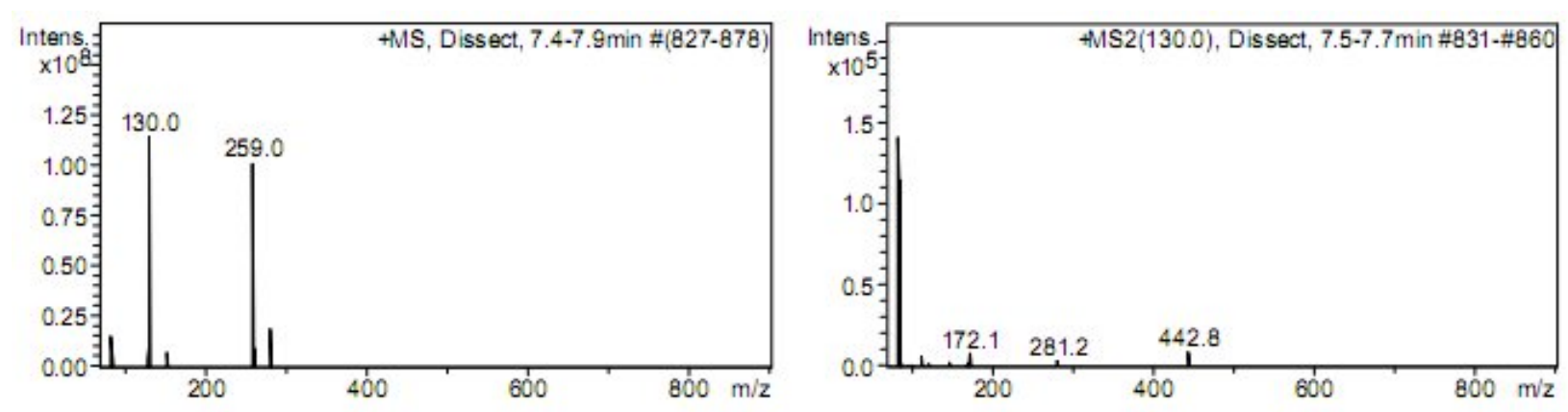

\begin{tabular}{rrr}
$\#$ & $\mathrm{~m} / \mathbf{z}$ & $\mathrm{I}$ \\
\hline 1 & 84.1 & 15383642 \\
2 & 130.0 & 114273400 \\
3 & 152.0 & 7621900 \\
4 & 259.0 & 101083928 \\
5 & 260.1 & 9985751 \\
6 & 261.0 & 665174 \\
7 & 280.6 & 826653 \\
8 & 281.0 & 19556470 \\
9 & 281.7 & 547832 \\
10 & 282.0 & 1124985
\end{tabular}

\begin{tabular}{rrr}
$\#$ & $\mathrm{~m} / \mathrm{z}$ & $\mathrm{I}$ \\
\hline 1 & 84.2 & 140966 \\
2 & 86.0 & 3258 \\
3 & 113.1 & 6327 \\
4 & 172.1 & 8154 \\
5 & 281.2 & 4010 \\
6 & 442.8 & 9251
\end{tabular}




\section{APPENDiX D: RATIONALE FOR PI-PLC AND AFFINITY PURIFICATION}

Unlike APN or DPP-IV, which contain N-terminal transmembrane domains (Benajiba and Maroux, 1981; Kenny and Maroux, 1982; Ogata et al., 1989), MDP is bound to the plasma membrane via a C-terminal GPI-anchor, which can be cleaved by treatment with bacterial PIPLC (Hooper et al., 1987); this presented a convenient strategy to purify MDP from other membrane-bound peptidases.

PI-PLC-released proteins were purified by affinity chromatography, using an AminoLink ${ }^{\circledR}$ Immobilization Kit (Thermo Scientific, Rockford, IL, USA). The competitive MDP inhibitor, cilastatin (1.91 mg), was dissolved in $2 \mathrm{~mL}$ coupling buffer and covalently coupled to the affinity column according to the manufacturer's recommendations.

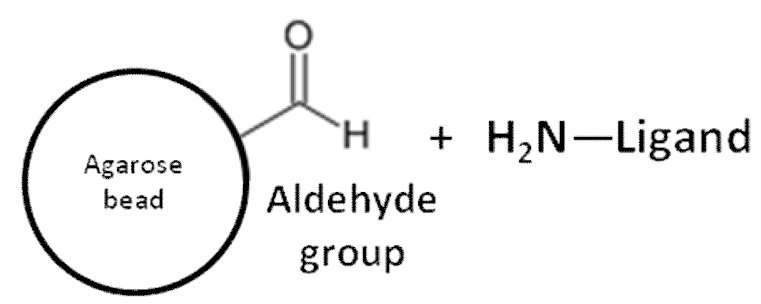

AminoLink ${ }^{\circledR}$ Resin

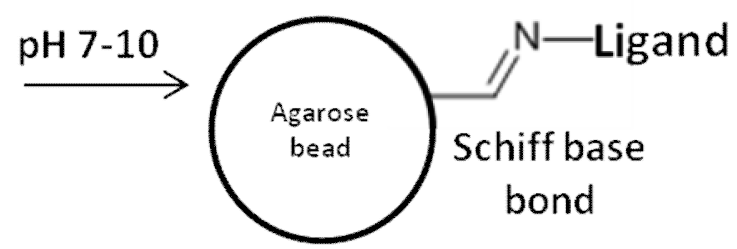

$\mathrm{NaCNBH}_{3}$ $\mathrm{pH} 7.2$

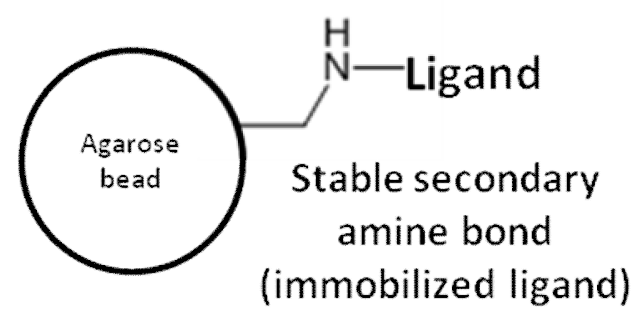

The column contains a cross-linked $4 \%$ beaded agarose resin with activated aldehyde groups that spontaneously react with primary amines; immobilization to the resin occurs when 
the cilastatin primary amine groups react with the resin aldehyde groups to form Schiff base bonds. The Schiff base bonds are reduced to stable secondary amine bonds by the addition of the mild reducing agent, sodium cyanoborohydride $\left(\mathrm{NaCNBH}_{3}\right)$. Remaining active sites were blocked with the supplied quenching buffer. Approximately $1.6 \mathrm{mg}$ cilastatin was bound to the column ( $84 \%$ coupling efficiency), as determined by UV absorbance of the cilastatin solution before and after coupling to the column; the absorbance at $250 \mathrm{~nm}\left(\mathrm{~A}_{250}\right)$ was determined using a Varian Cary $300 \mathrm{UV} /$ Vis spectrophotometer, with coupling buffer as the reference solvent. The column was stored upright at $4^{\circ} \mathrm{C}$ in $2 \mathrm{~mL}$ Buffer B $(50 \mathrm{mM}$ Tris-HCl, $0.1 \mathrm{mM} \mathrm{ZnCl} 2,50 \mathrm{mM}$ $\mathrm{NaCl}, \mathrm{pH}$ 7.0) containing $0.05 \%$ sodium azide. Following protein affinity purification procedures, the column was washed with $5 \mathrm{~mL}$ glycine $\bullet \mathrm{HCl}$ solution $(0.2 \mathrm{M}, \mathrm{pH} 3.0)$, regenerated with eight column volumes $(16 \mathrm{~mL})$ of Buffer $\mathrm{B}$, and stored upright at $4^{\circ} \mathrm{C}$ in $2 \mathrm{~mL}$ Buffer B with $0.05 \%$ sodium azide.

Flow-through and wash fractions were also collected for protein concentration determination by the Bradford assay (Bradford, 1976), and together with the concentrated eluate, subjected to one-dimensional SDS-PAGE for characterization and verification of protein purification. SDS polyacrylamide gels were prepared to a final concentration of $12 \%$ acrylamide (w/v) (Walker, 2002). Samples were mixed 1:1 with Laemmli buffer (Laemmli, 1970) containing $4 \%$ SDS and 10\% 2-mercaptoethanol (Sigma Chemicals, St. Louis, MO), and heated at $100^{\circ} \mathrm{C}$ for 3 min prior to loading. Precision Plus Protein ${ }^{\mathrm{TM}}$ Dual Color Standards (10-250 kDa; Bio-Rad, Missisauga, ON) were used as molecular weight standards. Electrophoresis was carried out in $1 \times$ SDS running buffer at $80 \mathrm{~V}$ for approximately $2 \mathrm{~h}$. To visualize bands, the gel was silver stained according to the method of (Blum et al., 1987) with the following modifications: silver nitrate 
$(0.1 \%)$ was used to impregnate the gel, and sodium carbonate $(2 \%)$ was used in the developer solution. 
APPENDIX E: STRUCTURES OF PEPTIDASE INHIBITORS
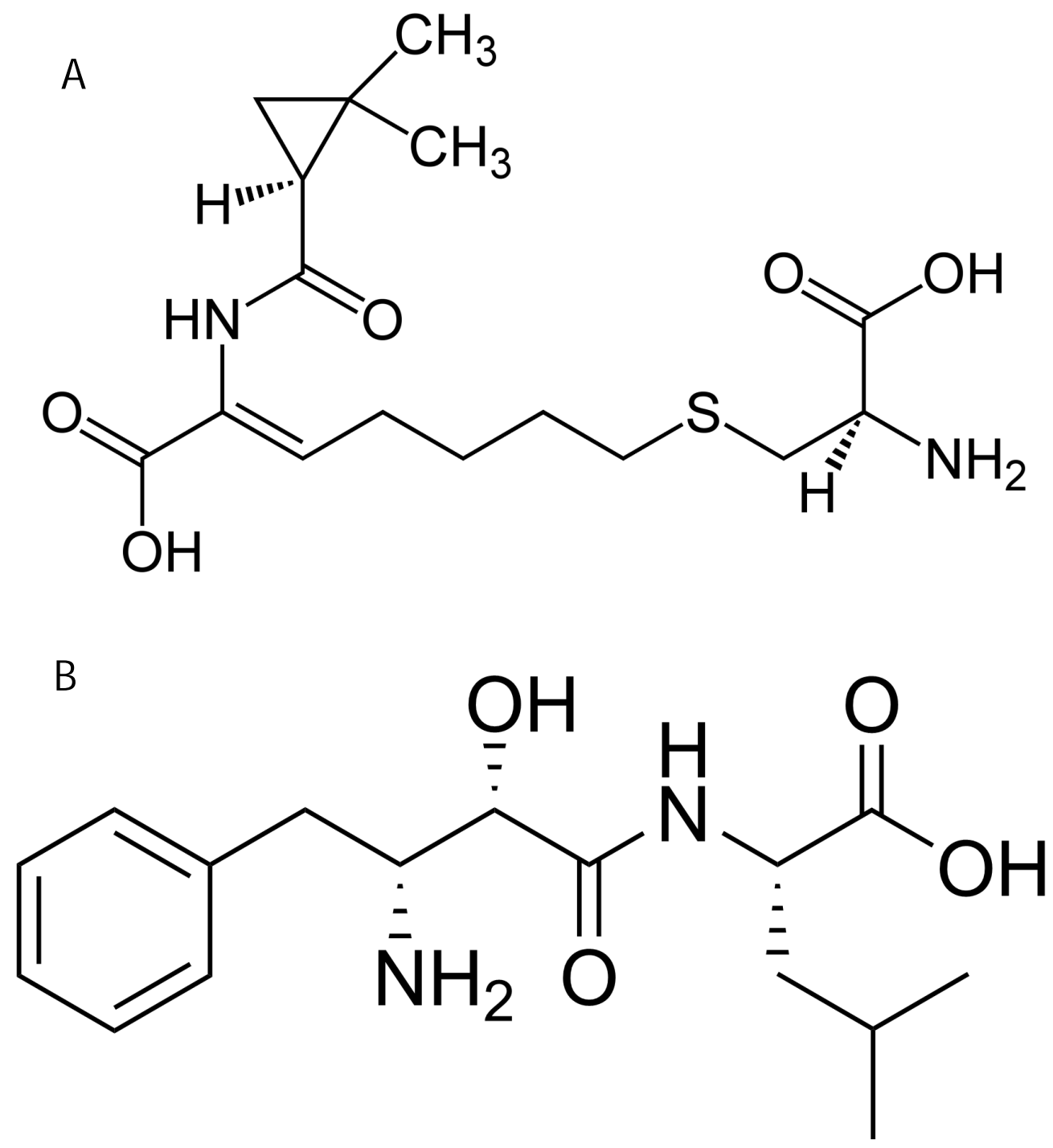

Chemical structure of (A) cilastatin and (B) bestatin. 


\section{APPENDIX F: METHOD FOR GENERATING HPLC CYS-GLY STANDARD CURVES}

Substrate concentration was plotted against the ratio between substrate peak area and internal standard peak area to generate a standard curve. Because the chemical structures of the GSH, Cys-Gly, and Cys conjugates are similar and their UV chromophores are the same, the standard curve for the Cys-Gly conjugate were used to determine the concentration for the corresponding Cys conjugate; similar values for extinction coefficients have been previously reported for conjugates of GSH, Cys-Gly and Cys (Egner et al., 2008; Hinchman et al., 1991). Enzyme assay initial rate and kinetic parameters were determined based on Cys conjugate product formation.

Preliminary activity assays were performed for DNP-CG at 2 and $4 \mathrm{mM}$ substrate concentrations. Including these values did not significant change the kinetic parameters, but increased the error and reduced the fit on the graph (data not shown). This is likely due to solubility issues in buffer at high concentrations of substrate. 
APPENDIX G: NINHYDRIN ACTIVITY ASSAY<smiles>O=C1c2ccccc2C(=O)C1(O)CO</smiles>

Ninhydrin<smiles>NC(=O)CCOC(=O)O</smiles>
Indanetrione

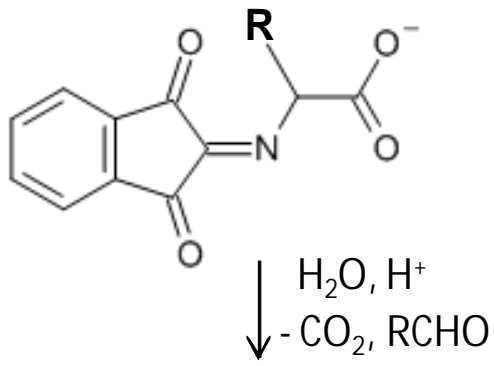<smiles>NC1C(=O)c2ccccc2C1=O</smiles><smiles>CCCCCCCCCCCC1C(=O)c2ccccc2C1[O-]</smiles>

Ruhemann's Purple

Adapted from Jelly et al., 2009; Patterson, 1976; Yemm and Cocking 1955. 